Portland State University

PDXScholar

7-28-2021

\title{
An Exploratory Study of Adjunct Faculty Professional Growth Experiences
}

Bethany Ann Potts

Portland State University

Follow this and additional works at: https://pdxscholar.library.pdx.edu/open_access_etds

Part of the Educational Leadership Commons, and the Higher Education Commons Let us know how access to this document benefits you.

\section{Recommended Citation}

Potts, Bethany Ann, "An Exploratory Study of Adjunct Faculty Professional Growth Experiences" (2021). Dissertations and Theses. Paper 5756.

https://doi.org/10.15760/etd.7627

This Dissertation is brought to you for free and open access. It has been accepted for inclusion in Dissertations and Theses by an authorized administrator of PDXScholar. Please contact us if we can make this document more accessible: pdxscholar@pdx.edu. 
An Exploratory Study of Adjunct Faculty Professional Growth Experiences

by

Bethany Ann Potts

A dissertation submitted in partial fulfillment of the requirements for the degree of

Doctor of Education

in

Educational Leadership: Postsecondary Education

Dissertation Committee:

Michael J. Smith, Chair

Karen Haley

Andy Job

Lynn Santelmann

Portland State University

2021 
(C) 2021 Bethany Ann Potts 


\begin{abstract}
Part-time non-tenure track faculty, also referred to as adjunct faculty, are the fastest growing instructional group in higher education, but they are provided minimal professional support from their employing institution(s). This lack of support is a problem because working conditions shape instructors' investment and efficacy of performance in their professional practice. Well established in the literature are inquiries into adjunct faculty working conditions that prioritize analysis of the organization over the lived experiences of the faculty. However, the lived experiences of adjunct faculty offer a unique and important lens from which to interrogate the impact of institutional policies and practices on individual employees.

In response, this study explored the individual professional growth experiences of four adjunct faculty at a large, urban, commuter, four-year, public, research university. An exploratory embedded single-case study model examined the relationship between participants' motivation, institutional engagement, and professional growth. Findings revealed that participants were motivated by their professional identities, which were shaped by academic and work experiences, as well as long-term goals. Participants' professional identities shaped the ways in which they engaged with students, their academic unit(s), and with the university. Additionally, participants' professional growth experiences differed, based on whether or not they felt respected in their instructional role and how their personal career stage needs were met. Findings suggest that collegial interactions and access to resources are essential elements that can positively impact adjunct faculty work experiences.
\end{abstract}




\section{DEDICATION}

This study is dedicated to the adjunct faculty and the department coordinators

who shared their experiences and time with me. For their tireless commitment to students and the determination to creatively problem-solve within their practice as educators, I am inspired and grateful. Thank you for sharing your journeys with me. 


\section{ACKNOWLEDGEMENTS}

There are many individuals who I owe words of thanks! To my partner, Cameron, I love you and I'm thankful for our shared time as students - a time that we never thought would end and yet, miraculously, it did. I can't wait to use the dining table for eating, rather than studying! You're cooking. To my Chair, Dr. Michael J. Smith, I'm thankful for your patient guidance and your kindness. From our first class together in the fall of 2016, I've enjoyed our conversations and the opportunity to engage in this journey with you. Thank you, thank you for being my Chair. To my committee, Dr. Karen Haley, Dr. Andy Job, and Dr. Lynn Santelmann, thank you for your thoughtful, critical feedback that improved my analysis. I am thankful for each of you and the individual ways in which you contributed to this work. To my parents, Barbara and Francis, thank you for always communicating your belief in my dreams. You taught me to question, to strive, and to work hard. I love you! To my family and friends, I appreciate the love, patience, and generous excitement you shared with me throughout the years. As I deeply felt the highs and lows of life as a doctoral student, you experienced each with me and never let me feel alone. Thank you! To Molly Griffith — thank you for saying yes to my seemingly random email request for an informational interview. I'm thankful for our work together and all that you added to my time in this program. To my cohort members - I'm grateful for the community of scholars that we developed, one group text, long walk, and Friday/Saturday class at a time. You made this a lot more fun. Linnea-we both know that I likely would not be at this point without you. Our year-four writing group held me accountable and dreams of life-after-dissertation propelled my productivity. I appreciate 
you! And finally, to my former students in New Orleans, you taught me what it was to work for something bigger than myself and you forced me to be better than I thought that I could be. As I continue to question our accepted systems of learning and education, I think about you and the lessons you unknowingly imparted. In the wise words of Anis Mojgani and Zadie Smith: Shake the dust. Fail better. 


\section{TABLE OF CONTENTS}

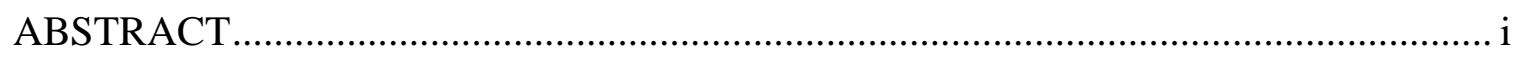

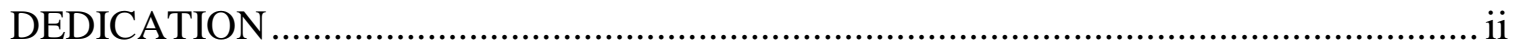

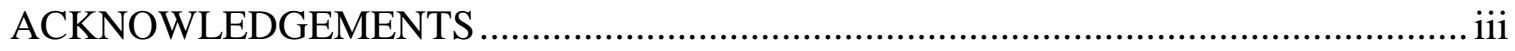

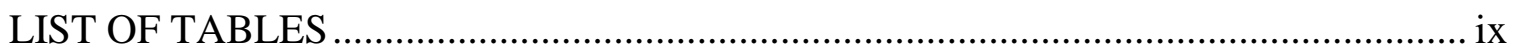

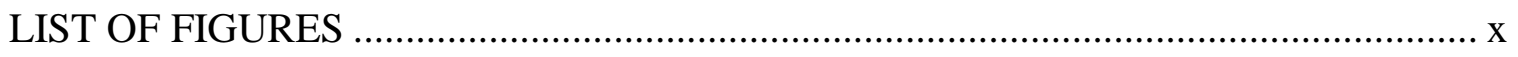

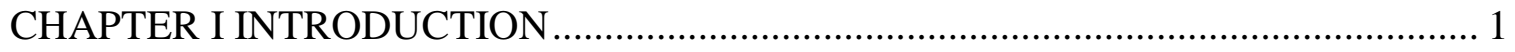

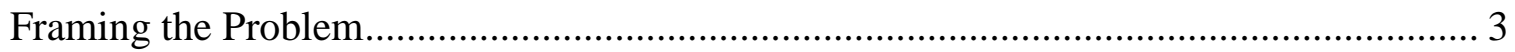

Adjunct Faculty in Higher Education ...................................................................... 4

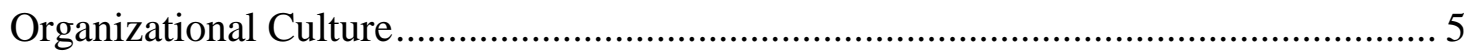

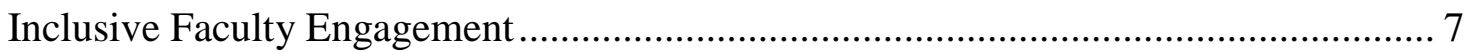

Institution-Facilitated Professional Development................................................... 8

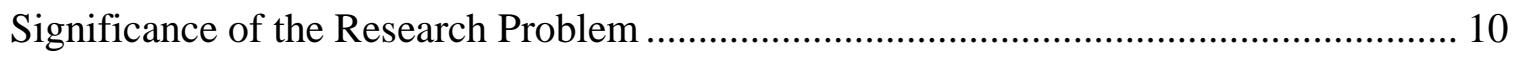

Guiding Conceptual Framework: The Essential Elements of Faculty Work.................... 11

Purpose of the Study and Methodology ..................................................................... 13

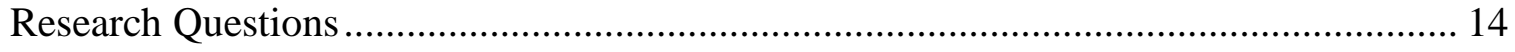

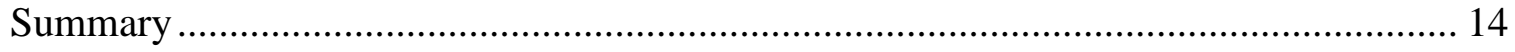

CHAPTER II REVIEW OF THE LITERATURE...................................................... 16

Adjunct Faculty in Higher Education ......................................................................... 17

Historical Context: Growth Over Time ………………....................................... 21

Employment Characteristics ................................................................................ 24

Adjunct Faculty in Higher Education: Summary.................................................... 27

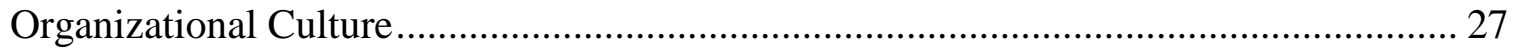

Organizational Culture and Adjunct Faculty ........................................................... 28

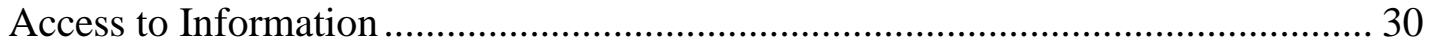

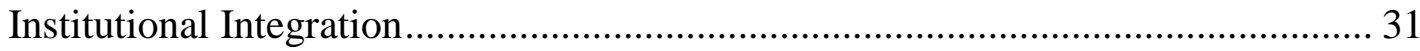

Inclusive Faculty Engagement Model ............................................................. 32

Organizational Culture and Adjunct Faculty: Summary ........................................... 34

Faculty Development in Higher Education................................................................ 35

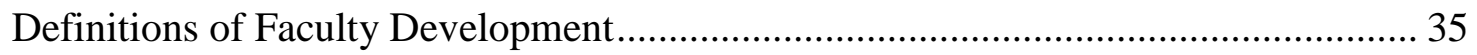

Motivators for Faculty Development Programming ………......................................... 38

Implications for Adjunct Faculty ........................................................................... 40 
Faculty Development in Higher Education: Summary ......................................... 43

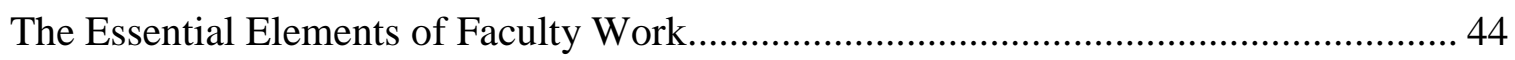

The Essential Elements: An Overview ................................................................. 46

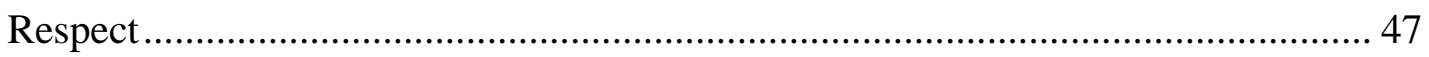

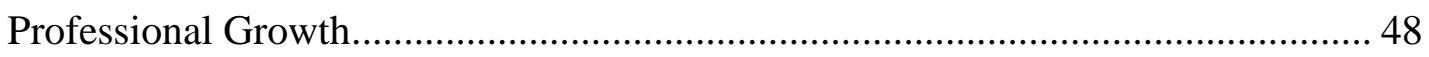

Limitations of the Framework: The Adjunct Experience ........................................ 49

An Inclusive Faculty Engagement Model: A Critical, Analytical Lens ................... 50

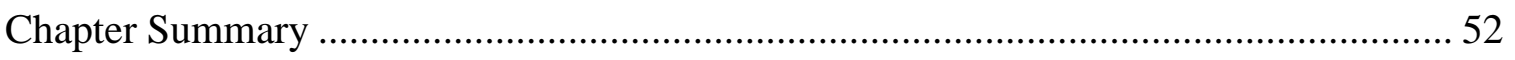

CHAPTER III RESEARCH METHODOLOGY ..................................................... 54

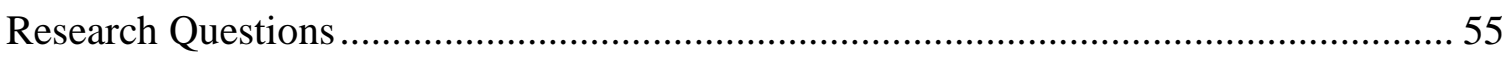

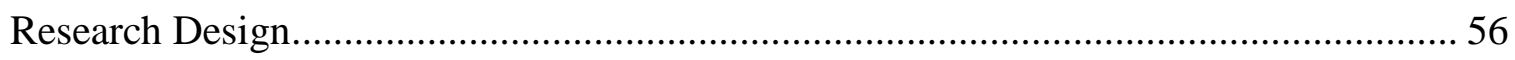

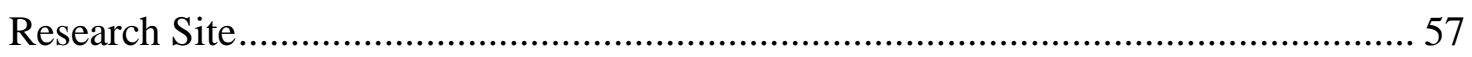

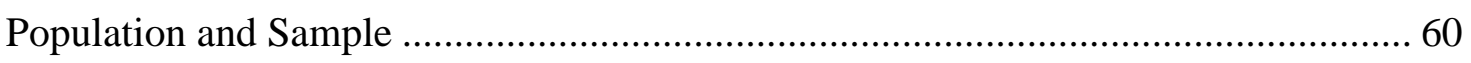

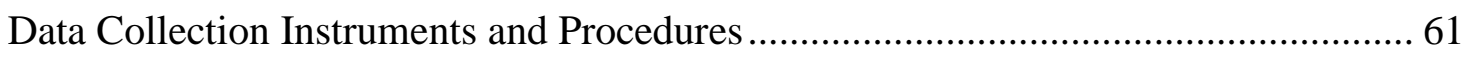

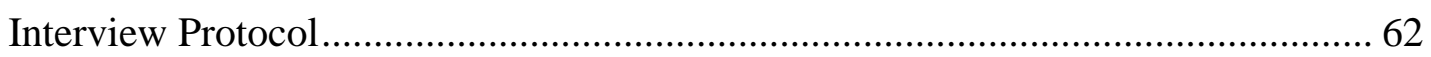

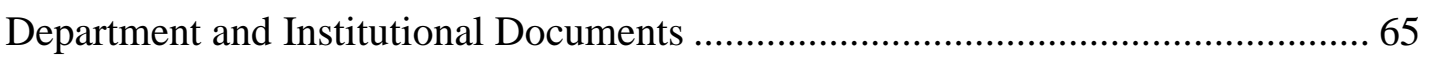

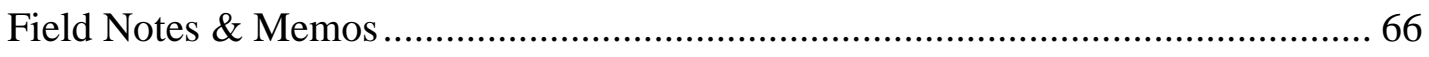

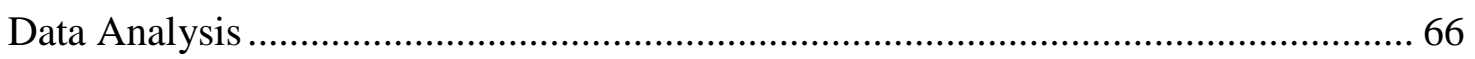

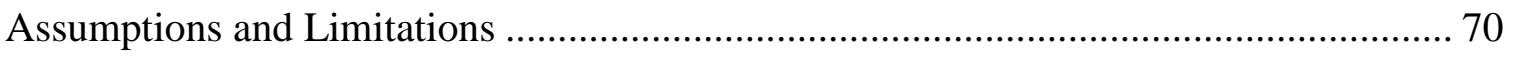

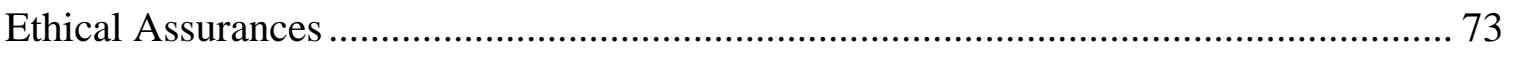

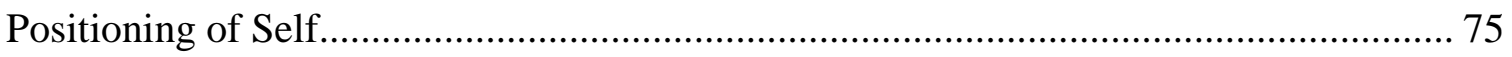

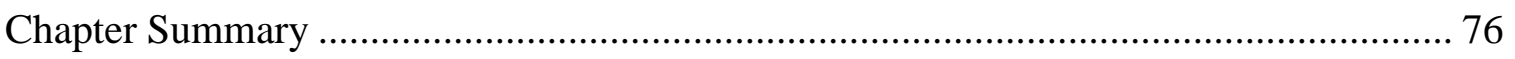

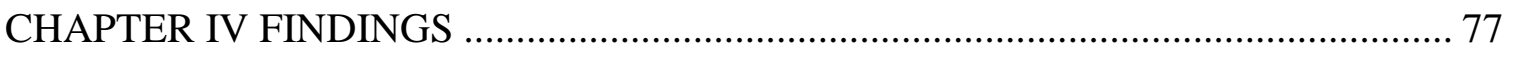

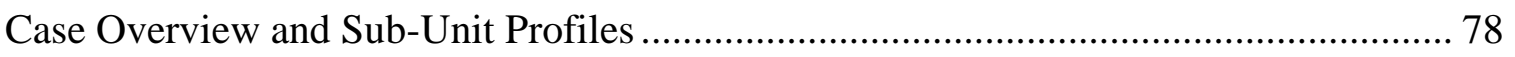

Sub-Units of Analysis: Adjunct Profiles.................................................................. 81

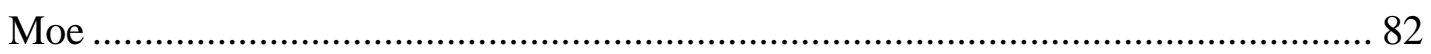

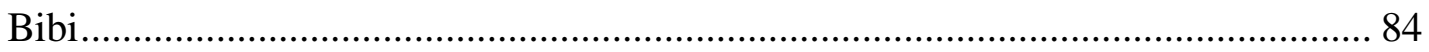

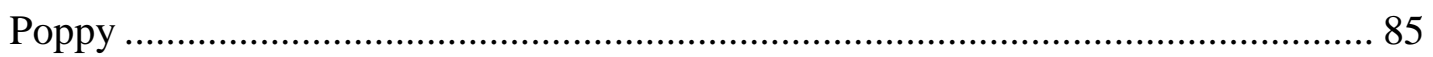

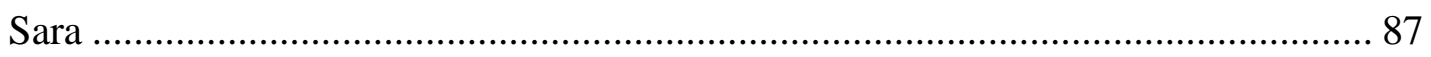

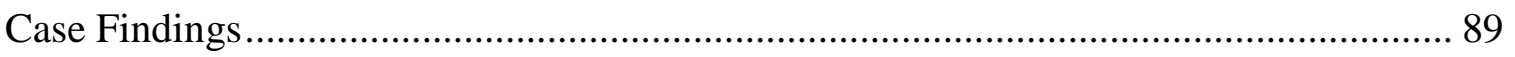

Theme One: Professional Identity Drives Motivation ............................................. 90

Theme Two: Professional Growth Experiences Differ, based on the Elements of

Respect and Career Stage Needs....................................................................... 90 


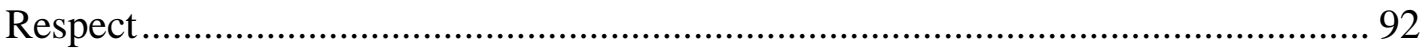

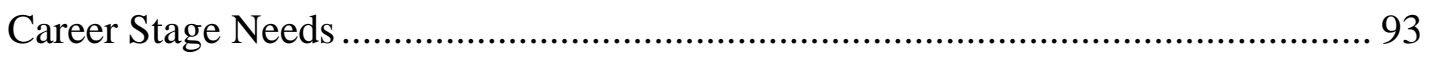

Moe: Instructor, PSU-Alumnus, and Adjunct Advocate ....................................... 96

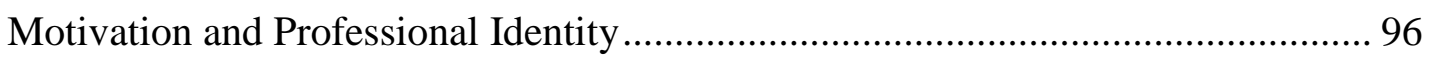

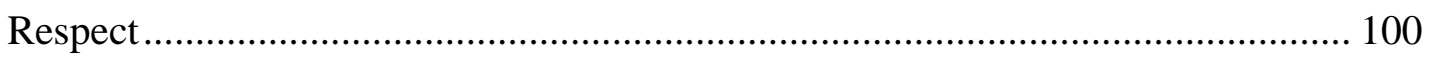

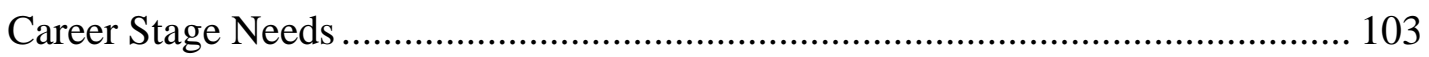

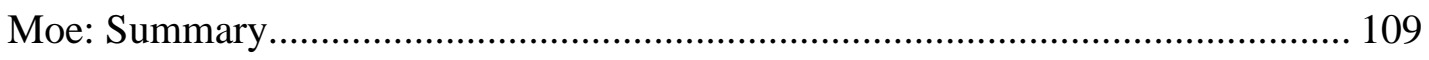

Bibi: Semi-Retired, Subject Matter Expert, Instructor ....................................... 110

Motivation and Professional Identity ............................................................. 110

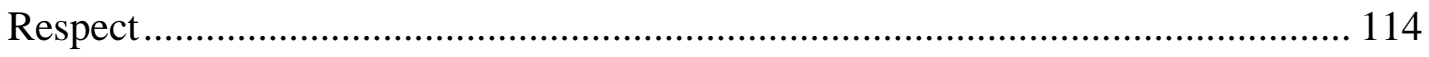

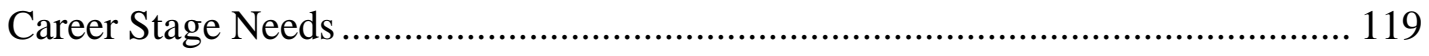

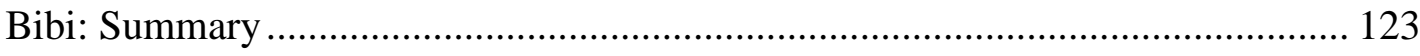

Poppy: Educator, Former NTTF, Hopeful Full-Timer ....................................... 124

Motivation and Professional Identity ........................................................... 124

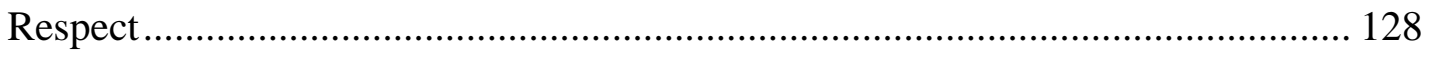

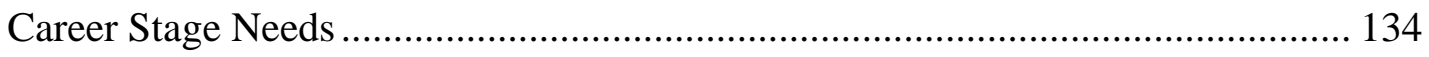

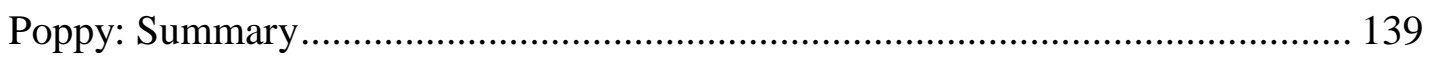

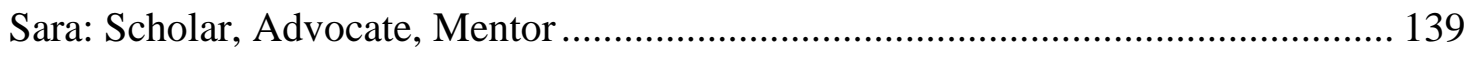

Motivation and Professional Identity ............................................................. 140

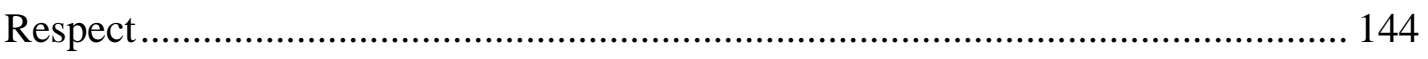

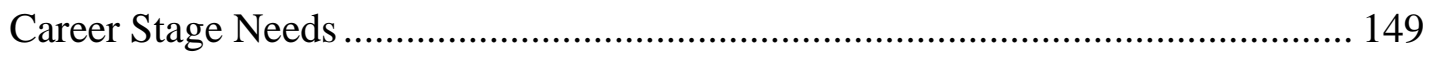

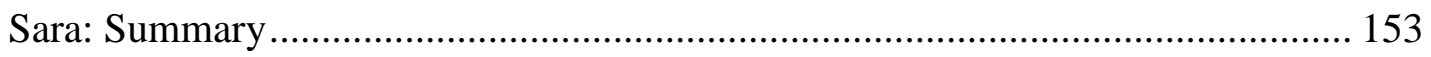

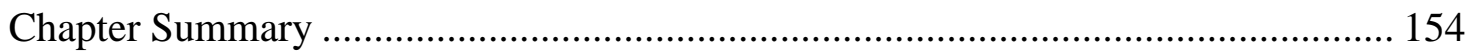

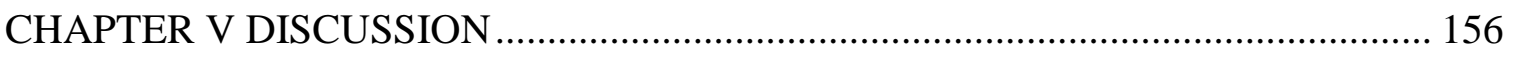

Motivation that Influences Adjunct Faculty Engagement .......................................... 157

Intrinsic Motivation: Professional Values and Pathways to Promotion .................... 159

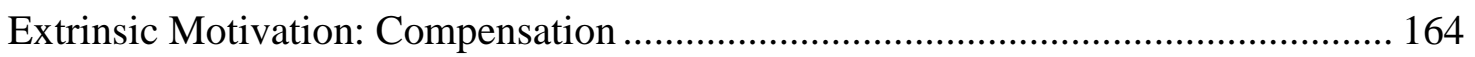

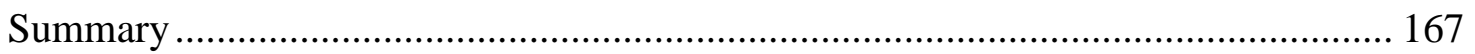

Institutional Engagement and Adjunct Faculty Professional Growth........................... 168

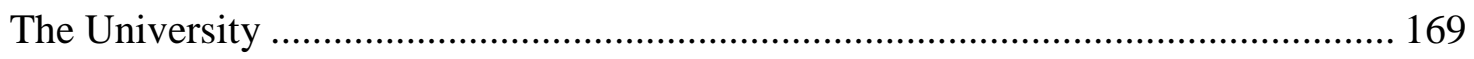

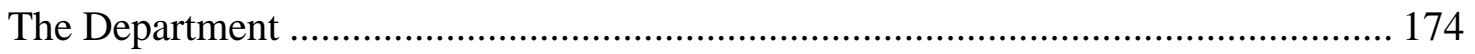

The Outside Non-PSU Instructional Environment ............................................ 177

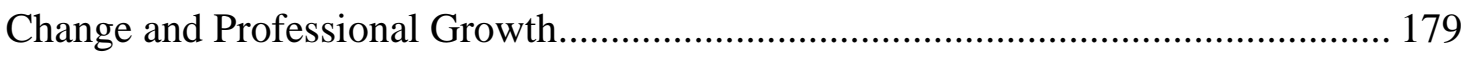


Implications for Practice and Future Research .................................................... 183

Implications for Practice: Universities and Departments .................................... 183

Implications and Recommendations for Future Research ................................... 186

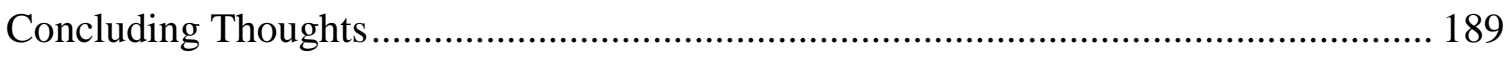

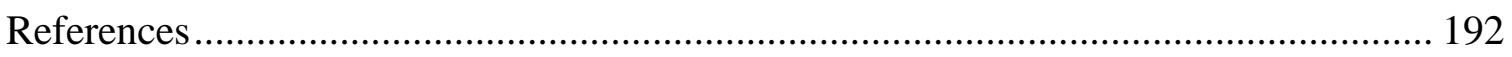

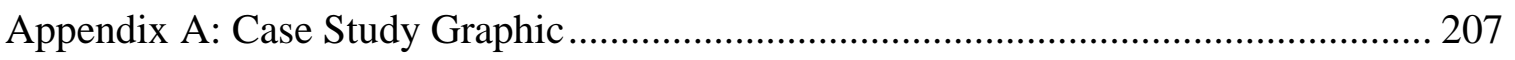

Appendix B: Data Collection/Analysis Timeline ..................................................... 208

Appendix C: Emails to Participants ........................................................................... 209

Appendix D: Adjunct Faculty Interview Protocol ................................................... 211

Appendix E: Department Coordinator Interview Protocol ....................................... 221

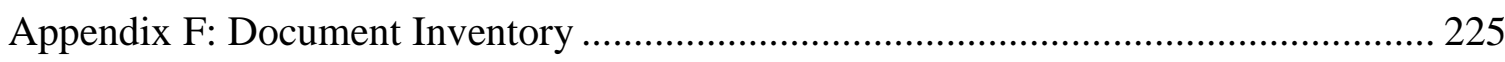

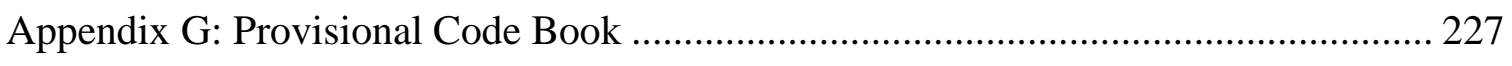

Appendix H: Qualitative Content Analysis Coding Frame ...................................... 228

Appendix I: Informed Consent Form for Adjunct Faculty Interviews ......................... 229

Appendix J: Informed Consent Form for Department Coordinator Interviews............. 233 


\section{LIST OF TABLES}

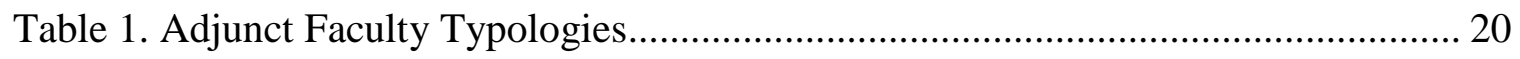

Table 2. Part-Time Instructional Faculty Race/Ethnicity ...........................................5 58

Table 3. Participant Findings: General Organization of the Data.................................. 95 


\section{LIST OF FIGURES}

Figure 1. Part-Time Faculty and Graduate Employees as a Percentage of Instructional

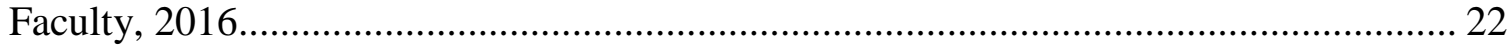

Figure 2. Inclusive Faculty Engagement Model ............................................................. 33

Figure 3. The Essential Elements of Faculty Work ..................................................... 46 


\section{CHAPTER I INTRODUCTION}

Adjunct faculty are the fastest growing instructional group in higher education, but they are provided minimal professional support from their employing institution(s) (American Association of University Professors, 2018a; Coalition on the Academic Workforce, 2012; Cohen \& Brawer, 2008; Kezar \& Maxey, 2013). This lack of support is a problem because working conditions are directly related to an adjunct's investment and efficacy of performance in their instructional role. When support is lacking, the problem can result in faculty disengagement and inconsistent pedagogical choices, which in turn can negatively affect student outcomes (Bourdeaux \& Schoenack, 2016; Thirolf, 2017). Historically, adjunct faculty numbers have seen a sharp population increase since 1969, rising from about $17 \%$ to almost $50 \%$ of the higher education faculty in 2017 (Kezar, 2016; National Center for Education Statistics, 2018). This upward trend is evident across all institution types and academic concentrations (Kezar, 2016; National Center for Education Statistics, 2018). Concurrently, institutions face complex changes, as shaped by budgetary pressures, shifts in enrolled student demographics, and increased adoption of instructional technologies (Green, 2018; Kezar, 2012a; Musu-Gillette et al., 2017; Snyder et al., 2016a; Snyder et al., 2016b; Snyder et al., 2018). In response, institutional focus on faculty development is one opportunity to support the instructional faculty who are charged with navigating these changes. Even so, faculty responsibilities are myriad and participation in non-instructional activities implies new time commitments, which presents a challenge when trying to integrate faculty development opportunities into the 
culture of the organization. Within an environment that employs a large part-time faculty base, this challenge is heightened.

For adjunct faculty, support and accountability in the classroom can take the form of professional development (PD) on institutional policies and pedagogical best practices. In a highly decentralized institution of higher education, faculty development opportunities are dependent on department-specific preferences and/or dissemination of information about campus-wide centers for teaching and learning (if they exist). As a result, instructional practices differ greatly across departments and individual instructors. For adjunct faculty, access to professional support presents an even greater challenge based on the part-time nature of their role and contractual limitations that hinder out-ofclass participation in campus-facilitated activities. This challenge adds to the inconsistent use of student-centered active learning strategies, due to the amount of time and support required to effectively implement such strategies (Baldwin \& Wawrzynski, 2011; Bourdeaux \& Schoenack, 2016). Despite limited resources (e.g., time and compensation), adjunct faculty are faced with instructional positions that necessitate professional engagement in order to meet the needs of their student populations. However, their employing departments and universities do not create intentional systems in which they are supported in that endeavor. As part-time faculty, they are not integrated nor are they encouraged to engage with the larger academic learning community. Instead, they are hired as a panacea for myriad needs (e.g., budget constraints, faculty leave, subject matter expertise, etc.) and then they exist on the periphery, or separate from, the organizational culture. 
In order to respond to these challenges and better understand the needs of parttime instructors, this study examined adjunct faculty professional growth experiences through the lens of the Framework for Rethinking Faculty Work from Gappa, Austin, \& Trice (2007) and the Inclusive Faculty Engagement Model from Thirolf (2017). Well documented in the literature are the deficiencies in adjunct faculty working conditions, including low pay and limited resources (Coalition on the Academic Workforce, 2012; Cohen \& Brawer, 2008; Kezar \& Maxey, 2013; Kezar \& Sam, 2011; Street, Maisto, Merves, \& Rhoades, 2012; Thirolf, 2017). Currently lacking in the literature is a focus on the lived experiences of adjunct faculty in higher education, rather than solely on the organizational structure or the culture of the larger institution. In response, the lived experiences of adjunct faculty at a four-year research university were explored in this case study, with a focus on their professional growth experiences and how those experiences were shaped by institutional integration and engagement.

\section{Framing the Problem}

Based on the contingent nature of their role and the differences in intrainstitutional organizational culture across academic units, the experiences of adjunct faculty are not uniform. Hiring, PD, and professional growth practices vary, based on the employing school/college and the policies upheld by the department leadership. As the fastest growing instructional population in higher education, the adjunct faculty body needs intentional policies that can best support their professional needs, and in turn, the experiences of the students with whom they work. The background of this problem will be comprehensively developed in Chapter II, with an overview detailed in the following 
paragraphs. This overview includes discussion of the adjunct faculty role in higher education, the organizational culture within institutions of higher education, the Inclusive Faculty Engagement Model (Thirolf, 2017), and professional growth, as defined by the Framework for Rethinking Faculty Work (Gappa et al., 2007). Key terms are defined throughout.

\section{Adjunct Faculty in Higher Education}

As one of three main faculty groups currently employed on college campuses (tenured/tenure-track, full-time non-tenure track, and part-time non-tenure track), the adjunct role, also referred to as contingent faculty or per-course teachers, is a non-tenure track research or instructional position (Berrett, 2011; Kezar \& Maxey, 2013). While the term "adjunct" can refer to both full-time non-tenure track (FTNTTF) and part-time nontenure track (PTNTTF) positions, depending on the institution (Berrett, 2011; Kezar, 2013), the PTNTTF body will be the focus of this study. The National Center for Education Statistics (2018) reports that part-time faculty comprise almost $50 \%$ of instructional faculty positions in institutions of higher education in the United States, with the highest concentration (over 60\%) at two-year associate's degree granting institutions (AAUP, 2018a). Based on this critical mass, a focus on policies and procedures that shape the employment experiences of this faculty group bears serious implications for the large number of students they instruct.

In response to this consistently growing population of faculty, institutions are faced with the challenge of providing sufficient array of professional growth opportunities. "A sufficient array" can be defined as opportunities that cover diverse 
subject matter, such as PD on instructional best practices or on faculty career stage needs, as well as opportunities that are intentionally scheduled during different times of the day and through different media (Lyons, 2007; Tarr, 2010). Facilitation of PD on diverse subject matter is essential due to the varied prior academic and professional experiences, as well as the future professional goals of adjunct faculty. Although over $90 \%$ of adjunct faculty report holding some level of a graduate degree (Coalition on the Academic Workforce, 2012), subject matter expertise does not equate with pedagogical experience. Therefore, institutional support for developing instructional skills is largely the responsibility of the employing institution (Coalition on the Academic Workforce, 2012; Cohen \& Brawer, 2008; Kezar \& Maxey, 2013). Whatever the subject matter, intentional scheduling for professional growth experiences is an imperative due to the limited contractual time of adjunct faculty and the high-likelihood of external work and personal commitments that create barriers for participation in out-of-class experiences. In order to encourage engagement and communicate an inclusive environment that welcomes adjunct faculty participation, departments and universities need to consider and value creative solutions for likely barriers to participation. The next section discusses how a university’s culture can shape enacted values and faculty work conditions.

\section{Organizational Culture}

The hierarchy of values embraced in higher education is a contributing force within the organizational culture of an institution. Tenure and research are highly valued, with teaching and non-tenure track pursuits trailing as necessary, yet secondary (Astin, 2016; Boyer, 1990). This is especially problematic given the heavy teaching burden 
assumed by PTNTTF and the dearth of resources they are afforded, including lower compensation than FTTTF, far less PD, and limited physical on-campus spaces (Coalition on the Academic Workforce, 2012; Collins, 2016; Kezar \& Maxey, 2013; Marion \& Gonzales, 2014; Street et al., 2012). As their role functions, they are immersed in a struggle over resources with their FTTT and their FTNTTF counterparts. For adjunct faculty, one implication of an organizational culture characterized by conflict and struggle is that engagement in assigned work and the larger organization is negatively affected (Maslach \& Leiter, 1997). Maslach and Leiter (1997) identify personal control within one's job as an element of organizational life with direct influence over a person's engagement, including energy exerted, general involvement, and the level of effectiveness with one's work. When adjunct faculty possess little control over course assignments, hiring practices, working conditions, and the level of supervision provided, engagement in the larger institution is negatively affected (Coalition on the Academic Workforce, 2012; Feldman \& Turnley, 2011; Kezar \& Maxey, 2013; Roueche et al., 1995; Street et al., 2012; Tyree et al., 2000). While repercussions differ based on adjunct faculty members' motivations for employment, implications for students include a lack of continuity and limited involvement with faculty outside of assigned class times (Louziotis, 2000). In addition, as engagement in the larger organization wanes, voluntary participation from adjunct faculty in campus-sponsored PD is susceptible to a similar decline (Coalition on the Academic Workforce, 2012; Feldman \& Turnley, 2011; Kezar \& Maxey, 2013; Roueche et al., 1995; Street et al., 2012; Tyree et al., 2000). This can 
result in limited faculty knowledge of campus support resources and adopted technologies for teaching and learning (Braxton \& Mundy, 2001).

\section{Inclusive Faculty Engagement}

An organization's culture dictates offered opportunities for employee engagement and integration. Similarly, a university's approach to faculty engagement highlights the organizational culture and the ways in which all faculty do, or do not, experience feelings of belonging and trust in the institution. Thirolf (2017) presents an Inclusive Faculty Engagement Model that prioritizes faculty integration and engagement as forces that can impact student academic success. She grounds her definition in two forms of integration: academic and social. Both forms of integration are derived from Tinto's (1993) model of student integration and are applied to the adjunct faculty population. Within the model, academic integration can facilitate feelings of connectedness and inclusion through communities of practice, while social integration accounts for interpersonal interactions between colleagues at an institution (Thirolf, 2017). The inclusive faculty engagement model is defined by an organizational culture that prioritizes academic and social integration for all faculty members. Thirolf (2017) identifies the absence of an inclusive engagement model for adjunct faculty in higher education and argues that their role is characterized by isolation rather than integration, which can produce feelings of exclusion and isolation. Based on the hierarchy of values in higher education, perceptions of adjunct faculty from the campus community often assume less ability and/or investment, in contrast with their full-time counterparts. As a result, negative perceptions can result in disengagement for adjunct faculty, experiences of disrespect, and missed 
opportunities for social networks in professional communities of practice (Kezar \& Sam, 2011; Thirolf, 2017).

Intentional institution-facilitated professional growth opportunities have the ability to integrate adjunct faculty both academically and socially into a community of practice. Kelly (2016) identifies PD focused on a specific academic discipline as a means by which institutions can engage adjunct faculty in the instructional community of the campus because they are "hungry for intellectual community and for recognition of themselves as professors within a discipline" (p.47). A coordinated institutional response, through the form of intentional PD, is an opportunity to integrate adjunct faculty into the larger academic community and to communicate investment in their instructional role on campus (Tarr, 2010; Thirolf, 2017).

\section{Institution-Facilitated Professional Development}

While FTTTF are responsible for research, teaching, and service, the formal responsibilities for instructional adjunct faculty are not as well defined, beyond the role of instruction. The instructional role of adjunct faculty is situated within a larger hierarchy of faculty roles, as explained by Astin (2016), who states that "whereas there is a clearly established performance standard — publication — for demonstrating smartness through research and scholarship, there is no consensus on determining how good a colleague is at teaching and advising" (p.87). Indeed, there is ambiguity around a set of common values for high quality postsecondary teaching (Bernstein \& Bass, 2005; Boyer, 1990). This dearth of commonly accepted values points to the suggestion that a "teaching-centric" role is less valuable in higher education and less-prestigious than other 
faculty roles (Tierney, 2004). As a result, departmental investment in the time required to develop and implement comprehensive training (e.g., onboarding, ongoing PD, etc.) on instructional best practices, whether for adjunct faculty or their full-time counterparts, is not a common priority.

Over time, faculty development programs in higher education have taken many forms. From a classroom-based, individualized endeavor (Francis, 1975) to a more holistic effort that encompasses personal, instructional, and organizational development (Bergquist \& Phillips, 1975; Lewis, 1996), faculty development is comprised of embedded processes within an institution that are formalized in different ways (Ouellett, 2010). For example, institution-wide, centers for teaching and learning facilitate faculty development with adopted technologies as well as on instructional best practices. Department-level learning opportunities are shaped by the culture of the unit and can encompass institutional or technical processes as well as expectations for classroom pedagogy (Case et al., 2016).

The part-time nature of the adjunct role hinders participation in institutionfacilitated faculty development opportunities. This hindrance is based on last-minute hiring practices and limited contractual allowances that formalize compensation for adjunct faculty in out-of-class participation in the campus community (Coalition on the Academic Workforce, 2012). Therefore, even when an institution has clearly-established processes and resources for supporting faculty learning and engagement, opportunities for adjunct faculty are limited and largely dependent on the culture of the employing department. Kuhlenschmidt (2010) identifies that department-level support is shaped by 
the culture of the unit and is related to the agility with which faculty embrace and incorporate new strategies for teaching and learning into their practice. If the department lacks buy-in for faculty development opportunities - at both the department and institution-level — intentional inclusion of adjunct faculty into those offerings will similarly be lacking.

\section{Significance of the Research Problem}

College enrollment is expected to increase by $12 \%$, from the fall of 2016 through the fall of 2026 (Snyder et al., 2018). This changing student population possesses characteristics that will necessitate informed instructional practitioners, skilled in working with those who lack college readiness or who come from groups traditionally underrepresented in US higher and postsecondary education (Cohen \& Brawer, 2008; Musu-Gillette et al., 2017; Snyder et al., 2016a; Snyder et al., 2016b; Snyder et al., 2018; Valentine, Konstantopoulos, \& Goldrick-Rab, 2017). According to Snyder, de Brey, and Dillow (2018), 39\% of public four-year college students seeking a bachelor's degree complete in four years. While this number does rise when considering completion rates for students in years five (55\%) and six (59\%), colleges and universities need to evaluate the efficacy of their curricular and co-curricular programs to identify if these programs are actually supporting students in pursuit of degree completion.

As a growing presence in college and university communities, analysis of the impact of adjunct faculty on student success is integral to this consideration (Berrett, 2011; Coalition on the Academic Workforce, 2012; Cohen \& Brawer, 2008; Kezar \& Maxey, 2013; Messina, 2011; Perez et al., 2012; Schmidt, 2012; Street et al., 2012). If 
“faculty working conditions are student learning conditions" (Maisto, 2012, p.201), as Maisto (2012) argues, then students bear the weight of insecure employment, limited professional integration into the campus community, and a lack of compensation for office hours, PD, and instructional planning (Coalition on the Academic Workforce, 2012; Cohen \& Brawer, 2008; Kezar \& Maxey, 2013; Messina, 2011; Street, Maisto, Merves, \& Rhoades, 2012). Research shows that adjunct faculty tend to spend less time preparing for class and they employ fewer active learning strategies than their full-time counterparts (Kezar, 2012a; Umbach, 2007). Both characteristics can be connected with limited time available within contractual agreements for supplemental out-of-class faculty activities, not excluding lesson planning and the time required for instructional innovation (e.g., integration of digital learning tools). The literature about adjunct faculty suggests that the problem with the contingent nature of their role is the impact of their working conditions (e.g., low pay, limited instructional resources, limited time oncampus, etc.), not the faculty themselves (Gappa \& Leslie, 1993; Kezar, 2012b). Therefore, in order to positively affect the academic experiences of students in higher education, a focus on institutional support for adjunct faculty, including opportunities for integration and engagement, is an imperative.

\section{Guiding Conceptual Framework: The Essential Elements of Faculty Work}

In order to explore the experiences of adjunct faculty in institutions of higher education, an understanding of the larger organizational culture is necessary. This study employed a conceptual framework that prioritizes both faculty and institutional characteristics as key components of organizational culture. The Framework for 
Rethinking Faculty Work from Gappa, Austin, and Trice (2007) identifies five essential elements of the faculty experience (i.e., employment equity, academic freedom and autonomy, flexibility, professional growth, and collegiality) that are shaped by the institution. This framework was selected because it argues that there is a reciprocal relationship between faculty and institutional characteristics, that influences outcomes for faculty experiences. This study assumed a similar relationship between adjunct faculty and their employing institutions. Based on the diverse typology of adjunct faculty and the variance in institutional processes by department, the Framework for Rethinking Faculty Work provided a lens from which to consider the different factors that shape their experience (Gappa et al., 2007). Although the framework does acknowledge efforts by colleges and universities to support non-tenure track faculty, Gappa, et al. (2007) do not argue that the employment experiences of part-time non-tenure track faculty are central to their explanations of the five essential elements. As a result, Thirolf's (2017) Inclusive Faculty Engagement Model, designed specifically for part-time faculty, was employed as a critical lens through which to examine the adjunct experience within the framework.

The essential element of professional growth, as defined by Gappa et al. (2007), was prioritized within the framework due to its examination of faculty development opportunities and the organizational structures that enable participation. The framework assumes a relationship between faculty engagement and opportunities for professional growth, sponsored by the college or university. As a result, this study examined how that relationship does or does not manifest itself with adjunct faculty. Gappa et al. (2007) provide policy recommendations for institutions to contribute to faculty professional 
growth, but currently only one consideration is identified for fixed-term faculty (which they define as inclusive of both full-time NTTF and part-time faculty). This recommendation encourages institutions to, "welcome the participation of fixed-term faculty in professional development activities, and design resources and events tailored to meet their needs" (Gappa et al., 2007, p.296). This study considered that recommendation, while also exploring best practices for meeting the professional growth needs of adjunct faculty — through their own voices.

\section{Purpose of the Study and Methodology}

Transparent institutional policies for adjunct faculty professional growth need to be proactively, rather than reactively, developed. However, in order to develop these policies, a clear understanding of current practice is necessary. In response, this study focused on the lived experiences of adjunct faculty at one four-year public research institution that employs over $40 \%$ of their instructional faculty part-time. With the goal of understanding different practices across the institution, adjunct faculty experiences were explored within the context of each faculty member's employing academic department. The essential element of professional growth from Gappa et al. (2007) and the Inclusive Faculty Engagement Model (Thirolf, 2017) were used as a lens from which to examine the implications of faculty motivation on engagement, as well as the connection between engagement and professional growth experiences. Findings of this analysis bear implications for institutional and departmental policies pertaining to the hiring, onboarding, and ongoing engagement of adjunct faculty in institutions of higher education. 
This study employed an exploratory qualitative embedded single-case study design. Localized at a large urban, commuter, public research institution (i.e., Portland State University), the university's adjunct faculty population was the unit of analysis and the experiences of four individual adjunct faculty (and their individual academic departments) were the sub-units of analysis. Methods of analysis included multiple semistructured interviews with adjunct faculty, semi-structured interviews with department coordinators from each adjunct faculty member's department, and document analysis of departmental and institutional policies.

\section{Research Questions}

This study explored the ways in which institutional engagement shapes professional growth for adjunct faculty at a four-year, public, urban, commuter research university, through the lens of the Framework for Rethinking Faculty Work (Gappa et al., 2007) and the Inclusive Faculty Engagement Model (Thirolf, 2017). Two research questions guided this inquiry in order to better understand the lived adjunct faculty experience:

1. What motivators influence adjunct faculty engagement at PSU?

2. How does institutional engagement shape an adjunct faculty member's professional growth at PSU?

\section{Summary}

As their role currently functions in institutions of higher education, adjunct faculty are marginalized as a group. They are not integrated into campus learning communities nor are they offered intentional opportunities for engagement. Within the 
essential element of professional growth from the Framework for Rethinking Faculty Work (Gappa et al., 2007), PD and opportunities for institution-facilitated engagement are characteristics that enhance faculty work experiences. However, the adjunct experience is largely absent from the framework and the definition of professional growth. It is well established in the literature that adjunct faculty interact with the institution in a different manner than full-time tenured, tenure-track, or non-tenure track faculty as a result of the limitations imposed by employment contracts and due to external obligations (Berrett, 2011; CCCSE, 2014; Coalition on the Academic Workforce, 2012; Kezar, 2012b; Kezar, 2013; Kezar \& Sam, 2011; Roueche et al., 1995; Thirolf, 2017). As a result, institutions bear the responsibility of designing opportunities for engagement that acknowledge these differences. The essential element of professional growth from the Framework for Rethinking Faculty Work (Gappa et al., 2007) provides a place from which to begin the conversation and Thirolf's (2017) Inclusive Faculty Engagement Model provides a critical lens from which to examine the implications of the framework for adjunct faculty. This study endeavored to foreground adjunct faculty voices and experiences as a pivotal lens for understanding the larger organization, at both the department and university levels. As policies and practices communicate enacted missions and values, the findings of this study highlight continued opportunities for organizational innovation, in order to create more inclusive environments for adjunct faculty and, in turn, more effectively shape the learning outcomes for future students. 


\section{CHAPTER II REVIEW OF THE LITERATURE}

Adjunct faculty are the fastest growing instructional base in higher education, but they are provided minimal professional support from their employing institution(s) (AAUP, 2018a; Coalition on the Academic Workforce, 2012; Cohen \& Brawer, 2008; Kezar \& Maxey, 2013). This is a problem because an instructor's investment in their work, as well as their efficacy of performance, are directly related to their working conditions. When professional support is lacking, the problem can result in a lack of engagement with the institution and inconsistent pedagogical choices, which in turn negatively affects student outcomes (Bourdeaux \& Schoenack, 2016). As adjunct numbers rise to almost $50 \%$ of the higher education faculty population, institutions are faced with the challenge of implementing intentional policies and programs that account for their role (Kezar, 2016). Faculty development that supports adjunct professional growth is one such area that necessitates institutional focus.

This chapter is structured in four parts, with a guiding focus on framing the adjunct faculty population in higher education and the organizational characteristics that shape their experience. To start, a holistic review of the adjunct faculty body, including historical context for population growth, is provided, as well as an overview of common adjunct faculty characteristics. Part two explores the topic of organizational culture, including discussion of the Inclusive Faculty Engagement Model from Thirolf (2017). Part three reviews the literature on faculty development models in higher education, identifying the implications and gaps in current structures for adjunct faculty. Part four 
follows with an analysis of the Framework for Rethinking Faculty Work from Gappa et al. (2007), prioritizing the essential element of professional growth.

\section{Adjunct Faculty in Higher Education}

The American Association of University Professors (AAUP) (2017) recognizes two main faculty groups: tenure line and contingent faculty. Tenure line faculty include full-time tenured faculty (FTTF) and full-time tenure-track faculty (FTTTF), while the contingent faculty group is comprised of full-time non-tenure-track faculty (FTNTTF), part-time non-tenure-track faculty (PTNTTF), and graduate student employees (AAUP, 2017). This paper focuses on the contingent faculty who are PTNTTF, also referred to as adjunct faculty (Berrett, 2011). The two terms, PTNTTF and adjunct, will be used interchangeably throughout the paper.

Among many contractual differences, the distinguishing characteristic between the tenure line and contingent faculty groups is simply, tenure (AAUP, 2017; Kezar \& Maxey, 2013). The tenure system in higher education is defined as, "the basic concept that faculty members who have served a proper period of apprenticeship shall enjoy security in their posts and be subject to removal only for 'adequate cause'" (Byse \& Joughin, 1959, p.v). Cameron (2010) states that the "goal of tenure is to create a contractual relationship between a professor and the college or university that is enforceable in a court of law" (p.1). Contingent faculty are not on the tenure line, and therefore lack consistent "security in their posts" (Byse \& Joughin, 1959, p.v) and they exist outside of a long-term relationship with their employer, as the term "contingent" implies (Cameron, 2010). 
Definitions for faculty academic ranks are defined in this section based on those employed by the study site, Portland State University. Per "The Annual Report on the Economic Status of the Profession, 2018-19” (AAUP, 2019), academic ranks assigned to full-time faculty are determined by individual institutions. "Not all institutions use all ranks, and the definitions vary by institution" (p.23). Within the tenure-line faculty group at Portland State University, there are multiple academic ranks for tenure-track faculty. Tenure-track ranks are titled Assistant Professor, Associate Professor, and Professor (AAUP, 2017; Portland State University, 2017). Emeritus is the rank awarded upon retirement "in recognition of outstanding performance" (Portland State University, 2017, p.17). Within the contingent faculty group there are progressive ranks available for FTNTTF with a focus on either instruction (Instructor, Senior Instructor I, and Senior Instructor II) or research (Research Assistant, Senior Research Assistant I, Senior Research Assistant II, Research Associate, Senior Research Associate I, and Senior Research Associate II) (Portland State University, 2017). The Professor of Practice or Clinical Professor ranks are identified as non-tenure track faculty appointments for "individuals whose primary work is in the areas of instructor in clinical or professional practice or in professionally-related community engagement" $(2017$, p.22). These ranks typically require a terminal degree, whereas the instructor ranks often require an advanced degree in the field of specialization. PTNTTF do not have progressive ranks, but they can fill either a research or instructional position (Berrett, 2011; Kezar \& Maxey, 2013; Portland State University, 2017). In addition, while not common practice, some institutions, including Portland State University, offer professional evaluations for 
adjunct faculty after a specific period of time in order to secure a part-time multi-term contract.

Depending on the institution, the term "adjunct" can refer to both full- and parttime non-tenure track positions (Berrett, 2011; Kezar, 2013). Today, almost 50\% of faculty in higher education report as adjunct in the following school types: public comprehensive, private-nonprofit comprehensive, public two-year, and private-nonprofit two-year (Berrett, 2011; Coalition on the Academic Workforce, 2012; Kezar, 2016; Kezar \& Maxey, 2013; Schmidt, 2012; Snyder et al., 2018). In an effort to support campus leaders in understanding part-time faculty, definitions of adjunct faculty "type" are used (see Table 1). Tuckman (1978) identifies seven categories for part-time faculty in higher education: "the semiretired, students, those wishing to become full-time (Hopeful Full-Timers), those with a full-time job (Full-Mooners), those with responsibilities in the home (Homeworkers), those with another part-time job (PartMooners), and all others (Part-Unknowners)" (p.307). Each category is distinguished by hours spent teaching, the institution(s) in which faculty work, socioeconomic background, specific position(s) held, and motivation for employment (1978). Gappa and Leslie (1993) limit the scope of Tuckman's (1978) categories with a more broad typology broken into four groups: career enders; specialists, experts, and professionals; aspiring academics; and freelancers. The categories, while broad, were created in an attempt to support campus leadership in understanding the diverse part-time faculty population. Career-enders are those who are or are close to being retired. Specialists, experts, and professionals are those who are employed full-time elsewhere and are hired for their 
subject-matter expertise. Aspiring academics are those who desire a full-time position and may be employed part-time on multiple campuses. Freelancers are characterized by external responsibilities (e.g., familial or professional) and they seek part-time teaching work for supplemental income. The Center for Community College Student Engagement (CCCSE) (2014) presents a similar, yet expanded, typology of adjunct roles, as presented by Tuckman (1978), including all of the original categories, in addition to online faculty.

Table 1.

Adjunct Faculty Typologies

\begin{tabular}{|c|c|c|}
\hline Tuckman (1978) & Gappa and Leslie (1993) & $\begin{array}{c}\text { Center for Community } \\
\text { College Student } \\
\text { Engagement (2014) } \\
\end{array}$ \\
\hline $\begin{array}{l}\text { 1. The semiretired } \\
\text { 2. Students } \\
\text { 3. Hopeful Full-Timers } \\
\text { (those wishing to } \\
\text { become full-time) } \\
\text { 4. Full-Mooners (those } \\
\text { with a full-time job) } \\
\text { 5. Homeworkers (those } \\
\text { with responsibilities in } \\
\text { the home) } \\
\text { 6. Part-Mooners (those } \\
\text { with another part-time } \\
\text { job } \\
\text { 7. Part-Unknowners (all } \\
\text { others) }\end{array}$ & $\begin{array}{l}\text { 1. Career Enders } \\
\text { 2. Specialists, Experts, } \\
\text { and Professionals } \\
\text { 3. Aspiring Academics } \\
\text { 4. Freelancers }\end{array}$ & $\begin{array}{l}\text { 1. Faculty hoping to use } \\
\text { part-time teaching as a } \\
\text { springboard to full- } \\
\text { time appointment } \\
\text { 2. Faculty who piece } \\
\text { together a full work } \\
\text { load by teaching at } \\
\text { multiple institutions } \\
\text { 3. Faculty who choose to } \\
\text { work part-time while } \\
\text { balancing other } \\
\text { demands } \\
\text { 4. Career professionals } \\
\text { who teach about the } \\
\text { fields in which they } \\
\text { work } \\
\text { 5. Online Faculty } \\
\text { 6. Graduate Students } \\
\text { 7. Retirees } \\
\text { 8. Administrators and } \\
\text { Staff }\end{array}$ \\
\hline
\end{tabular}

Note. Adjunct faculty typologies as defined by Tuckman (1978), Gappa and Leslie (1993), and the Center for Community College Student Engagement (2014). 
In each typology (see Table 1) defined by Tuckman (1978), Gappa and Leslie (1993), and the CCCSE (2014), there is significant variability across each adjunct "type," which highlights the complexity of the adjunct role and the external factors impacting engagement with their employing institution(s). Distinctions in adjunct faculty characteristics are important to consider as institutions identify opportunities for engagement and professional support. The next sections review the historical context for adjunct faculty growth over time and employment characteristics for part-time faculty.

\section{Historical Context: Growth Over Time}

Starting in the 1970s, adjunct faculty employment numbers have been on the rise in the United States (Charfauros \& Tierney, 1999; Cohen \& Brawer, 2008; Gappa \& Leslie, 1993; Kezar, 2012a; Kezar, 2016; Snyder, de Brey, and Dillow, 2018). For example, Snyder, de Brey, and Dillow (2018) report 743,983 part-time faculty employed in all degree-granting postsecondary institutions in 2015, versus 104,000 in 1970. Over this period of time, the percentage of full-time faculty across all degree-granting institution types fell from $77.8 \%$ to $52 \%$ (2018). At present, across institution types, the highest concentration of part-time faculty are found in Associate's (i.e., includes community colleges and colleges that confer more than $50 \%$ of degrees at the associate's level) and Master's (i.e., institutions that award at least 50 master's degrees and fewer than 20 doctoral degrees per year) degree-granting institutions (American Association of University Professors, 2018a). An important distinction, however, is the difference between part-time graduate employees and part-time faculty. The American Association of University Professors (AAUP) (2018a) reports that graduate-student employees 
perform labor (i.e., course instruction, grading, etc.) that is completed by part-time faculty at different institution types. Figure 1 demonstrates that over $40 \%$ of instructional faculty at four-year R1, R2, R3, and Master's degree-granting institutions are employed less than full-time (as both part-time and graduate employees) (2018a). Therefore, it's important to note that this study specifically examined the professional growth experiences of part-time faculty at a four-year institution, rather than the experiences of graduate employees performing similar duties.

\section{Figure 1.}

Part-time Faculty and Graduate Employees as a Percentage of Instructional Faculty, 2016

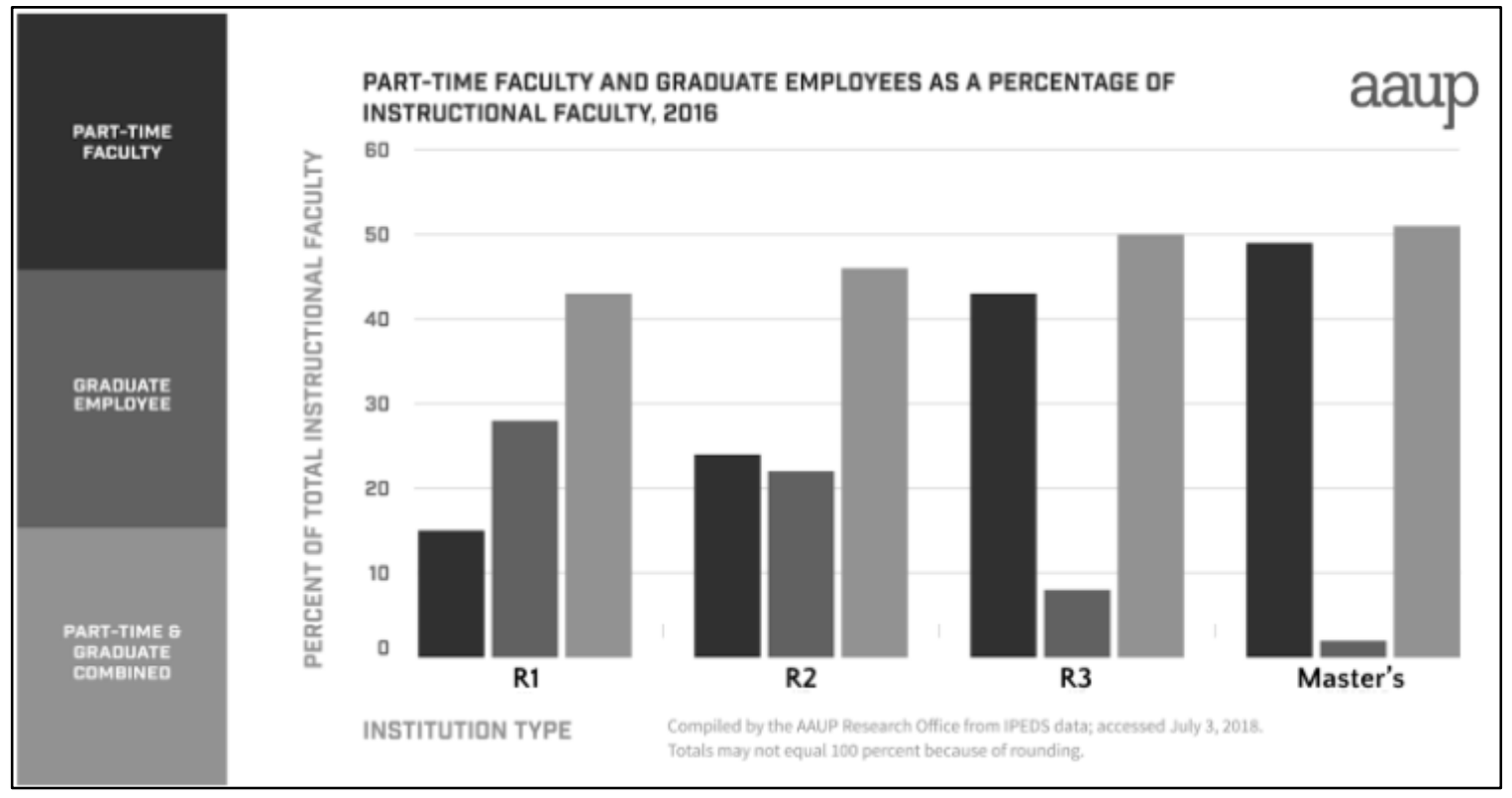

Note. Institution types are designated using Carnegie classification for institutions of higher learning. Figure from the American Association of University Professors (2018a). Institute type labels were edited for readability.

Significant part-time faculty growth has occurred and is documented in the literature starting in the 1970s (AAUP, 2018a; Charfauros \& Tierney, 1999; Kezar, 2012a), therefore, historical context for this rise will be reviewed starting with that origin. 
Kezar (2012a) states that part-time faculty were hired at two-year institutions in the 1970s as subject matter experts in the professional and/or vocational fields. Four-year institutions followed suit and recognized the opportunity to provide practical expertise from adjunct faculty in their pre-professional programs. The 1980s brought on the combination of decreased state budgets for higher education and an increase in student enrollment. In response, postsecondary institutions sought fiscally flexible solutions to meet the needs of their changing student populations. Across institution types, adjunct faculty employment expanded from subject matter experts in the professional and vocational fields to instructional leaders in academic subjects (e.g., math and English). Kezar (2012a) addresses the move in the United States to a more "massified" (p.xvi) system of higher education that brought on the need for more remedial course options, many of which adjunct faculty were hired to teach. Over the next two decades, declines in state funds and rising institutional operational costs necessitated organizational shifts, including hikes in student tuition and increased hiring of both full- and part-time nontenure track faculty. Decreased hiring of tenured and/or tenure-track faculty provided an opportunity to control costs, specifically with the hiring of PTNTTF whose pay and benefits were lower than that of their FTNTTF counterparts (Kezar, 2012a). Umbach (2007) argues that this decrease negatively affects student learning and retention, based on adverse working conditions for both full- and part-time faculty. Kezar (2012a) attributes a shift in cultural and institutional values as an additional contributing trend to the rise in adjunct numbers. Negative public perceptions of tenure and a lack of confidence in public higher education, borne of shifts in the business sector and declining 
government fiscal support, instigated changes in hiring practices. With a growing number of leaders from the corporate world serving on college and university boards of directors, cultural shifts in faculty hiring practices mirrored those of the general American workforce (Kezar, 2016). As budgetary challenges persist and institutions seek to engage “more students in a more efficient—less expensive-manner" (Charfauros \& Tierney, 1999, p.142), reliance on adjunct faculty continues to be a solution sought by administrators. This reliance addresses institutional budgetary needs, but it neglects those of the faculty. Faculty seeking full-time employment are met with fewer opportunities and increased responsibilities upon hire. For part-time faculty, the nature of their role is as a cost-saving measure, so all conditions of employment are derived from that goal. These challenges are ubiquitous across four-year public colleges and universities, due to the decrease in public funding for higher education.

\section{Employment Characteristics}

Tenure policies for full-time faculty are situated within a formalized and widely accepted agreement for procedures to ensure academic freedom in colleges and universities (1940 Statement of Principles on Academic Freedom and Tenure, n.d.). However, this same uniformity is lacking for adjunct faculty. Gappa and Leslie (1993) identify that "approaches to employment policies and practices are based on strong institutional beliefs about the value and appropriate use of part-time faculty" (p.141). This implies variability in employment policies, by institution, rather than uniformity across the profession. For example, if an institution believes that adjunct faculty value is rooted in their quality of instruction, policies and practices will "translate this belief into 
practice" (p.141). Conversely, the same can be said for employment policies that affirm an institution's belief that adjunct faculty are valued for their cost-saving benefits. Because their associated value is malleable based on shifting institutional needs, formal recognition within policy statements from disciplinary societies are uncommon and highly concentrated in literature from the past 20 years (Kezar \& Sam, 2010). Even so, interdisciplinary coalitions, including the Coalition on the Academic Workforce, as well as professional organizations, such as the AAUP and the National Education Association (NEA), have developed policy statements related to NTTF groups (Coalition on the Academic Workforce, 2012; Contingent Faculty, 2017; Kezar \& Sam, 2010).

These policy statements provide clear definition of organizational beliefs and embedded values, as well as recommendations for institutional policies for adjunct faculty. For example, the NEA policy statement on contingent faculty states that the, ...NEA believes that it is time to end the abuse and inappropriate use of part-time and temporary faculty by colleges and universities. Part-time faculty should be treated no differently than full-time, tenured or permanent faculty for purposes of employment conditions, including eligibility to collectively bargain. (Contingent Faculty, 2017)

This position asserts that part-time faculty are currently being inappropriately treated (e.g., separate salary schedules and exclusion from faculty governance) across institutions of higher education, specifically in contrast to their full-time tenured/tenure-track or nontenure-track counterparts. The NEA asserts that "employment conditions" (2017, n.p.) should be the same for all faculty groups. However, within a system of academic capitalism, tenure policies automatically ascribe employment conditions, namelycompensation - according to the faculty member's academic rank (AAUP, 2017; Boyer, 
1990; Portland State University, 2017). For example, compensation per credit hour for instructional faculty differs greatly for TTF, FTNTTF, and PTNTTF. In addition, there is clear variance in compensation for faculty rank across institutions and disciplines (Chronicle Data, 2018). While the NEA statement presents recommendations and associated rationale for 1) initial hiring of part-time faculty, 2) opportunities for conversion to full-time status, 3) resource allocation, 4) salary schedules, and 5) shared governance, each recommendation remains vague and dependent on the individual discretion of each institution of higher education (Contingent Faculty, 2017).

In the community college space, Cohen \& Brawer (2008) describe a disposable and convenience-based relationship between part-time faculty and their institution. This relationship results in lower pay for adjuncts, last-minute hiring practices, and limited professional development opportunities (Cohen \& Brawer, 2008; Messina, 2011; Street, Maisto, Merves, \& Rhoades, 2012). A similar image of employment characteristics for adjunct faculty is mirrored within four-year colleges and universities. Adjunct faculty are depicted as "teachers on wheels" (Street et al., 2012, p.2), and they, on average, receive lower pay-per-course than their full-time counterparts, as well as inconsistent employee benefits. Inconsistent benefits include compensation for out-of-class activities, such as department meetings or office hours, as well as pay for late class cancellations (AAUP, 2018b; Coalition on the Academic Workforce, 2012; Kezar \& Maxey, 2013; Street et al., 2012). In addition, documented support for on-the-job training, including professional development on best practices for teaching and learning, is not commonly included within adjunct faculty employment contracts. To their employing institution, adjunct 
faculty are hired based on the premise that they are contingent and disposable. They continue to be hired as institutions seek opportunities for cost-saving.

\section{Adjunct Faculty in Higher Education: Summary}

Beginning in the 1970s, adjunct faculty numbers have increased across two- and four-year degree-granting institutions of higher education (Kezar, 2016; Snyder et al., 2018). As contingent faculty, the adjunct role is categorized based on different motivators for part-time employment (CCCSE, 2014; Gappa \& Leslie, 1993; Tuckman, 1978). Within the larger organization, they often assume the majority of the undergraduate teaching load and they are situated as distant from valued academic roles (e.g., tenure, research, etc.), as well as peripheral to their department culture. As such, contractual agreements for their employment traditionally do not account for their professional growth needs, including development opportunities and department integration. The next section of this literature review will discuss organizational culture and how it shapes the adjunct experience.

\section{Organizational Culture}

Since World War II, the polarization between teaching and research has increased, with a common perception that the two practices are "incompatible opposites" (Keast \& Macy, 1973, p.10). As the faculty body who assumes the majority of the teaching load, adjunct faculty are positioned as distant from the research and servicefocused activities embraced by full-time faculty on the tenure line (Berrett, 2011; Cameron, 2010; Keast \& Macy, 1973; Kezar, 2013). Their role is defined as peripheral to the ecosystem of the larger institution. Therefore, examination of the adjunct experience 
within an organization's culture provides a lens from which to understand power, access to resources, and perceptions of belonging. This section will review literature on organizational culture and a model for inclusive faculty engagement. Access to information and institutional integration will be highlighted as elements of organizational culture that shape the adjunct experience.

\section{Organizational Culture and Adjunct Faculty}

Bolman and Deal (2013) state that "culture is both a product and a process. As a product, it embodies wisdom accumulated from experience. As a process, it is renewed and re-created as newcomers learn the old ways and eventually become teachers themselves" (p.263). As both a product and a process, culture is derived from the organization in which it exists and it is ever-evolving as internal and external forces shift. Through this lens, adjunct faculty inhabit a malleable space within an institution's culture that changes according to the organization's response to competing forces (e.g., funding, institutional values, enrollment changes, department needs, etc.).

Tierney (1988) identifies six categories within a framework of organizational culture: environment, mission, socialization, information, strategy, and leadership. Each category provides a unique lens from which to analyze a college or university's culture in distinct parts and as competing forces on the whole. Tierney's (1988) framework for organizational culture provides an interpretive approach for analyzing the culture of individual campuses, and the impact on the faculty climate within that institution (Marion \& Gonzales, 2014). In addition, Tierney (2011) addresses the enacted environment of organizational culture through an acknowledgement of the social construction of meaning 
and culture, as developed through individual interpretation of "historical traditions, current situational contexts, and individual perceptions" (p.11). This form of organizational culture acknowledges the "immense capacity" (p.12) of the institution to create its own environment.

An alternative lens for understanding organizational culture is found through Handy's (1993) deductive typology of four categories. Handy (1993) argues that an organization's culture will align with one of the following: a power culture, a role culture, a task culture, or a person culture. In connection with this typology, Schein (2010), argues that culture can be described through behaviors and climate, as demonstrated through a group of people in an organization. Common behaviors include: group norms, espoused values, formal philosophy, and rules of the game (Marion \& Gonzales, 2014). Schein (2010) defines climate as, "the feeling that is conveyed in a group by the physical layout and the way in which members of the organization interact with each other, customers, and outsiders" (p.15). Included in this definition is an acknowledgement of the symbolic values of cultural climate, including embedded skills, habits of thinking, and shared meaning (Marion and Gonzales, 2014).

The behaviors and climate of postsecondary institutions can be broken into multiple cultures: the institution as a whole, the faculty, and individual departments within the larger institution. Applying Handy’s (1993) typology, two- and four-year colleges can be categorized as aligning with a role culture because they are complex institutions in which departmental responsibilities are "clearly delineated and operationalized" (Marion \& Gonzales, 2014, p.268). Within this culture, adjunct faculty 
fulfill a specific need (e.g., response to financial limitations, changes in student enrollment, etc.) and are assigned their professional responsibilities and institutional support accordingly (Coalition on the Academic Workforce, 2012). The next two sections review elements of organizational culture that impact adjunct faculty experiences: access to information and institutional integration.

\section{Access to Information}

From initial recruitment through subsequent employment, the ways in which adjunct faculty interact with information dictates their perception of their role within the institution. These interactions can derive from how information is or is not provided, as well as how it is accessed. West (2010) states that there is a general desire to be "part of the university community" (p.22) and to develop relationships with colleagues. However, these desires are not traditionally met (Feldman \& Turnley, 2011; Flaherty, 2015; Flaherty, 2016; Tyree et al., 2000). Feldman and Turnley (2011) identify three areas in which effective management of adjunct faculty can improve: recruitment, working conditions, and supervision. In each, transparency and consistency are paramount. For example, they articulate that adjunct faculty "...need to have realistic ideas of what their jobs will entail and whether permanent employment in the same university is a likely outcome" (Feldman \& Turnley, 2011, p.13). If incorrect information is provided, or there is a dearth of information, adjunct faculty will perceive their role as "second-class citizens" (Feldman \& Turnley, 2011, p.8) and as inconsequential within the larger goals of the institution. In terms of ongoing supervision, adjunct faculty express the need for "more communication with supervisors, more mentoring from senior colleagues, and 
greater integration into their work groups" (Feldman \& Turnley, 2011, p.14). This form of comprehensive supervision and departmental integration for adjunct faculty enables a transparent flow of information, as well as the opportunity for developed social capital and engagement within their academic unit(s).

\section{Institutional Integration}

Negative institutional assumptions about adjunct faculty investment and ability are connected to the organizational culture (Kezar \& Sam, 2011; Thirolf, 2017). These assumptions occur when there is a dearth of support for the adjunct role, including inconsistent communication from supervisors, limited mentoring from colleagues, and a lack of integration into work groups (Feldman \& Turnley, 2011). Gappa (2000) argues that feelings of isolation stem from the part-time nature of the adjunct faculty role: “...instead of feeling connected to or integrated into campus life, [adjunct faculty] often feel alienated, powerless, and invisible. This is frequently due to departmental culture and the leadership (or lack thereof) of department chairs" (Gappa, 2000, p.81). With organizational culture as the determining factor for the adjunct experience, institutional leaders bear the burden of facilitating an environment in which this faculty group is formally recognized and engaged. Departmental decision-making is one opportunity to improve part-time faculty integration, especially when those decisions will affect adjunct faculty (Gappa, 2000). They express a desire to be involved and consulted during such decisions and identify this form of engagement as acknowledgement of professional status in the academic community (Gappa, 2000). One example of how this can occur is through alternative employment contracts that go beyond simply identifying part-time 
faculty as contingent workers. Instead, these contracts formally recognize adjunct employees by defining a professional structure for their relationship with the institution, including physical workspace, professional evaluation(s), and promotion through parttime multi-year appointments (Flaherty, 2015; Flaherty, 2016; Portland State University, 2015). Contracts that accomplish this level of integration acknowledge the adjunct role as a professional member of the campus community, and the necessity for contracted guidelines regarding institutional support.

\section{Inclusive Faculty Engagement Model}

As it currently functions, adjunct faculty are not integrated into institutions of higher education. Thirolf (2017) offers an Inclusive Faculty Engagement Model (see Figure 2), that prioritizes part-time faculty engagement as a direct contributor to student academic success. The model defines engagement as "the actions and behaviors that faculty and institutions take to facilitate and support faculty professional growth" (Thirolf, 2017, p.305). Engagement is therefore not solely dependent on individual investment on the part of the faculty member, but is born of a collaborative relationship between faculty and the larger institution.

Thirolf (2017) grounds the definition of inclusive faculty engagement on Tinto's (1993) model of student integration. This model states that, "integration is the opposite of feeling excluded, segregated, or isolated" (Thirolf, 2017, p.305). Tinto (1993) identifies two forms of integration: academic and social. Academic integration accounts for inclusion and feelings of connectedness in intellectual communities as well as in the larger institution (Thirolf, 2017; Tinto, 1993). Social integration refers to a "perception of 
fit" (Thirolf, 2017, p.305) or a sense of belonging, based on interactions with individuals in the college, including peers and faculty. Thirolf (2017) applies these concepts to parttime faculty and draws from Roueche, Roueche, and Milliron's (1995; 1996) part-time faculty integration model, which articulates how institutions can increase part-time faculty integration into the school culture as well as feelings of belonging and trust.

\section{Figure 2.}

\section{Inclusive Faculty Engagement Model}

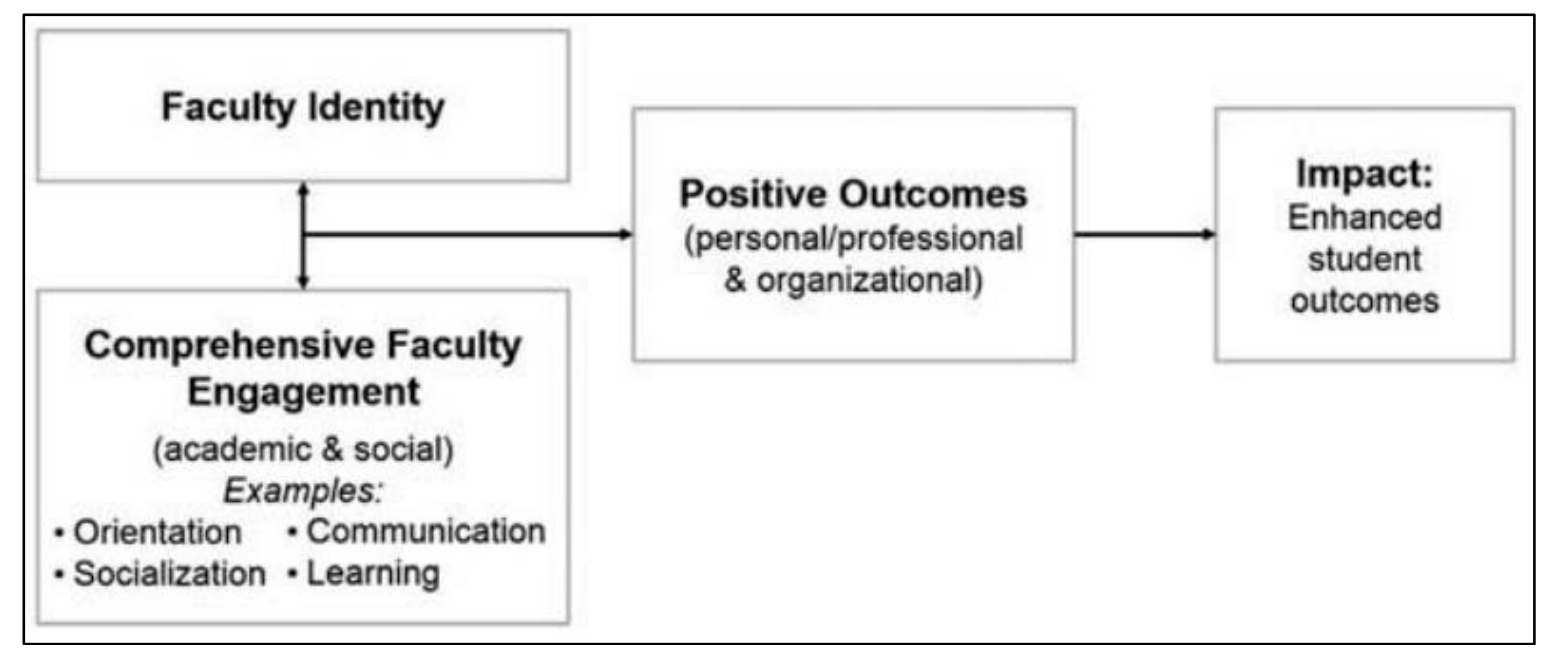

Note. The Inclusive Faculty Engagement Model (Thirolf, 2017) prioritizes faculty identity and comprehensive faculty engagement as connected with positive outcomes for faculty, the organization, and for students.

Using this model, in order to engage adjunct faculty in the university community, the institution needs to facilitate a collaborative relationship that allows for academic and social integration. Without this collective and intentional approach to part-time faculty engagement, professional needs will be unmet (Maslow, 1970; Roueche, Roueche, \& Milliron, 1996; Thirolf, 2017; Tyree et al., 2000). One example of unmet professional needs is identified by Tyree, Grunder, and O'Connell (2000), who focus on adjunct faculty members' physiological needs. As the base of Maslow's (1970) Hierarchy, Tyree 
et al. (2000) define unfulfilled physiological needs for part-time faculty as "the lack of an adequate wage scale; having to work more than one job for a living wage; lack of health benefits; and pay-docked for sick days" (Tyree et al., 2000, p.26). Additional examples within Maslow's (1970) Hierarchy include adjunct faculty members' limited recognition for their academic qualifications (esteem needs), a lack of support and funds for their attendance at academic conferences that enable professional development (cognitive needs), and a lack of full-time employment opportunities or promotional pathways (selfactualizing needs) (Tyree et al., 2000).

Based on these identified unmet needs, the part-time faculty role is not characterized by a sense of belonging or integration, which Thirolf (2017) defines as a "state of being whereby a faculty member feels a sense of belonging to their academic department and college [and a] sense of feeling intellectually and professionally connected to a department or campus" (p.306). This absence frames the problem of limited institutional support for adjunct faculty — the fastest growing faculty population who assume the majority of the teaching load in many institutions (Berrett, 2011; Kezar, 2013).

\section{Organizational Culture and Adjunct Faculty: Summary}

Within an organization's culture, adjunct faculty embody a malleable role that is shaped by competing forces. Deriving from systemic attributes that are environmentally, politically, and socially motivated, access to information and professional integration into the larger campus community are uniquely determined based on individual institutional culture. Thirolf's (2017) Inclusive Faculty Engagement Model prioritizes academic and 
social integration in the organizational culture as contributing to positive outcomes for adjunct faculty, the larger institution, and students. The next section will explore the literature on faculty development. This topic is considered, in line with Thirolf's (2017) Model, as a way to better understand academic and social integration within institutionfacilitated opportunities for professional development and faculty growth.

\section{Faculty Development in Higher Education}

When professional development (PD) is facilitated as a valued element of an organization's culture, it is an opportunity to foster employee engagement as well as buyin with larger institutional goals (Feldman \& Turnley, 2011; Francis, 1975; Gappa, 2000; Ouellett, 2010). As a learning environment, colleges and universities embody an ethos that champions personal growth and collective development. This ethos is challenged by competing priorities (i.e., financial and political forces), but it can be affirmed and communicated through institution-facilitated opportunities for faculty development. This section of the literature review will provide a framework for the evolving function of PD in higher education, including definitions, faculty motivators for participation, institutional motivators for facilitation, and common best practices employed on college/university campuses. Implications for adjunct faculty will be discussed through examination of organizational elements that shape their experiences.

\section{Definitions of Faculty Development}

Faculty development programs in higher education have evolved over time from more decentralized offerings by department, to centralized offices focused on the scholarship and practice of teaching and learning (Ouellett, 2010). Francis (1975) defined 
faculty development as a "process which seeks to modify the attitudes, skills, and behavior of faculty members toward greater competence and effectiveness in meeting student needs, their own needs, and the needs of the institution" (p.720). Through this lens, successful faculty development programs "change the way faculty feel about their professional roles, increase their knowledge and skills in those roles, and alter the way they carry them out in practice" (Francis, 1975, p.720). Francis' (1975) model of faculty development is one that focuses on faculty awareness of best practices for teaching and learning through a three-stage developmental model (consciousness-raising, focalawareness stage, and subsidiary-awareness). This model applies Lewin's (1947) change model for organizations to the ways in which institutions approach instructional development. Francis' (1975) multi-stage model differs from those developed by Bergquist and Phillips (1975), Lewis (1996), and Diamond (2002), who argue that faculty development encompasses more than individual or instructional development. First introduced by Bergquist and Phillips (1975) and later expanded upon by Lewis (1996), their three-part model of faculty development is inclusive of personal, instructional, and organizational development. Personal development includes "self-reflection, vitality, and growth;" instructional development relates to "course and student-based initiatives;" and organizational development includes, "program, departmental, and institution-wide efforts" (Ouellett, 2010, pp.7-8). Diamond (2002) asserts that the combination of the three (i.e., personal, instructional, and organizational) enables a more holistic and effective development model by which to support both students and faculty in the process of teaching and learning. Although the three-part definition of faculty development shows 
a shift in the paradigm and departs from Francis' (1975) model that centers instructional development, both models consider organizational elements, including professional attitudes and institutional resources, that shape faculty development programs at an institution. Each model and definition of faculty development prioritizes an intentional inquiry into the current organizational culture and "prevailing attitudes about instruction" (Francis, 1975, p.722) in order to design effective educational experiences.

Changes in higher education, including shifts in institutional expectations for faculty, continue to shape faculty development models (Ouellett, 2010). A 2006 study conducted by Sorcinelli et al. (2006) analyzed the reported priorities of 494 faculty developers from the Professional and Organizational Development Network in Higher Education (the POD Network) (McKee et al., 2013). Two of the five identified priorities focus on changes in the faculty population. Specifically, the challenge of "balancing increasingly complex and demanding faculty roles" was the highest rated priority, and "addressing the needs of part-time faculty" was rated the fourth (Ouellett, 2010, p.9; Sorcinelli, 2006). Changes in the faculty population and the responsibilities assigned to that role for both full- and part-time faculty remain a relevant trend (AAUP, 2018a; Charfauros \& Tierney, 1999; Kezar, 2012a; Snyder et al., 2018). As such, the identified priorities from the 2006 POD Network study continue to shape institutional decisionmaking around faculty development.

In practice, faculty development programming is commonly initiated through a center for teaching and learning (Frey, 2012; Lieberman, 2005). Offered trainings can include just-in-time one-on-one consultations about digital learning tools, one-time 
workshops, and both short- and long-term programs focused on myriad topics (e.g., course design, flipped classroom, etc.). Formerly referred to as "expert centers" (Frey, 2013, p.30), current centers for teaching and learning encourage faculty inquiry into student-centered pedagogy along with supporting broader institutional goals for organizational learning (Lieberman, 2005; Ouellett, 2010). Their scope can include course development, management of the institution's learning technology portfolio (in partnership with a campus information technology team), and assessment services (Bates \& Sangra, 2011; Lieberman, 2005). In addition, individual academic departments are also dynamic in supporting faculty development, including use of adopted learning technologies and support for faculty professional growth, based on individual faculty interests and needs. Departmental support, however, is largely dependent on the direction of the Dean or the Department Chair and the culture of the tenured or tenure-track faculty (Feldman \& Turnley, 2011; Gappa, 2000; Kuhlenschmidt, 2010; Case et al., 2016). Motivators for Faculty Development Programming

Motivators for faculty development programming in higher education can be examined through two lenses: 1) institutional motivation for providing PD to faculty, and 2) faculty member motivation for participation. On the part of the institution, commitment to faculty development is not a new trend, but instead is a practice that has seen shifts in motivation over time. For example, sabbatical leave was instituted at Harvard in 1810 with the goal of supporting faculty members' development as scholars (Lewis, 1996; Ouellett, 2010). Lewis (1996) identifies the practice of sabbatical leave as one of the first forms of faculty development. This form of support was the most common 
example of institutional investment in faculty, with the motivation to develop faculty as published researchers (Ouellett, 2010). The 1960s introduced shifts in institutional programming for faculty development, based on the student rights movement in higher education. This movement prioritized the student voice, through feedback for faculty and in the curriculum (Gaff \& Simpson, 1994; Ouellett, 2010). In connection with this shift, Ouellett (2010) states that there was a "reimagination" (p.4) of faculty life and professional success, beyond traditional definitions that were motivated solely by the scholarship of research. Institutions acknowledged the need to develop faculty as instructional leaders and the motivation to do so continues to evolve on college and university campuses today. For example, in both two- and four-year institutions, this evolution includes a desire to recognize faculty for excellence in teaching, through institutional awards for both full- and part-time faculty. Institutional motivators for facilitating faculty development programming can also be understood in connection with faculty motivators for participation.

Faculty motivators for engaging with institution-facilitated development opportunities can be connected with both extrinsic and intrinsic factors. Merriam and Bierema (2013) state that extrinsic motivation commonly provides a means to an end and is drawn from external factors, including the potential for connection and recognition from colleagues, or promotional opportunities. Intrinsic motivators differ in that they are deeply personal and internal to the individual (2013). Driving forces include a commitment to students, the desire to further knowledge in an academic discipline, and/or for mastery of a subject or practice. Both extrinsic and intrinsic motivators find 
connection with cognitive and need-driven motivational theories (Lewin, 1947; Maslow, 1970). Cognitive motivation theory posits that rewards for learning have different meanings for each person and that personal perceptions are dependent on prior experiences (Merriam \& Bierema, 2013). This theory is largely rooted in intrinsic motivators and focused on the connection between an individual's thoughts and actions. Need-driven motivational theories are derived from Maslow's (1970) hierarchy of needs that accounts for both internal and external factors that drive human behaviors. In practice, faculty are also held accountable by workplace motivators, including those connected with employment (i.e., required participation, etc.). Dependent on faculty rank, academic discipline, and the employing college/university, motivational factors will differ. In addition, institutional incentives for participation, including those attached to tenure and promotion, will differentially benefit full- versus part-time faculty. The diverse typology of faculty roles assumes myriad motivational factors that influence participation in institution-facilitated faculty development experiences (CCCSE, 2014; Gappa and Leslie, 1991; Tuckman, 1978). For adjunct faculty, when their position does not require engagement with the university (outside of their contracted instructional responsibilities), a decision or desire to participate in development opportunities is largely driven by intrinsic motivation. Personal values and professional goals will drive the adjunct faculty member's decision to engage with the institution

\section{Implications for Adjunct Faculty}

Faculty development programs have experienced changes over time, based on shifts in institutional culture. From programs focused solely on individual instructional 
development (Francis, 1975) to a more holistic model that includes personal, instructional, and organizational development (Bergquist \& Phillips, 1975; Diamond, 2002; Lewis, 1996), faculty development is an embedded institutional process in which the culture of the institution is projected and by which faculty can develop as both scholars and instructional leaders. However, intentional organizational change with adjunct faculty professional development has not consistently occurred over time and it does not account for the diverse typology of adjunct roles nor the limitations of part-time employment (CCCSE, 2014; Gappa \& Leslie, 1993; Tuckman, 1978).

Tarr (2010) states that development offerings for adjunct faculty should be initiated by the "campus units responsible for these faculty members" (p.352). Although that responsibility differs by institution, the literature (Lyons, 2007; Smith \& Wright, 2000; Tarr, 2010) suggests that programs that are systematic and comprehensive are more effective for adjunct faculty, than those that are disconnected and unrelated. Due to the complexity and variance of implementation across institutions, Tarr (2010) recommends a collaborative internal approach, in order to facilitate effective adjunct faculty development. A collaborative approach has the potential to increase consistency across the adjunct experience, despite the mediating differences of employing departments. Even so, this recommendation begs the question of whether the differences in academic discipline do require unique approaches to adjunct faculty professional support. Consistency across the adjunct experience assumes consistency in adjunct employment experiences. However, that consistency is unlikely, based on the diverse typology of adjunct types and departmental differences. 
When supporting the work of adjunct faculty, Lyons (2007) provides recommendations for institution-facilitated $\mathrm{PD}$, including clear connection with the institutional mission and key stakeholders. Participant feedback and continuous program evaluation is also prioritized (2007). Identified areas of need for adjunct faculty development include an orientation to the institution, training on instructional and classroom management skills, as well as initial and ongoing PD opportunities (Lyons, 2007; Tarr, 2010). However, due to the limitations of the adjunct role (i.e., limited contractual hours, compensation guidelines, external PTNTTF responsibilities, etc.), institutions of higher education need to consider intentional ways to facilitate PD with a part-time faculty audience in mind. Tarr (2010) encourages institutions to consider diverse scheduling options when delivering PD for adjunct faculty. Programming in the evenings and on the weekends as well as through online platforms is one such approach (2010). Another consideration is about whether to offer learning opportunities that include faculty from all ranks (TTF, FTNTTF, PTNTTF) or to limit specific offerings to only adjunct faculty. Kelly (2016) argues that creating criteria for participation in PD offerings, by academic discipline, is one way to facilitate intellectual communities of practice, in which both full- and part-time faculty can engage and interact. Tarr (2010) encourages institutions to consider the purpose of the programming and whether those goals can best be achieved in a homogenous group of only adjunct faculty or if they are best met with a diverse grouping of faculty ranks. An additional consideration regarding PD for institutions is about compensation for adjunct faculty participants. When faculty receive monetary support, more faculty development is pursued (Centra, 1976). However, 
compensation for adjunct faculty participation in PD is not common practice (Coalition on the Academic Workforce, 2012; Kezar \& Maxey, 2013; Street et al., 2012; Tarr, 2010). Limitations in collective bargaining agreements and/or in faculty employment contracts often hinder compensation for participation in faculty development programming. Even so, consideration for compensation-whether as direct reimbursement, incentivized salary increases, or pathways to multi-term contracts-is an essential motivating consideration (Centra, 1976; Portland State University, 2015; Tarr, 2010).

\section{Faculty Development in Higher Education: Summary}

To review, faculty development programs in institutions of higher education have evolved over time. From decentralized to centralized programming focused on the practice of teaching, faculty development experiences continue to change based on the culture of the college or university (Bergquist \& Phillips, 1975; Diamond, 2002; Francis, 1975; Lewis, 1996; Ouellett, 2010; Sorcinelli et al., 2006). Institutional motivation for offering faculty PD has evolved from a singular focus on sabbatical leave for research pursuits to a more holistic commitment to student learning and the development of faculty as instructional leaders (Ouellett, 2010). Faculty motivation for participation is based on both intrinsic and extrinsic factors, including personal values and professional goals, as well as requirements connected to employment (Merriam \& Bierema, 2013). For adjunct faculty, participation in institution-facilitated PD is a challenge based on the part-time nature of their role and contractual limitations that hinder compensation for participation. Even so, recommendations in the literature encourage institutions to be 
intentional when scheduling PD for all faculty (Kelly, 2016; Lyons, 2007; Tarr, 2010). This intentional approach includes consideration of alternative scheduling options, increased efforts to reimburse or compensate faculty participation, and inclusion of adjunct voices during program evaluation. The next section will review the literature on the Framework for Rethinking Faculty Work from Gappa et al. (2007) and the essential element of professional growth will be discussed.

\section{The Essential Elements of Faculty Work}

The Framework for Rethinking Faculty Work from Gappa et al. (2007) is the conceptual framework guiding this study. This framework considers the organizational culture of an institution, including both faculty and institutional characteristics, that shape the faculty work experience. Faculty characteristics are defined through demographics and appointment types, while institutional characteristics include: culture and norms, mission, resources, reward structure, leadership, and governance structure (Gappa et al., 2007). Similar to Thirolf (2017), Gappa et al. (2007) argue that there is a reciprocal relationship between faculty and institutional characteristics that shape the faculty work experience. That experience is centered around an essential element of respect and is broken into five key areas: employment equity, academic freedom and autonomy, flexibility, professional growth, and collegiality.

The framework (see Figure 3) seeks to answer two strategic questions. The first is, "what are the essential elements of faculty work and the academic workplace that, when in place, enhance institutional efforts to recruit and retain highly capable faculty?" (Gappa et al., 2007, p.128). The second question is, "what specific institutional policies 
and practices contribute to an academic workplace that supports all faculty members in carrying out excellent work in service to institutional missions?” (p.128). An answer to the first question is positioned as the five essential elements (i.e., employment equity, academic freedom and autonomy, flexibility, professional growth, and collegiality). The second question is examined through considerations of policies and practices that fall within the categories of the essential elements. The defining boundaries of this framework are also important to note. Although the framework is identified as a "rethinking" of traditional foundations of the academic career, it is still dependent on fulltime faculty roles, whether on or off of the tenure-line. The employment experiences of part-time non-tenure track faculty are not central within recommendations for policies or organizational procedures stemming from the essential elements. Kezar (2012b) provides an overlay of policy recommendations for institutions to employ the essential elements of the framework from Gappa et al. (2007), with consideration for both full- and part-time non-tenure track faculty and those recommendations were considered in the application of the framework for this study. 


\section{Figure 3.}

The Essential Elements of Faculty Work

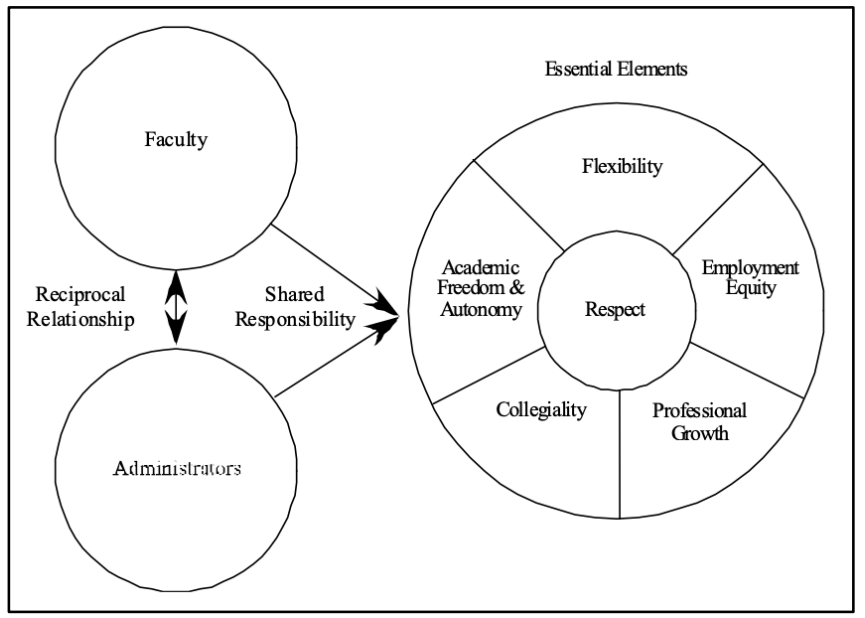

Note. The Essential Elements of Faculty Work, as derived from Gappa \& Austin (2010), Figure 1 "Essential Elements of Faculty Work" (p.9).

\section{The Essential Elements: An Overview}

The essential elements of faculty work are identified as factors that shape faculty satisfaction which are “...critically important in enabling colleges and universities to achieve faculty workplaces that support and enhance the contributions of all faculty members, regardless of their appointment types” (Gappa et al., 2007, pp.137-138). Although manifestation of each element varies by institution, based on institutional culture, resources available, and faculty characteristics (i.e., appointment types, course assignments, etc.), Gappa et al. (2007) argue that they should be considered foundational in designing faculty work. The elements of respect and professional growth are discussed in this section as interrelated and actionable components of an organization's professional culture that shape the adjunct experience. 


\section{Respect}

Within the framework, respect is identified as the core of the essential elements impacting faculty work. Respect, in this context, is defined as “...a fundamental entitlement for every faculty member[...] at the core of any reciprocal relationship between faculty members and their institutions" (Gappa et al., 2007, p.139). This definition prioritizes the intrinsic factors of employee motivation and work satisfaction, based on theories from Herzberg (1966), Maslow (1970), and Alderfer (1972). As foundational for the efficacy of the five essential elements, respect is required because if the faculty member does not feel respected, based on intrinsic and external factors (Herzberg, 1966; Maslow, 1970), they are less likely to value and or benefit from the other elements of the framework (Gappa et al., 2007).

Recommendations to foster a culture of respect for faculty include encouraging proactive leadership at all levels and engaging in "pulse taking" (Gappa et al., 2007, p.148) as a form of auditing the organizational culture. Bolman and Deal's (2013) organizational framework examines culture through four lenses: structural, political, human resources, and symbolic. Gappa et al. (2007) suggest that leaders employ the four lenses as a way to critically assess an institution's culture of respect. Feelings of respect for faculty come from their individual and collective treatment at an institution and their treatment is evidenced through organizational policies and practices that shape their dayto-day work experiences (Gappa et al., 2007). 


\section{Professional Growth}

Professional growth opportunities are those that "enable faculty members to broaden and deepen their knowledge, abilities, and skills, to address challenges, concerns, and needs, and to find deeper satisfaction in their work" (Gappa et al., 2007, p.280). Participation in professional growth opportunities positively contributes to an individual faculty member's growth as well as to the strength of the larger institution (2007). Based on the growing number of faculty employed in non-tenure track roles, Gappa et al. (2007) identify the need for innovative professional growth opportunities that are accessible to all faculty, including to faculty employed on a fixed-term and/or part-time contract.

Within the definition of this essential element, eight recommendations for institutions to support professional growth opportunities for all faculty are offered (Gappa et al, 2007):

1. Professional Growth through Information and Resources

2. Professional Growth through Work-Related Assignments

3. Professional Growth through Flexible Unit Planning

4. Professional Growth through Collegial Interaction

5. Professional Growth through Individualized Growth Plans

6. Professional Development that Addresses Institutional Mission

7. Professional Growth Focused on Fixed-Term Faculty

8. Professional Growth Focused on Career-Stage Needs

Recommendation seven is focused specifically on the needs of full- and part-time fixedterm faculty, which calls for an organizational culture that welcomes the participation of fixed-term faculty in professional development. Based on the recommendations provided, participation is supported through intentional design of resources and activities with the fixed-term faculty member in mind. Intentional design includes offering learning opportunities and/or orientations that do not require on-campus participation as well as 
encouraging flexible points of access (i.e., alternative office hours) for centralized faculty development centers (Gappa et al., 2007).

\section{Limitations of the Framework: The Adjunct Experience}

Through the Framework for Rethinking Faculty Work, adjunct faculty are acknowledged within the discussion of fixed-term faculty, however their experience differs greatly from that of full-time fixed-term faculty and those specific nuances are not addressed (Gappa et al., 2007). Specifically, the part-time nature of their role presumes less available time on campus and contractual limitations around participation in shared governance and/or professional development. As a result, a critical lens is necessary in order to more accurately assess how they experience the essential elements of the framework.

Each of the five essential elements is related to a different component of the faculty work experience, but identified definitions of each element foreground the fulltime faculty member experience (Gappa et al., 2007). For example, the essential element of flexibility includes policy recommendations that address the needs of full-time tenured, tenure-track, or non-tenure-track faculty. Recommendations focus on the topics of work-life balance and parental leave, which are still salient for part-time faculty, but that function in a different manner. It is an unspoken assumption that adjunct faculty experience workplace flexibility based on the part-time nature of their role (i.e., 0.49 FTE or less) (Thirolf, 2017). However, this perception is not inclusive of the diverse typology of adjunct faculty that comprise instructional roles in institutions of higher education (CCCSE, 2014; Gappa \& Leslie, 1993; Tuckman, 1978). For example, adjunct faculty 
often hold multiple positions external to their employing institution (e.g., additional adjunct work, full-time employment, etc.). In her discussion of policy recommendations based on the framework from Gappa et al. (2007), Kezar (2012b) identifies that service to the institution through participation in shared governance is one opportunity to provide flexibility in the workplace for both full- and part-time non-tenure track faculty. As she defines it, this involvement would be included in their employment contract as a way to compensate them and formally build-in time for responsibilities other than instruction.

Consideration of professional growth opportunities for adjunct faculty include intentional design of PD opportunities that accommodate myriad scheduling needs as well as a prioritization of topics that are oriented more toward teaching (Kezar, 2012b). The element of professional growth also accounts for formal systems of evaluation and promotion (2012b). When explored in relationship to the core element of respect, there is a connection with the intrinsic and extrinsic ways in which adjunct faculty perceive their value to the institution. Through a critical lens, it is evident that adjunct faculty are marginally considered in institutional practices for professional growth. However, prioritization of policies and procedures that shape adjunct faculty professional growth can be integral to an intentional shift in an organization's culture and how it accounts for the diverse experiences of a part-time instructional base.

\section{An Inclusive Faculty Engagement Model: A Critical, Analytical Lens}

Within the larger Framework for Rethinking Faculty Work (Gappa et al., 2007), professional growth is an essential element that shapes the environment in which adjunct faculty work. It is intertwined with the organizational culture of the institution and 
experienced differentially, based on the appointment-type of the faculty member. Institution-sponsored PD opportunities communicate an investment in professional growth when they are intentionally designed for adjunct faculty. Additionally, professional growth opportunities that encourage the integration and engagement of adjunct faculty within a department or university, also enable the essential element of respect. As such, Thirolf's (2017) Inclusive Faculty Engagement Model provides an important lens from which to consider how integration and engagement function within the Framework from Gappa et al. (2007).

Thirolf (2017) defines engagement as activity-based, whereas integration is perception-based. Applied to the elements of respect and professional growth from Gappa et al. (2007), both definitions encourage a reciprocal relationship between the adjunct faculty member and the institution. In order to support professional growth experiences for adjunct faculty, intentional connection between opportunities for engagement and integration should be considered. For example, PD offered by a university does not encourage the integration of adjunct faculty if it is consistently offered during times that conflict with adjunct schedules. Additionally, for adjunct faculty, perceptions of inclusion are developed over time as their department and the larger university communicate their purpose. When a part-time instructor chooses to engage with the university in noninstructional activities, they are contributing their time and professional perspective to a larger learning community. As such, they will have the opportunity to develop collegial relationships and experience feelings of respect from other faculty. As a reciprocal relationship, the institution has the opportunity to impact positive outcomes for adjunct 
faculty through a culture that values their engagement. When this reciprocity occurs, Thirolf (2017) states that student learning outcomes are positively enhanced.

In this case study, Thirolf's (2017) Inclusive Faculty Engagement Model was employed in order to better understand how engagement and integration function within the essential element of professional growth (Gappa et al., 2007). The Framework for Rethinking Faculty Work (Gappa et al., 2007) prioritizes the full-time faculty experience, so Thirolf (2017) provided a critical lens through which to question how the experiences of part-time faculty operate within the Framework.

\section{Chapter Summary}

To review, this chapter discussed the literature focused on adjunct faculty in higher education, organizational culture within colleges and universities, the Inclusive Faculty Engagement Model (Thirolf, 2017), faculty development in higher education, and the Framework for Rethinking Faculty Work (Gappa et al., 2007). The literature reviewed in this chapter establishes that adjunct faculty are positioned as less than their full-time counterparts within the professional culture of institutions of higher education. This hierarchy hinders opportunities for part-time faculty engagement and integration (Thirolf, 2017). As such, adjunct faculty feel a lack of respect from their employing institution, which can negatively influence their professional growth experiences. Gappa et al. (2007) directly link the essential element of respect as influential for other elements of faculty work (employment equity, academic freedom and autonomy, flexibility, professional growth, and collegiality). However, consideration of the adjunct experience is largely absent from their Framework for Rethinking Work (Gappa et al., 2007). The 
literature identifies that adjunct faculty interact with their institution(s) in a different manner than full-time tenured, tenure-track, or non-tenure track faculty, as a result of the limitations imposed by employment contracts and due to external obligations (Coalition on the Academic Workforce, 2012; Kezar, 2012b; Kezar, 2013; Kezar, 2016; Kezar \& Maxey, 2013; Marion \& Gonzales, 2014; Street et al., 2012; Tarr, 2010). As a result, institutions bear the responsibility of designing opportunities for engagement that acknowledge these differences. The Framework for Rethinking Faculty Work (Gappa et al., 2007), through the critical lens of Thirolf’s (2017) Inclusive Faculty Engagement Model for part-time faculty, provided a place from which to begin the conversation and better understand adjunct faculty engagement and professional growth.

As such, this study was guided by two research questions in order to better understand the lived adjunct faculty. The first asked: What motivators influence adjunct faculty engagement at Portland State University? The second asked: How does institutional engagement shape an adjunct faculty member's professional growth at Portland State University?

The next chapter outlines the design for a qualitative exploratory embedded single-case study that prioritized the lived experiences of adjunct faculty situated at a large, four-year, public, research institution. Examination of organizational culture, motivation, faculty engagement, and professional growth guided the identified methods and the study design. 


\section{CHAPTER III RESEARCH METHODOLOGY}

As the fastest growing instructor group in higher education, the part-time nature of the adjunct faculty role necessitates professional support from their employing institutions (AAUP, 2018a; Coalition on the Academic Workforce, 2012; Cohen \& Brawer, 2008; Kezar \& Maxey, 2013). Kezar (2012a) states that college and university campuses are acknowledging the presence of growing adjunct numbers, but implementation of intentional policies and practices targeted at their professional inclusion vary and are largely undocumented. Hoikala (2012) calls on adjunct faculty to "demonstrate their role as pedagogical innovators and leaders" (p.144) in order to "demonstrate their assets" (p.144) to the institution and to provide a rationale for organizational change. However, as it currently functions, the part-time faculty role is not characterized by a sense of belonging or integration that facilitates intellectual and professional connection to the campus community (Thirolf, 2017). Instead, there is a disconnect between the instructional function of the adjunct role and their connection with the employing organization. Opportunities for professional growth are only enabled when integration with the employing organization occurs through intentional policies and programs (Thirolf, 2017). When that connection is lacking, the adjunct faculty role functions as solely contingent and opportunities for integration are dependent on the individual agency of the faculty member.

This study sought to better understand adjunct faculty professional growth experiences, including why they choose to engage with the university and how that engagement shapes their professional growth. The Framework for Rethinking Faculty 
Work from Gappa et al. (2007) was employed as the guiding conceptual framework for this inquiry, with a focus on the essential element of professional growth. As a critical lens through which to examine the experiences of adjunct faculty within the framework, Thirolf's (2017) Inclusive Faculty Engagement Model was also used in order to understand how integration and engagement impact the professional growth journeys of part-time faculty.

\section{Research Questions}

This study was guided by two research questions in order to better understand the professional growth experiences of adjunct faculty. The research questions were:

1. What motivators influence adjunct faculty engagement at Portland State University?

2. How does institutional engagement shape an adjunct faculty member's professional growth at Portland State University?

The second question is a how or why question, as recommended by Yin (2018) when engaging in a case study analysis. The questions are bound by the context of Portland State University and are therefore particular, rather than general (Maxwell, 2013). While they do not presume generalizability, I assume that the findings from this study yielded larger relevant themes for adjuncts at comparable institutions of higher education. This study collected qualitative data that was not confined to observable or measurable data, which aligns with a realist approach to qualitative research (Maxwell, 2013). The protocol (semi-structured interviews and document analysis) included questions that treat "unobserved phenomena as real, and their data as evidence" (Maxwell, 2013, p.80). This 
realist approach did not "inhibit...theorizing about phenomena that are not directly observable" (p.81). For example, in this study, an unobserved phenomenon that emerged was the unspoken power structure that influences organizational culture for different faculty roles.

\section{Research Design}

The research design was an exploratory qualitative embedded single-case study (see Appendix A for the study design visual). A case study approach best fit the goals for this inquiry because the engagement and professional growth experiences of adjunct faculty were directly connected to a bounded context (the employing institution) that needed detailed inquiry and description (Yin, 2018). Yin (2018) states that a case study provides the opportunity to explore a contemporary event with clear boundaries in response to how or why research questions. A single case-study design examines one bounded case and the embedded nature refers to examination of multiple sub-units within the larger unit of analysis, which provides an opportunity for more detailed inquiry into the case (Yin, 2018).

A qualitative approach was selected because this case study was interested in understanding how people make sense of their world and their experiences within that context (Merriam \& Tisdell, 2016). As a qualitative case study, the approach for this study "[included] the voices of participants, the reflexivity of the researcher, and a complex description and interpretation of the problem" (Creswell, 2013, p.37). This approach was most appropriate because it allowed me to explore the individual 
experiences of adjunct faculty at Portland State University, within the context of their individual department(s).

For this study, the boundaries for the case were established as the current adjunct faculty population at Portland State University. Four individual adjunct faculty from different schools/colleges served as the sub-units of analysis (see Appendix A). The subunits of analysis were used to investigate the individual experiences of four adjunct faculty across different academic units at Portland State University, with specific focus on adjunct faculty engagement and professional growth. Inquiry within the sub-units of analysis was guided by: interviews with four adjunct faculty members; document analysis of department- and university-level policies about adjunct faculty engagement and professional growth; and interviews with department coordinators (i.e., individuals who facilitate adjunct faculty hiring or support within the individual academic units; titles varied by school/college).

\section{Research Site}

Portland State University is a large, public, urban, commuter, four-year research institution, based in Portland, OR within the Pacific Northwest area of the United States of America. During the 2018-2019 school year, Portland State University was home to 27,285 students, with 21,841 undergraduate students and 5,444 graduate students (Office of Institutional Research and Planning, 2021). Portland State University is organized into nine academic units, focused on the arts, engineering/computer science, liberal arts and sciences, urban and public affairs, business, education, public health, social work, and undergraduate honors. Across all academic units, 1,597 full- and part-time instructional 
faculty are employed (Office of Institutional Research and Planning, 2018). Within that total, 669 instructional faculty are classified as part-time non-tenure track (PTNTTF), which is $42 \%$ of the total instructional faculty population (2018). Based on institutional data from the Office of Institutional Research and Planning (OIRP) (2018) 58.1\% of adjunct faculty identify as female and $41.9 \%$ identify as male (2018). $77 \%$ of adjunct faculty identify as white (see Table 2 for a breakdown of reported race/ethnicity).

Table 2.

Part-Time Instructional Faculty Race/Ethnicity

\begin{tabular}{|l|l|}
\hline Race/Ethnicity & Percentage \\
\hline Asian & $6.0 \%(\mathrm{n}=40)$ \\
\hline Multiple Race & $3.9 \%(\mathrm{n}=26)$ \\
\hline White & $77 \%(\mathrm{n}=515)$ \\
\hline Decline to Respond & $5.7 \%(\mathrm{n}=38)$ \\
\hline Black & $1.6 \%(\mathrm{n}=11)$ \\
\hline Hispanic & $4.8 \%(\mathrm{n}=32)$ \\
\hline Native American & $1.0 \%(\mathrm{n}=7)$ \\
\hline
\end{tabular}

Note. This table includes race/ethnicity data about part-time instructional faculty, as drawn from the Office of Institutional Research and Policy (2018).

Additionally, based on the "Common Data Set 2018-2019" published by the Office of Institutional Research and Planning (n.d.), about $16 \%$ of part-time instructional faculty hold a doctorate or another terminal degree, about $38 \%$ have a non-terminal master's, $24 \%$ have a bachelor's degree, and about $22 \%$ have a degree level that is unknown (note: the Common Data Set reported 664 total part-time instructional faculty during the 
2018/2019 academic year because the set excludes part-time faculty on sabbatical or leave with/without pay).

At Portland State University, institutional support for adjunct faculty is facilitated in myriad ways. At the department and at the school/college level, department and/or course coordinators (with varied titles) most commonly facilitate PD opportunities. At the institution-level, the Office of Academic Innovation (OAI) provides connection to training and development opportunities for all instructional faculty. Adjunct faculty are initially connected with a website that includes PD and training resources through OAI during onboarding with the Office of Human Resources. Article 13, Sections 1 and 2 of the CBA for years 2015-2020 specifies that there are funds available, per fiscal year, for adjunct faculty education and adjunct faculty PD (Portland State University, 2015). Access to both funding sources requires an application that is then reviewed and approved by the union, the Office of Academic Affairs and/or the Department Chair (or designee). Such forms of learning are supplemental and pursued individually, unless otherwise facilitated through the employing department. In terms of promotional opportunities, adjunct faculty have access to an optional professional evaluation within their department, as specified in Article 7, Section 7-Professional Evaluation within the CBA for years 2015-2020 (Portland State University, 2015). The professional evaluation is intended to provide feedback and developmental guidance for adjunct faculty who have been employed by the university for three years or 20 credits (whichever occurs first) (2015). It is also used to determine "if a two-year appointment is appropriate" (Portland State University, 2015, p.13). 
As a current staff member and student at Portland State University, I had access to the research site based on professional association. I selected PSU as the research site based on my access to the university and based on convenience sampling. Access to adjunct faculty during the initial participant recruiting process was facilitated by internal professional referrals from colleagues within my network and based on research using the PSU website. My positionality as a student researcher was supported through the responses provided by adjunct faculty and department coordinators who were willing to share referrals to their contacts. In addition to professional association, as a four-year research university, PSU employs a high percentage of part-time instructional faculty, which was one of the initial curiosities that piqued my interest in this problem of practice. Based on the Carnegie Classification of Institutions of Higher Education (2017), PSU is classified as an R2: Doctoral University with high research activity. The American Association of University Professors (AAUP) (2018a) reported that R2 institutions employ about $25 \%$ of their instructional faculty part-time, excluding graduate students, based on IPEDS data. That said, PSU's part-time instructional faculty population exceeds 40\% (Office of Institutional Research and Planning, 2018). So, as a research site, PSU facilitated the opportunity to explore adjunct faculty professional growth experiences within a large, public, four-year research university that employs an uncharacteristically large part-time instructional population.

\section{Population and Sample}

During the 2018-2019 academic year, 669 part-time instructional faculty were employed at Portland State University across all academic units. That total part-time 
faculty population was identified as the boundaries for the case study. From there, four adjunct faculty from four different academic departments (and different schools/colleges) were the sub-units of analysis. Eligibility for participation was based on whether or not the adjunct was currently teaching courses at the university (during the 2019/2020 academic year) and if they had taught at least one academic credit during the 2018/2019 academic school year. Convenience sampling was employed and adjunct faculty were recruited based on referrals from other adjunct faculty as well as from department leaders at PSU. Contact information was gathered through the referrals and from the PSU website. Adjunct faculty were initially contacted by email (see Appendix C for email message) and were invited to participate in the study through a minimum of two separate interviews. If a participant responded positively to the initial email invitation, but shared that they could not participate due to scheduling conflicts, I responded with a request for referrals to other adjunct faculty at the university.

\section{Data Collection Instruments and Procedures}

This study collected data in the following ways: a minimum of two interviews with four adjunct faculty members (nine total adjunct faculty interviews were conducted), at least one interview with one department coordinator from each academic unit (six total department coordinator interviews were conducted), document analysis of departmentand institution-level documented policies/procedures (52 total documents were analyzed), and from field notes. Appendix B includes a timeline for data collection throughout the study. The process for data collection within each of the sub-units of analysis started with adjunct faculty interviews, followed by interviews with department coordinators. 
Documents were collected throughout the interview process. The sections that follow will review the data collection instruments and procedures used, starting with the interview protocol for the adjunct and department coordinator interviews.

\section{Interview Protocol}

Seidman (2013) states that a primary approach to understanding a complex educational organization is through the experiences of the individual people who make up that institution. In this study, the individual experiences of adjunct faculty were foregrounded as a way to better understand the organization from the individual personlevel. A series of two-to-three 60-minute semi-structured interviews took place with each of the four adjunct faculty participants (see Appendix D for adjunct interview protocol). The semi-structured approach is a more flexible protocol than a highly-structured interview and it assumes that "individual respondents define the world in unique ways" (Merriam \& Tisdell, 2016, p.110). Due to the variety of experiences lived by adjunct faculty in higher education, this study was conducted with an assumption that similar diversity of experience would emerge at PSU. There was specific data required from all respondents in this study (i.e., why and how adjunct faculty are choosing to engage with PSU and how that engagement impacts their professional growth), therefore an interview guide with a mix of "more and less structured interview questions" (Merriam \& Tisdell, 2016, p.110) was utilized for the interview protocol.

Prior to engaging in the sequence of two-to-three interviews with each of the four identified adjunct faculty members, an informal pilot of the adjunct interview protocol was conducted with two PTNTTF members at Portland State University. The faculty 
identified for the pilot of the interview questions were gathered through convenience sampling, based on recommendations from other faculty and staff at PSU. Based on the outcomes of the two pilot interviews, the adjunct interview protocol (see Appendix D) was refined to better focus on the guiding research questions. Example follow-up questions were also added to the adjunct and department coordinator interview guides, where appropriate.

Interviews with adjunct faculty were initially scheduled as two 60-minute appointments, typically about two weeks apart. One adjunct participant required a third interview date, based on the length of his responses and the depth of the conversation (two interviews did not allow for data to be gathered for all desired questions). Interview date(s) and time(s) were determined based on each adjunct faculty participant's availability during the winter 2020 quarter at PSU. The first interview gathered descriptive data about the adjunct's professional capacity at PSU. Contextual data to better understand their typology as an adjunct was also requested. For example, adjuncts were asked if they teach part-time at more than one institution and/or if they have other non-instructional employment. Finally, adjunct faculty were asked questions about their onboarding experience as well as examples of professional integration and support (per topics from the Inclusive Faculty Engagement Model from Thirolf (2017)). Interview number two focused on the adjunct's experiences with professional development and professional growth. Questions included reference to topics from the Framework for Rethinking Faculty Work (Gappa et al., 2007). For example, institutional mission, teaching philosophy, career planning, and professional goals were each the focus of 
different questions in the interview guide. For each adjunct faculty member, at least one interview occurred before the interview with the department coordinator(s) from their unit.

Interviews with at least one department coordinator from the individual department and/or the school/college in which each adjunct faculty member works followed (see Appendix E for department coordinator interview protocol). Interviews took place throughout the winter, spring, and summer 2020 quarters. Individuals interviewed as "department coordinators" held varying titles, but common responsibilities included hiring, onboarding, evaluation, and/or connection to training or PD resources (among other responsibilities). The sample for these interviews was selected based on recommendations from the adjunct participants. During adjunct interviews, each individual referenced at least one administrator and/or contact within their academic unit. Those individuals comprised the initial sample of department coordinators who received outreach. Similar to the adjunct participant recruitment, an email was sent to the department coordinator, inviting them to participate (see Appendix $\mathrm{C}$ for email invitation). Following the initial outreach to the first group of participants, a snowball sample approach was employed in order to allow for flexibility in the data collection process. With this approach, the first set of participants led to new participants, based on information shared during the interview (Bertaux, 1981; Seidman, 2013). For example, one department coordinator referenced another administrator in their academic unit who facilitates adjunct faculty evaluations. The department coordinator recommended that I should also speak with that individual, in order to access information about those 
experiences. Interviews with department coordinators focused on departmental policies and processes pertaining to department culture and institution-facilitated PD opportunities. Each interview was semi-structured and about 60 minutes in length.

All interviews in this study were recorded with Otter.ai as well as on a digital voice recorder (for back-up). Following each interview, I would listen to the audio recording in Otter.ai and I would review the generated transcription, fixing any inaccuracies in the text. This process enabled additional reflection about each interview, which I reflected upon in my researcher memos. All transcriptions were uploaded to Dedoose (the data analysis software used for the study) for analysis.

\section{Department and Institutional Documents}

The final procedure in the data collection process was document analysis. A total of 52 documents were collected from the adjunct faculty participants, their employing school/college, the Office of Academic Innovation (OAI), the Office of Human Resources (HR), and from the Portland State University Faculty Association (PSUFA)the adjunct faculty union at PSU. Appendix F includes the full document inventory. At the adjunct (or sub-unit) level, an example of documents gathered include an adjunct handbook, a teaching philosophy, department expectations, and a revised appointment contract. From the university-level, examples include an email from OAI highlighting summer professional development (PD) opportunities, an adjunct onboarding checklist from HR, and the collective bargaining agreement from PSUFA (to name a few examples). 
Documents were gathered during and after the interview process with both adjunct faculty and department coordinators. Some documents were provided directly from the adjunct and department coordinator participants. Others were discovered on the PSU website or around campus (e.g., a poster from PSUFA displayed in an elevator) and identified as relevant following the interviews, based on the guiding research questions.

\section{Field Notes \& Memos}

Throughout the study, I reflected on the data collection process and observations from the interviews through field notes, documented in a personal journal and electronically in a secure Google Document (which was then downloaded to a secure external hard drive). Recommendations for how to engage in the process of creating and analyzing field notes were considered from Emerson, Fretz, and Shaw (2011).

Specifically, the practices of creating jottings both before and after an interview and writing up full field notes following an interview were used. Reflective memos were also created throughout the data collection and analysis processes. During different stages of the study, memos were documented on a daily, weekly, or monthly basis in a personal journal as well as in Dedoose. The practice of creating researcher memos acknowledges the role of the researcher as a primary data collection instrument in this qualitative study. Additionally, reflection on emergent themes, challenges, questions, and personal biases added to the internal validity of the study design and the data collected.

\section{Data Analysis}

A combination of provisional and open coding was employed as the initial method of analysis in this study for the adjunct faculty interviews, the department 
coordinator interviews, and with my field notes (Creswell, 2013; Saldaña, 2009). Glaser and Strauss (1967) caution that pre-selected categories can limit new findings. Therefore, provisional codes, drawn from the Framework for Rethinking Faculty Work (Gappa et al., 2007) and the Inclusive Faculty Engagement Model (Thirolf, 2017), were employed in combination with open codes (see Appendix G for provisional code book). Saldaña (2009) states that provisional coding uses a predetermined set of codes, based on concepts from relevant research literature. Creswell (2013) encourages the researcher to begin with five or six codes that are then expanded to between 25-30 categories that can be combined into five to six major themes. This process is referred to as data reduction. Open coding, also labeled as “initial coding” by Saldaña (2009), is a process by which the researcher can break down qualitative data in order to compare them for similarities and differences. It is intended as an open-ended approach that can provide the researcher with "analytic leads for further analysis" (Saldaña, 2009, p.87). This study employed open coding along with provisional coding in order to identify any gaps in the conceptual frameworks used (the Framework for Rethinking Faculty Work and the Inclusive Faculty Engagement Model). Open coding was also used in order to analyze my field notes, employing recommendations from Emerson, Fretz, and Shaw (2011). "Students," "pay," and "faculty identity" are examples of open codes identified during analysis of the interview transcripts and field notes. After initial categories were established from the open and provisional codes, as suggested by Creswell (2013), in vivo coding was employed as a way to both categorize the information gathered and to capture the voices of those interviewed (Saldaña, 2009). In vivo coding employs codes that refer to a word 
or short phrase from the qualitative data record (Saldaña, 2009). In other words, it is made up of "the terms used by [participants] themselves" (Strauss, 1987, p.33). One in vivo code used was "a spreading of," which referred to the adjunct faculty members' myriad responsibilities and their work at multiple institutions of higher education. Other in vivo codes were "career adjuncts," "altruistic adjuncts," and "resume-building adjuncts"- which were all descriptive categories of adjunct types.

Content analysis of the documents gathered occurred as the last data analysis step in this study. The documents gathered were analyzed using qualitative content analysis (QCA), as recommended by Krippendorff (2004), Merriam and Tisdell (2016) and Schreier $(2012 ; 2014)$. QCA is "an unobtrusive technique that allows researchers to analyze relatively unstructured data in view of the meanings, symbolic qualities, and expressive contents they have and of the communicative roles they play in the lives of the data's sources" (Krippendorff, 2004, p.44). QCA was used because it acknowledges the positionality of the researcher and the interactive nature of that relationship, between the researcher, the content, and the analytical process (Merriam \& Tisdell, 2016). This form of analysis is distinct from quantitative content analysis due to the centrality of the researcher in the protocol (Altheide \& Schneider, 2013; Merriam \& Tisdell, 2016). For example, Schreier (2012) identifies the reflexivity of the researcher in developing a coding frame. Specifically, the influence of the researcher's background and assumptions in the development and application of specific codes are one example of this centrality. In QCA, the researcher acknowledges their role in co-producing the data as well as specific rationale for the categories of the coding frame (Schreier, 2012). 
Krippendorff (2004) identifies one category of content analysis as extrapolations, which are defined as "inferences of unobserved instances in the intervals between or beyond the observations (data points)" (p.47). Extrapolations can include trends, patterns, and differences in a data set. Content analysis of the documents gathered for this study focused on the extrapolation of trends and differences in the data, as guided by Schreier's (2014) recommended steps for QCA. The steps included: 1) deciding on a research question, 2) selecting material, 3) building a coding frame, 4) segmentation, 5) trial coding, 6) evaluating and modifying the coding frame, 7) main analysis, and 8) presenting and interpreting the findings (2012). The coding frame was developed based on provisional codes that emerged as key findings during the interviews with adjunct faculty and department coordinators (see Appendix H for QCA Coding Frame). Main categories were identified based off aspects of the material that I wanted to explore, guided by provisional codes from the interview analysis. Schreier (2014) states that subcategories specify what emerges in the material, in line with the main categories. For example, a main category in this study was "professional development" and subcategories were "PSU sponsored," "motivation," and "course coordinator meetings." Schreier (2014) states that there can be different coding frames for each document, if needed, and the frames are built prior to engaging in analysis of the selected materials. However, this study employed one coding frame for the analysis of all documents.

All data in the study were securely managed by Dedoose, a qualitative data analysis software. I also securely backed-up all data on a personal external hard drive. 


\section{Assumptions and Limitations}

The unit of analysis for this study was adjunct faculty at Portland State University, and the sub-units of analysis allowed for exploration into the nuances of individual professional experiences within the larger institution. Based on this structure, differences in experience for adjunct faculty members were highlighted, as illustrated by participant voices and content analysis of department- and institution-level documents. In addition to an assumption of varied experiences for adjunct faculty members, based on their employing school/college, design of this study was initiated with an assumption that the interviews with adjunct faculty would highlight gaps in the Framework for Rethinking Faculty Work (Gappa et al., 2007), as it pertains to adjunct faculty. The guiding research questions for this study prioritized the essential element of professional growth within the framework, therefore identified gaps concentrated on that element. Additionally, the Inclusive Faculty Engagement Model (Thirolf, 2017) was employed as a way to understand those gaps because it prioritizes part-time faculty engagement and integration.

This study endeavored to understand why adjunct faculty choose to engage with PSU, and how that engagement impacts their professional growth experiences. An exploratory embedded single-case study design enabled inquiry into the organizational culture of multiple departments, with a focus on the experiences of four adjunct faculty members. The embedded case study structure foregrounded their individual voices as central to understanding the phenomenon of the adjunct experience at PSU. Even so, four adjunct faculty voices are a limited number and the data gathered from those faculty 
members cannot be assumed as representative of all adjunct faculty at the university. This limitation was anticipated and recommendations for future research in Chapter V acknowledge additional opportunities for exploration.

Additionally, I recognize the differential access to employment security and the positional power that exists for varying faculty roles in higher education. Therefore, this study assumed that not all adjunct faculty would feel comfortable engaging in the research, due to fear of retaliation from their employer. Based on the contingent nature of their role, employment from term-to-term is not guaranteed and is dependent on coursesection needs, budgetary constraints, and course evaluations, among other factors. That said, an unforeseen challenge emerged with department coordinator willingness to participate in the study, based on a similar fear of retaliation. This challenge arose for department coordinators who were not in senior leadership positions. As a result, I continued to prioritize protection of participants' anonymity throughout the data collection and analysis process. This protection was communicated during all phases of the data collection process, including during the initial recruitment stage. Unfortunately, reassurances of anonymity did not assuage the concerns of specific department coordinators. As such, the sample size for department coordinators was smaller than it might have otherwise been.

Finally, this study was interrupted by the COVID-19 pandemic. This occurrence impacted the study in many ways. Logistically, the project timeline was extended as inperson interviews were no longer permitted, and a new Institutional Review Board approval was required in order to conduct virtual interviews. As course delivery 
immediately pivoted to fully-online at PSU, I wanted to respect the added challenges dominating individuals' schedules. As such, the timeline for department coordinator interviews was extended, based on that added caution (department coordinator interviews concluded in September 2020). Additionally, one adjunct faculty participant (a fifth participant) had not yet engaged in their first interview when Portland State University shifted to fully-remote operations. Although I worked to continue to engage this individual, before and after a new IRB protocol was approved, the adjunct no longer responded to outreach. Therefore, the sample for adjunct faculty remained at four participants, rather than five, because I chose not to recruit any additional adjunct participants after that point. In terms of assumptions about the impact of COVID-19, I anticipated that the public health crisis would have astronomical effects on the work experiences of adjunct faculty. However, when contacted for member checks, adjunct faculty did not report or disclose any significant changes to their experience. Some department coordinators did communicate changes to their responsibilities and/or how their support of adjunct faculty changed formats, based on a fully virtual learning environment. For example, one department coordinator shared that they started offering weekly virtual teaching support workshops as well as one-on-one meetings with instructional technology experts in the department. Additionally, this department's adjunct orientation pivoted to quarterly one-on-one virtual calls, from the original annual in-person group meeting. 


\section{Ethical Assurances}

Consideration throughout the research design process was given to construct validity and the reliability of the data collection procedures (Yin, 2018). Yin (2018) defines construct validity as "identifying correct operational measures for the concepts being studied" (p.42). Construct validity can be achieved by using multiple sources of evidence and by employing member checks after interviews (Yin, 2018). The design for this study intentionally employed three forms of data collection: interviews with adjunct faculty, interviews with department coordinators, and document analysis. The multiple forms of data collected enabled triangulation, which Maxwell (2013) states "reduces the risk of chance associations and of systematic biases due to a specific method" (p.128). The reliability of the data collection procedures was prioritized through clear documentation of the case study protocol, including documentation of my pre- and postinterview memos.

Member checks were employed as a way to increase the internal validity of this study. Merriam and Tisdell (2016) also term this as "respondent validation" (p.246). At the conclusion of each participant's final interview, I shared that follow-up would be sent by email in order to confirm the information discussed during the interviews. Maxwell (2013) states that member checking is the,

...single most important way of ruling out the possibility of misinterpreting the meaning of what participants say and do and the perspective they have on what is going on, as well as being an important way of identifying your own biases and misunderstanding of what you observed. (pp.126-127)

All participants were contacted by email regarding the member check. All four adjunct faculty responded with feedback as did four of the six department coordinators. All 
comments from participants were shared by email, except for one department coordinator who preferred to share their feedback over Zoom. As was previously mentioned, the participants did not have any significant changes to the original data provided. Two department coordinators shared updates regarding how their department has responded to COVID-19 and shifted remote support for adjunct faculty.

In order to respect and prioritize the safety of all participants, informed consent prefaced all data collection before interviews (see Appendices I and J for informed consent forms). Interview data did not contain identifying information that linked directly with the participant. Pseudonyms were adopted and used on all data collection documents. Interviews were audio-recorded using Otter.ai and a digital voice recorder. Using the generated transcript from Otter.ai, I manually listened to the audio recording and I reviewed the transcript for inaccuracies. Interview transcripts were then downloaded and saved to an external hard drive (stored in my home) and they were also uploaded to Dedoose (which is also password protected). None of the storage spaces used are publicly accessible.

Finally, out of respect for the time shared by adjunct faculty and department coordinator participants in this study, Visa gift cards were offered to all participants in the amount of $\$ 20$ per interview. All participants accepted the gift cards, excluding one department coordinator who asked me to instead donate the funds. That Visa gift card was donated anonymously to a person impacted by the wild fires in Oregon in the fall of 2020. 


\section{Positioning of Self}

Based on my experiences as a classroom teacher at both the K-12 and postsecondary education levels, I approached the problem of practice for this study with an internalized belief that teacher actions impact student actions. In order to positively shape student learning across the K-16+ continuum, I believe that intentional faculty development experiences have the opportunity to dynamically shape instructional choices that can determine student outcomes. Even so, the culture of an organization dictates how faculty and students navigate their distinct roles within a learning environment. In order to advocate for both faculty and student experiences within an institution's culture, one area of impact is on employment policies. This study adopted that vein of thinking through focus on the experiences of adjunct faculty within the organizational culture of PSU. The diverse taxonomy of adjunct faculty highlights their myriad motivators for seeking part-time employment, however it is the responsibility of the organization to engage their adjunct faculty within the professional space of the larger academic community. I believe that without intentional programming and incentives for participation at both the university and department level, adjunct faculty will continue to function as separate from the whole, which ultimately, negatively impacts students and faculty (both full- and part-time).

My approach to the research was informed by a constructivist worldview that shaped the design for this study and the chosen focus on professional growth. A constructivist way of knowing prioritizes multiple perspectives in the meaning-making process, including the reflexivity of the researcher (Creswell \& Creswell, 2018). Based 
on the diverse taxonomy of adjunct faculty members and the inconsistent manner in which they are integrated into the professional culture across institutions of higher education, a constructivist approach through a case study design made space for the individual experiences of adjunct faculty members within a contextualized environment. The focus on engagement and professional growth was approached from a belief that learning is socially constructed. While each element (engagement and professional growth) can take myriad formats, engagement with a community of practice can mitigate the isolating attributes of the adjunct role.

\section{Chapter Summary}

This exploratory qualitative embedded single-case study explored adjunct faculty motivators for engaging with PSU, and the impact of that engagement on their individual professional growth. It sought to understand how engagement with an institution contributes to adjunct faculty professional growth, through the lens of the Framework for Rethinking Faculty Work (Gappa et al., 2007) and the Inclusive Faculty Engagement Model (Thirolf, 2017). Adjunct faculty interviews, department coordinator interviews, document analysis, and field notes were used as data collection procedures. Through the lens of the two research questions, the data were analyzed and ongoing attention to the design, collection, and analytical process persisted in order to ensure construct validity and the reliability of the study. The findings of the study are discussed in the next chapter (Chapter IV Findings). 


\section{CHAPTER IV FINDINGS}

The purpose of this study was to better understand the lived professional growth experiences of adjunct faculty at Portland State University. Through the lens of Thirolf's (2017) Inclusive Faculty Engagement Model and the Framework for Rethinking Faculty Work from Gappa et al. (2007), this chapter reviews findings about the adjunct participants' individual experiences with institutional engagement and professional growth. Adjuncts represent over $40 \%$ of the instructional faculty population at PSU. Therefore, careful analysis of their engagement bears significance for future institutional planning practices for hiring, professional development, and promotional opportunities for this large and consequential group of PSU employees. In turn, this research operates with the understanding that "faculty working conditions are student learning conditions" (Maisto, 2012, p.201), therefore this research also bears significance for future student populations at PSU.

This chapter includes an overview of the results from this embedded case study with findings organized around the larger case (adjunct faculty at Portland State University) and the four sub-units (individual adjunct experiences). Profiles are provided for each adjunct faculty member, including descriptive information about their academic and professional experiences, as well as their employment and academic department(s). Findings are presented based on emergent themes that developed for the adjunct faculty in this study. Individual adjunct experiences are prioritized in the presentation of the data, with a more holistic discussion of the findings following in Chapter V Discussion. 
Interview and document data were analyzed through the Framework for Rethinking Faculty Work (Gappa et al., 2007) and the Inclusive Faculty Engagement Model (Thirolf, 2017). Emergent themes were identified, based on provisional, open, and in vivo codes from the interview transcripts, as well as during qualitative content analysis for all documents gathered. The themes discussed in this chapter are: 1) adjunct faculty members' professional identity drives their motivation as instructors, and 2) professional growth experiences differ for adjunct faculty, based on the elements of respect and career stage needs. The research questions guiding the analysis of data for this embedded case study are:

1. What motivators influence adjunct faculty engagement at PSU?

2. How does institutional engagement shape an adjunct faculty member's professional growth at PSU?

The research questions will be discussed and responded to, in the context of the case study findings, in Chapter V Discussion.

\section{Case Overview and Sub-Unit Profiles}

This section of the findings includes descriptive data about Portland State University (PSU) and the instructional adjunct faculty population employed at the school. Data were gathered from the Office of Human Resources (HR), the Office of Institutional Research and Planning (OIRP), and the Portland State University Faculty Association (PSUFA) and it was analyzed through qualitative content analysis. To review, the university employs 1,597 total instructional faculty members (Office of Institutional 
Research and Planning, 2018). Of the total number of instructional faculty across nine academic units, 42\% ( $\mathrm{N}=669)$ are considered adjunct faculty (2018).

Based on a 2019 survey disseminated by the adjunct faculty union (PSUFA), 49\% of part-time faculty respondents have been with the university for two-to-five years, $19 \%$ for six-to-ten years, $12 \%$ for $11-15$ years, and $10 \%$ for more than 15 years. $11 \%$ of adjunct faculty reported being in their first year at the time of the survey (Portland State University Faculty Association, 2019). Years of employment at PSU bears significance for adjunct faculty members' eligibility for a professional evaluation, which, when successful, yields a part-time two-year appointment (Portland State University, 2015). After three years of employment at PSU or a minimum of 20 credits taught, whichever occurs first, an adjunct faculty member is offered the option to participate in a professional evaluation. Participation is voluntary and there are no repercussions for an adjunct faculty member who elects not to have the evaluation-other than forgoing the option of a part-time multi-year appointment (2015). The professional evaluation, and subsequent two-year contract, is the one promotional opportunity for adjunct faculty at the university. Even so, the multi-year contract is not a guarantee of continuous appointment nor does it afford an increase in compensation. Specific contract language states, "the university reserves the right to cancel one or all of the courses listed, should enrollment, in the judgement of the University, be insufficient" (Portland State University, 2018, p.1). As such, the multi-year contract is not a guarantee of course assignments or increased job security. 
At PSU, adjunct faculty represent the diverse taxonomy of adjunct types identified by scholars and professional organizations (CCCSE, 2014; Gappa and Leslie, 1993; Tuckman, 1978). Of those adjuncts surveyed by the PSUFA (2019), many fall within Tuckman's (1978) definition of the "part-mooner," which means 30\% teach parttime at one or more colleges or universities (other than PSU), 33\% work part-time outside of higher education in their field or discipline, and $20 \%$ work part-time outside of higher education and not in their field or discipline (PSUFA, 2019). A separate population (18\%), the "full-mooner[s]" (Tuckman, 1978), report full-time employment responsibilities, separate from their instructional position at PSU. Pay parity for adjunct faculty is a key issue, as driven by advocacy and organizing efforts of the PSUFA. While a large portion of adjunct faculty supplement their PSU income with outside work, financial support from a household member/partner/spouse, a pension plan, personal investments, and/or food stamps, $11 \%$ of adjunct faculty report that they earn $100 \%$ of their income through PSU (PSUFA, 2019). At PSU, the discussion around equitable financial compensation for adjunct faculty involves evaluation of pay-per-credit as well as additional responsibilities, including course development and office hours. One adjunct faculty member shared, "I am asked to support students in many ways that are completely uncompensated, but essential to [the university]" (PSUFA, 2020). Recommendations from PSU adjunct faculty include increasing the base pay rate and developing a structure that involves pay raises for advancement within adjunct ranks and/or compensation for specialized expertise and education (2020). 
Professional growth resources and opportunities at PSU include those offered through the Office of Human Resources (HR), the Office of Academic Innovation (OAI), the PSUFA, and through individual academic units (i.e., the school/college or the academic department). Professional growth resources provided by HR focus on employment policies, workplace tools, and information about representation through the adjunct union (PSUFA). The OAI facilitates instructional support for all faculty at the university via full-service teaching support through the Faculty Help Desk, virtual teaching consultations, and custom course design opportunities. In addition, a free professional development experience through OAI, called the Certificate of Innovation in College Teaching (CICT), is open to both PSU graduate students and adjunct faculty. Through the PSUFA, adjunct faculty have access to a community of other part-time nontenure track faculty (PTNTTF). Professional growth opportunities include, but are not limited to, social engagement with other PTNTTF, access to information about resources offered through the union and/or through PSU, and advocacy for employment rights based on their collective bargaining agreement (CBA). Individual academic units facilitate professional growth experiences in different ways. Adjunct-specific onboarding, course coordinator meetings, and annual award opportunities are a few examples. In short, professional growth resources and opportunities for adjunct faculty exist in various formats at PSU, whether through HR, OAI, the PSUFA, or a specific academic unit.

\section{Sub-Units of Analysis: Adjunct Profiles}

The next sections include individual profiles for each of the four individuals who represent "sub-units of analysis" for this case study. Each profile will focus on the 
experience of one adjunct faculty member at PSU, beginning with the characteristics of each adjunct faculty member as well as information about their academic unit. To review, generally these data were gathered through a minimum of two individual interviews with each adjunct faculty member along with interviews with "department coordinators" from each person's academic unit. Finally, documents were gathered from each academic unit, as well as from the larger university (i.e., HR, OAI, PSUFA) (see Appendix F for the comprehensive document list). All people interviewed were de-identified in interview transcripts and pseudonyms are used in chapters four and five in order to maintain confidentiality. In addition, school, college, and department names are also omitted because, if included, participant identities could potentially be determined, due to the small sample size. That said, where appropriate based on emergent themes in the data, reference to specific characteristics of a faculty member's academic discipline is included.

Moe

The first sub-unit of analysis in this case study is focused on the experiences of "Moe," an adjunct at PSU since the summer of 2017, who initially started his experience as a Graduate Teaching Assistant (GTA) in 2015. His GTA role had a two-year timelimit, and was in alignment with the conclusion of his first master's program (he was enrolled in a second master's during the time of our interviews), which ended with an offer to transition into an adjunct teaching capacity. Moe was listed as an "adjunct" on the department website but told me that he did not know whether that title was correct. Moe shared that he has consistently been offered one class each quarter at PSU during his 
time as an adjunct saying that, "I always have gotten classes. I've never been skipped in a term that I wanted a class." In addition to his adjunct work at PSU, Moe is also involved in a paid position with his union (PSUFA) and he teaches one class per quarter part-time at Portland Community College. Within Tuckman's (1978) typology of adjunct roles, Moe most aligns with a "hopeful full-timer."

Moe's academic unit offers two undergraduate majors, two undergraduate minors, three master's degrees, two $\mathrm{PhD}$ programs and two graduate certificates. $\mathrm{A} \mathrm{PhD}$ is the terminal degree in Moe’s academic discipline. "Marc," a Department Coordinator, reported that tenure-track lines in the department that employs Moe have decreased and been replaced predominantly by non-tenure track full-time instructors with continuous appointments. It is no surprise then that Marc shared that the number of full-time nontenure track (FTNTTF) instructors on fixed term contracts has risen. He stated that the number of adjunct faculty fluctuates each quarter, based on student enrollment and the number of course sections requiring part-time faculty coverage.

In terms of folks who facilitate academic support for adjunct faculty in the department, "course coordinators" and the Department Chair were identified by Moe and the two department coordinators interviewed (Marc and Marshall). The course coordinator is the go-to individual for a specific course and their responsibilities include disseminating information about the syllabus and any necessary course-specific resources (i.e., electronic resources, textbooks, etc.) in the beginning of the quarter. Throughout the quarter, course coordinators facilitate regular communication and meetings with the GTAs and the adjunct faculty, for whom participation is optional since they are not 
compensated for their time. Support provided for adjunct faculty by the Department Chair includes dissemination of department and university-wide information and facilitation of the adjunct faculty evaluation process.

\section{Bibi}

The second sub-unit of analysis focuses on the experiences of "Bibi" who has been an adjunct faculty member at PSU since the winter quarter of 2015. The PSU website shows his title as an "Adjunct Professor," though he was not certain if that was accurate. During his time as an adjunct, Bibi served on the Diversity Council for the university "for a short time" and he previously served as a mentor for students in a graduate program within his academic department. Prior to his time at PSU, Bibi earned a master's degree and worked full-time in his industry for almost 20 years. His master's degree is considered one of the terminal degrees in his field, for practitioners. From what Bibi told me, he could be classified as "semiretired," on Tuckman's (1978) typology, and as a "specialist, [expert], and professional" on Gappa and Leslie's (1993) typology. Over the last five years, Bibi has spent most of his adjunct time at PSU, although there was a brief overlap with a professional role outside of the university when he was first hired. Additionally, he has one quarter of teaching experience at Mt. Hood Community College (MHCC), filling in for a colleague.

Bibi's instructional work at PSU has occurred in one school and academic unit that includes seven distinct areas of concentration. At the undergraduate level, there are eight different majors offered and five minors, while at the graduate level there are nine different master's level programs, along with 16 undergraduate and graduate certificates. 
According to a department coordinator, "Cleo," as the enrollment of undergraduates in the department increases, the number of adjunct faculty rises, but the number of full-time faculty lines have not increased to match this growth. In terms of instructional support, Bibi has a different course coordinator for each of the courses that he teaches throughout the year, with each course coordinator providing curricular and instructional guidance facilitated through quarterly meetings. The school does not have Department Chairs, so adjunct faculty receive their professional evaluation from an Assistant Dean (i.e., the Assistant Deans are the chair-equivalent role for the purpose of the evaluation). For Bibi's academic unit, personnel and contract oversight are facilitated through the Assistant Deans while instructional support is offered through the course coordinators.

\section{Poppy}

The third sub-unit of analysis focuses on the experiences of Poppy, an adjunct faculty member at PSU for six quarters whose title is "Adjunct Senior Instructor 2." Her instructional role at PSU started during her master's degree when she worked as a GTA, which transitioned into adjunct work upon the conclusion of her program. After the first quarter as an adjunct, she was offered a full-time non-tenure track and continuous appointment. Sadly, after eight years as full-time non-tenure track faculty (FTNTTF), Poppy was laid off and she was instead offered a part-time role, due to low student enrollment in the department. Poppy's master's degree is the common degree held by the FTNTTF in her main academic department. Outside of her work at PSU, Poppy teaches at Portland Community College (PCC) and at MHCC, depending upon the enrollment needs of each community college. She has also worked as a consultant for the University 
of Portland on a limited contract basis. According to Tuckman's (1978) typology, Poppy can be described as a "hopeful full-timer," because she aspires to resume a full-time instructor position. Poppy shared that "...it would be fantastic if there were another fulltime opportunity that were to ever come up, but I don't really know that that's a goal that I'm like, actively pursuing. It's more of like a dream."

Poppy has instructional experience in two different academic departments at PSU. The majority of her teaching as a GTA, as FTNTTF, and as an adjunct occurred in one department, which will be referred to as Department A. Department B is an academic unit in which she taught for two quarters, due to a collaborative partnership between Departments A and B. The two departments differ in the number of faculty employed (i.e., Department A employs about half the number of faculty as Department B) and student credit hours completed (i.e., students complete about twice the number of credit hours in Department B, versus A), but the number of undergraduate programs offered are similar (i.e., two main majors and/or programs).

Instructional support for adjunct faculty in Department A is provided by multiple department coordinators with various responsibilities. The faculty coordinator was referenced as a main source of support and a go-to source of information for Poppy, who shared that if she can't get a question answered by her faculty coordinator, she would refer it to her program director. In Department B, Poppy did not access instructional support during her two-quarter assignment, although she was initially provided information about her course assignment (i.e., a syllabus) from a tenure-track faculty member. Poppy's time in Department B was a temporary, short-term assignment that 
drew on her experiences in Department A. As a result, most of Poppy's contributions to this study came from her experiences in Department A.

\section{Sara}

The fourth sub-unit of analysis is focused on "Sara," who has been an adjunct at PSU since the spring of 2018. Per her contract, Sara's official title is “Adjunct Senior Instructor," although the website states that her title is "Instructor." Sara's work history at PSU began with her role as a researcher on a federally-funded project, which she cites as her first experience working at the university. Outside of her current instructor role, Sara serves in a leadership position for the adjunct union at PSU (PSUFA) and she has also served as a faculty mentor for an undergraduate research program for first-generation, low income, and under-represented students. Outside of PSU, she teaches part-time at Chemeketa Community College, Pacific University, and she previously delivered professional development courses for faculty at Clark College. Although her instructional work at PSU has been in undergraduate-level courses, Sara's prior experiences before PSU include instruction and advising for students in both undergraduate and graduatelevel programs, where she also served as a mentor and guide for student scholars. Additionally, she holds a PhD in her academic discipline, which is the terminal degree in her field. Using Tuckman's (1978) typology of adjunct roles, Sara best aligns with the "hopeful full-timer" description, which makes her similar to Moe and Poppy. One day she would like to become a full-time faculty member.

At the time of her interviews, Sara's instructional experiences at PSU occurred in one department, but since that time, she teaches in two additional departments at PSU, 
which bring the total to three departments. The academic department that Sara referenced in our interviews offers one undergraduate major and three minors, described by department coordinator, "Doug," who noted that "[our] adjunct needs change quite drastically from year-to-year" due to sabbatical and research buy-out patterns. He stated that there isn't a consistent number of courses taught by adjunct faculty from year-toyear.

In Sara's department, adjunct faculty instructional support is provided by the Director after initiation during the hiring process and continuing through the adjunct's employment. Support includes connections to course syllabi and as well as facilitation of professional evaluations. Additionally, any general information regarding instructional, departmental updates, or employment expectations are all disseminated to adjuncts by the Director.

I just presented the four participants who also represent the four sub-units of analysis included in this study about the individual professional growth experiences of adjunct faculty at PSU. Their experiences are not discussed as a representation of the whole adjunct faculty population at PSU; rather, they are merely highlights and stories of the unique characteristics and experiences of adjuncts. The findings presented in the next section highlight the individual experiences of Moe, Bibi, Poppy and Sara, including individual motivators for working part-time at PSU and their long-term professional goals. 


\section{Case Findings}

This section includes salient themes that emerged during faculty and department coordinator interviews, as well as during document analysis. Organized around each individual faculty member, the themes of faculty professional identity and motivation are discussed first, followed by elements that shape adjunct faculty professional growth (Gappa et al., 2007). Adjunct faculty are a population with diverse motivators for working in their part-time roles and the findings from this study highlight the ways in which those varying motivators shape their experience, in combination with the organizational culture of their academic unit. That said, this research is not presented as representative of the adjunct faculty population as a whole, but instead offers a glimpse of four individual adjunct faculty participants whose experiences occur within a particular urban, commuter, four-year public higher education context. This specificity and individuality is especially important when seeking to understand professional growth experiences and motivators for institutional engagement. The data is "person" based and is presented as such. Institutional and departmental context is intricately connected to the individual person and their experiences and wishes for professional growth. As a result, the sections that follow are organized in order to highlight both the person-based and context-based analysis of the data. Before presenting individual adjunct participant findings, definitions of the two most salient themes are discussed. First is "theme one," or professional identity drives motivation, and "theme two" is that professional growth experiences are based on the elements of respect and career stage needs. 


\section{Theme One: Professional Identity Drives Motivation}

The dynamic impact of an adjunct faculty member's professional identity was an emergent theme in this study, specifically, the ways in which their individual professional identities shaped their motivation to engage with the university in their role as an instructor. Professional identities were described based on prior academic and work experiences as well as expressed future goals. Engagement was described by adjunct faculty as participation in out-of-class experiences with other colleagues at PSU (e.g., faculty meetings, professional development, collegial interactions within the department), as well as meaningful engagement with students both in and out of the classroom (whether it be fully remote, hybrid, or face-to-face (f2f)). Three of the four adjunct faculty participants also discussed engagement with the union (PSUFA), including attendance at union meetings, participation in leadership roles, and organizing work oncampus. For each of the four participants (who represent four sub-units of analysis within this case study), the notion of professional identity drove the ways in which they engaged with their department and the institution. Professional identities were (and continue to be) shaped by adjunct faculty members' educational and work experiences, as well as their long-term goals. As their professional identities continue to evolve, adjunct faculty described changes in their chosen forms of engagement.

\section{Theme Two: Professional Growth Experiences Differ, based on the Elements of Respect and Career Stage Needs}

The second emergent theme in this study was that professional growth experiences differ for adjunct faculty, based on the elements of respect and career stage 
needs. Adjunct faculty shared information about their professional identities and their specific roles in and outside of PSU. They reported professional growth experiences shaped by their work in an academic department, the resources available to support that work, and the general culture of the unit. Adjunct faculty described their department as a representation of PSU in general, or as different from other units, based on what they learned from adjunct colleagues at the university. The grounding thread for each individual was the essential element of respect, which adjunct faculty positively or negatively associated with 1) access to information and resources and/or 2) collegial interactions. In addition, adjunct faculty reflected openly about the ways in which their department contributed to their career stage needs and how their chosen methods of engagement at PSU were based on whether or not their professional needs were met. Career stage needs for faculty were defined based on their professional growth goals, and their prior academic and work experiences. An analysis of traditional faculty career stages does not fully represent the findings here as trajectories are often messy and unconventional. For example, although the experiences of Moe and Poppy were fairly straightforward, due to their individual pathways from graduate student to instructor, Sara and Bibi presented employment histories across different professional sectors, geographical locations, and goals (these experiences for all four participants will be discussed in the sections that follow). Each faculty member's career stage can be understood as an individual journey, motivated by and aligned with their professional identity and goals. 
Therefore, for these findings within this second emergent theme, participants focused on the essential element of respect, followed by each faculty member's experience with professional growth as determined by their career stage needs. Both elements are defined next, based on the findings from the study.

\section{Respect}

The essential element of respect surfaced as a contributing factor to each adjunct faculty member's professional growth experiences. Respect was perceived based on meaningful collegial relationships with individuals in an adjunct faculty member's main academic unit, or with colleagues outside of one's department (i.e., individuals on a committee, a university President, adjunct faculty in PSUFA, etc.). Where positive professional relationships occurred, the adjunct communicated feelings of respect and value for their work. For example, Poppy reflected on the impact of her positive collegial relationships: “...if you're having these little conversations and feeling included and supported, then, it definitely makes me feel much more engaged and like I want to do a much better job." The absence of meaningful collegial interactions resulted in the opposite, with adjunct faculty communicating a lack of respect and value from the department for their part-time role. For example, Sara expressed feeling disrespected and devalued within her department, based on interactions with colleagues during the hiring process for an open full-time appointment (that she was not offered). Sara shared, ...it really shaped and framed the feelings of value that I had from my chair, from my department, from the hiring committee, from the full-time tenured faculty members on the hiring committee who chose not to give me an interview for the jobs I was already teaching. 
Access to information and resources was another contributing element to experiences of respect for adjunct faculty. This access largely focused on time and pay as factors that shaped adjunct faculty members' satisfaction within their roles. The adjunct faculty interviewed in this study expressed different levels of satisfaction, whether about PSU in general and/or specifically based on their employing academic unit. Their satisfaction was connected to their level of respect felt, based on collegial interactions and/or access to information and resources. The next section defines how professional growth emerged in this study, as it pertains to faculty member career stage needs.

\section{Career Stage Needs}

Each adjunct faculty member interviewed for this study was at a different point in their career, with distinct motivators and goals that aligned with that stage. Even so, their hiring process was designed to establish each faculty member's integration into the department/academic unit and provided an introduction to colleagues and resources. Based on where each faculty member was in their career as an instructor, the hiring process established expectations about their future employment experience in the department/academic unit. Following the hiring process, adjunct faculty communicated varying levels of agency regarding their ongoing employment from term-to-term. Some described their decision to teach specific classes each quarter as a process in which they could expect a certain level of control, whereas others described their course assignments as out of their control. For the latter, their term-to-term work could be understood as dependent upon enrollment cycles and thus inconsistent. These participants taught each quarter without the confidence of consistent employment since, due to enrollment trends, 
at any moment their classes could be cancelled. Nevertheless, they were held accountable by way of the optional professional evaluation process which served as the primary professional development opportunity available to adjunct faculty at various career stages. Interestingly, passing this evaluation did not impact their agency or professional stability; instead, it was described as an experience that they chose to pursue based on its promise for a two-year projection of assignment rights, but a process that ultimately shaped their professional experiences very little.

Moe, Bibi, Poppy, and Sara shared different employment experiences associated with their individual career stage at PSU. Each individual is entrenched in two different career stages. The first stage is their overall career as a professional in their field which accounts for the cumulative experience of their work prior to and at PSU. The second stage is their adjunct role at PSU. Both stages interact as distinct pathways that the individual is navigating and each of the four adjuncts expressed a dimension of dissatisfaction with how their individual professional needs are being addressed, based on their career stage at PSU.

The sections that follow include findings for each of the four adjunct participants. Emergent findings from each participant are discussed in the following order: Moe, Bibi, Poppy, and Sara (see Table 3). 
Table 3.

Participant Findings: General Organization of the Data

\begin{tabular}{|c|c|c|c|}
\hline & Part One & Part Two & Part Three \\
\hline $\begin{array}{c}\text { Section 1: } \\
\text { Moe }\end{array}$ & $\begin{array}{l}\text { Theme 1: Motivation } \\
\text { \& Professional } \\
\text { Identity } \\
\text { Department Context: } \\
\text { Marc \& Marshall }\end{array}$ & $\begin{array}{l}\text { Theme 2.1: } \\
\text { Professional } \\
\text { Growth-Respect } \\
\text { Department Context: } \\
\text { Marc \& Marshall } \\
\end{array}$ & $\begin{array}{l}\text { Theme 2.2: } \\
\text { Professional Growth- } \\
\text { Career Stage Needs } \\
\text { Department Context: } \\
\text { Marc \& Marshall }\end{array}$ \\
\hline $\begin{array}{c}\text { Section 2: } \\
\text { Bibi }\end{array}$ & $\begin{array}{l}\text { Theme 1: Motivation } \\
\text { \& Professional } \\
\text { Identity } \\
\text { Department Context: } \\
\text { Cleo \& Swift }\end{array}$ & $\begin{array}{l}\text { Theme 2.1: } \\
\text { Professional } \\
\text { Growth-Respect } \\
\text { Department Context: } \\
\text { Cleo \& Swift }\end{array}$ & $\begin{array}{l}\text { Theme 2.2: } \\
\text { Professional Growth- } \\
\text { Career Stage Needs } \\
\text { Department Context: } \\
\text { Cleo \& Swift }\end{array}$ \\
\hline $\begin{array}{c}\text { Section 3: } \\
\text { Poppy }\end{array}$ & $\begin{array}{l}\text { Theme 1: Motivation } \\
\text { \& Professional } \\
\text { Identity } \\
\text { Department Context: } \\
\text { Noel }\end{array}$ & $\begin{array}{l}\text { Theme 2.1: } \\
\text { Professional } \\
\text { Growth-Respect } \\
\text { Department Context: } \\
\text { Noel }\end{array}$ & $\begin{array}{l}\text { Theme 2.2: } \\
\text { Professional Growth- } \\
\text { Career Stage Needs } \\
\text { Department Context: } \\
\text { Noel }\end{array}$ \\
\hline $\begin{array}{c}\text { Section 4: } \\
\text { Sara }\end{array}$ & $\begin{array}{l}\text { Theme 1: Motivation } \\
\text { \& Professional } \\
\text { Identity } \\
\text { Department Context: } \\
\text { Doug }\end{array}$ & $\begin{array}{l}\text { Theme 2.1: } \\
\text { Professional } \\
\text { Growth-Respect } \\
\text { Department Context: } \\
\text { Doug }\end{array}$ & $\begin{array}{l}\text { Theme 2.2: } \\
\text { Professional Growth- } \\
\text { Career Stage Needs } \\
\text { Department Context: } \\
\text { Doug }\end{array}$ \\
\hline
\end{tabular}

Note. Emergent findings are presented for each participant in the order listed above. For example, Moe's experiences, described in three parts, comprise the first sections of the findings, before transitioning to Bibi (and then Poppy and Sara).

For each participant, findings are organized around the two themes of: 1) professional identity drives motivation, and 2) professional growth experiences differ, based on the elements of respect and career stage needs (see Table 3). Department context is also included for each theme, based on the findings from department coordinator interviews and qualitative content analysis (see Appendix F for document list).

The next section includes findings from Moe, the first adjunct participant. 


\section{Moe: Instructor, PSU-Alumnus, and Adjunct Advocate}

This section focuses on the experiences of Moe, an early-career instructor with prior learning experiences as a student at PSU. His engagement at the university encompasses learning experiences and advocacy work for other adjunct faculty (through PSUFA). Moe's long-term goals focus on full-time instructional roles. As a result, expectations for his department are framed through that same lens. When expectations are unmet, it is often because they did not further, or at the minimum — align with, his professional goals. Findings for Moe start with an analysis of how his professional identity shapes his motivation. An analysis of his professional growth experience follows.

\section{Motivation and Professional Identity}

Moe described his professional identity as both a teacher and as a student. At the time of our interviews, he was in his second master's degree at PSU and his role as an adjunct faculty member seemed to be linked with that student identity. His initial connection with his employing academic unit was as a graduate student and as a Graduate Teaching Assistant (GTA) during his first master's degree. Moe identified minimal differences between his initial GTA role and his current adjunct position. He stated,

...so here I was a GTA...And my job was the same, except I, they checked in on me maybe a little bit more. Not really, I think you just were, I think you just had to go to the course coordination meetings. And oh and they did the thing where they made you send them your syllabus. And we had one observation in the first term that we were teaching. But I know some people didn't even get that.

Moe explained his role as an adjunct through comparison with his GTA position, namely, that there were few differences. However, he also expressed an evolution of his own understanding about his professional identity at PSU. He called out the tension in his dual 
role and the meaning-making that framed how he interprets his relationship with the university. When asked about whether his professional development and training needs are met as an adjunct faculty member at PSU, Moe expressed competing mindsets for how he could respond to that question. He shared,

I'm realizing I'm more of an employee than I am a student, and then the student mindset I'm like, I'm getting free education. This is good. But an employee mindset of like, they need me to do this. If they want me to do it well, they should encourage me to do it well. And so, like, it's not on me to like, seek these things out. They should be seeking me out.

Through a student mindset, he attributes more appreciation or satisfaction with the professional development provided. Through an employee mindset, he expresses dissatisfaction.

Moe's description of his professional identity included a desire to better understand his "place" as an adjunct at PSU. When asked to confirm if his title was "Adjunct," based on information listed on the PSU website, he responded "no idea. I would have thought that there would be a two there or potentially a senior. But I have no idea what the ranking system means. And as far as I understand, nobody knows.” In addition to not knowing his official title, Moe shared a desire for the university to better communicate the purpose of his role as an adjunct. This desire was not linked to the need for a specific title, but was instead connected to the pursuit of deeper understanding. He identified two different definitions for how PSU might define him. The first definition was of an in-development adjunct instructor who is gaining experience at PSU in pursuit of a full-time role. The second definition was "filler labor." For the first definition, he assumes that the university would be invested in his continued development, and as such, 
he expects that they would provide professional development in order to make him a "better product." For the "filler labor" role, he would not expect professional development (PD) or continued investment from the institution ("Then I would at least know why they're not providing it, because they don't care.’).

Of the opportunities offered for adjuncts at PSU, Moe identified multiple ways in which he sought development as an educator in his field. In his department, Moe participates in the optional Friday speaker series and course coordinator meetings, although his attendance at the course coordinator meetings is not consistent because that time is unpaid and optional (it is required for GTAs). Outside of his department, he participates in workshops through the OAI and he is a leader with PSUFA. Informally, he also referenced a lot of ad-hoc resource sharing with other adjuncts in his department and within the union. Even so, in contrast with the access to resources and professional development offered at PCC, where he also teaches, Moe does not believe that PSU nor his department are meeting his PD needs. He described his needs as a desire to develop as an instructor, in pursuit of future full-time work. Moe shared,

If I'm trying to develop my profession, like if I'm trying to get better at my job, like you need to get trained on those things and I wouldn't even know what I was missing. It feels so absent.

He expressed a desire for development within his "profession," which could be understood as a reference to his career stage needs (discussed later in this section).

Moe communicated an in-progress mental transition from his identity as a student to his identity as an adjunct. At the time of our interviews, that transition was still a tension for him because, logistically, Moe did inhabit two identities at PSU: student and 
employee. His goal to pursue full-time instructional work (“...if I could get a full-time job, I would take it") drove his motivation to develop and learn within the field, which perpetuated the dual identity. He described himself as a student of his craft and his level of engagement with the institution was framed by that goal. In addition, Moe referenced a clear desire to serve his students as an effective instructor, which emerged as another motivator for his chosen forms of engagement. When he discussed professional development experiences through OAI and/or through identification of desired training topics, those forms of engagement were connected with the opportunity to better serve students (i.e., disability services training, community engaged learning, how to better design instructional materials, etc.). Moe identified as both an employee and a student at PSU, but his overarching professional identity was as a teacher. He communicated a desire to teach full-time, which influenced his interest in continued development as an effective instructor.

Motivation and Professional Identity: Departmental Context. The department in which Moe works hires many of their former graduate students as adjunct faculty. This trend was not isolated to Moe's experience and was confirmed by one of the Department Coordinators interviewed for the study. As former students, they are perceived as already familiar with the department and in need of less initial support. One Department Coordinator, "Marc," described the support offered in the following way:

Most of our adjunct faculty have been students of ours before, over the years. And they teach one or two courses a term, depending on their schedule. Yeah, so they are more familiar. We don't do anything else other than working with course coordinators. 
The student to adjunct pipeline is perceived by the department as supporting their graduates in building their resume and acquiring more experience in the classroom. Within that context, the role, in itself, is identified as continued professional development. Even so, Moe did not perceive his role in itself as sufficiently fulfilling his professional development needs. His motivation to engage with the department, as well as in learning opportunities across the university, was driven by the desire to continue to develop as an instructor and to position himself effectively for full-time work in the future.

\section{Respect}

Moe is a hopeful full-timer (Tuckman, 1978), so his engagement with the department and the university includes opportunities to further develop his practice as an instructor. For Moe, that development is shaped by collaborative learning with peers and colleagues. He perceives being respected for his contributions as an adjunct faculty member when he is included in experiences with other faculty in the department. However, Moe identified feeling separate from the unit, based on the different location of the adjunct offices from that of the rest of the department. He associated feeling bad about the location of the adjunct offices because they are in a different building and excluded from the daily operations of the department. Moe described this physical exclusion as simultaneously an afterthought or an error in planning from department leadership, as well as a blatant commentary on the role of adjuncts in his department.

Moe's perception of being overlooked in the spatial planning for the department was based on his years of employment as a GTA and as an adjunct. He was working as 
an adjunct when the department moved into a new office suite. The entire department moved into the new suite and they "didn't make a room for adjuncts." This was not the experience of his adjunct colleagues in a different department, who also moved into a new office suite in the same building. Moe shared that his colleagues' department had "a nice adjunct office that's just like very centrally located." In contrast, the adjunct faculty in Moe's department were provided office space in a separate building, about one block away. That building was home to one other department, but Moe shared that it felt like they were in an abandoned building. He laughed as he shared the story of working alone in that space one day when a university employee arrived in order to turn off certain utilities because they were told that no one was working from that floor anymore. "It [made] me feel bad," he reflected.

Now, located in a physically separate space, Moe has to be intentional about going "to the department." He described it as "over there," and a place where he travels "every once in a while." Moe shared that his limited interactions in the main department suite negatively shape his feelings of inclusion with colleagues. For example, on one occasion when Moe visited the main suite, a full-time instructor with whom he had previously engaged said, “oh, it's really nice to see you...you're, you teach here?” This experience represented a problem for Moe because that specific faculty member is an individual with the same level of education (a master's degree) who holds a position that Moe is interested in applying to in the future, when that person retires. He shared, "I should know that person. And I should have a relationship with that person." However, based on the physical distance of Moe's adjunct office from the main department space, 
he identified that he has limited opportunities to develop relationships with his full-time colleagues.

When asked if he feels respected and supported by his department at PSU, Moe answered "no." He attributed that lack of respect and support to multiple reasons, but the first was his physical separation from the unit. Moe said, "if my office were with the rest of the department, that would make me feel like I was part of one of them.” As a parttime instructor at PSU, Moe perceives that his role "only exist[s] in the classroom" and he is not "a part of the infrastructure in any, in any fashion." Moe referenced omission of adjunct faculty voices during decision making, curricular conversations, and building planning as an example of how he is not part of the "infrastructure." The separate office spaces solidified Moe's feelings of separation and disrespect.

Respect: Department Context. Both department coordinators interviewed from Moe's academic unit identified the separate office space scenario as problematic. Marc identified that they were trying to find a solution. However, with the university's physical shutdown due to the COVID-19 pandemic, changes had been stalled. "Marshall" described the separate office space for adjunct faculty as the opposite of what should occur. He shared,

...we need to make it so our adjuncts feel like they belong and are invested in what we're trying to do. You know? And we go and shove them down into the crappiest old building on-campus...And you know, we're all open to chatting and talking, but they got to come find us if they care.

Marshall's reflection is interesting when compared with Moe's frustration about the office space. They shared an understanding that locating adjunct faculty in a different building did not positively influence belonging or investment. Marshall also affirmed Moe's 
statements that the onus was on the adjunct faculty member to visit the main department suite in order to socialize with staff and full-time faculty. He reflected on his prior behavior in saying, "I'm the course coordinator. I've never been over. I've never even walked over there." The role of the course coordinator was identified by both Marc and Marshall as a source of communication for adjunct faculty, but that communication typically occurs through email. Marc shared that adjunct faculty are not required to attend course coordinator meetings because they are unpaid events. He said, "all the adjuncts who are part of the same cohort of instructors are certainly welcome to participate and many do. The more experienced they are, the less likely they are to do that." Moe identified that he did not typically choose to attend course coordinators meetings any more (whereas he did as a GTA), because it was unpaid time. As a result, in-person collegial interactions with other faculty in the department were most commonly limited to other adjunct faculty. While a shared adjunct workspace strengthens a community of faculty with shared lived experiences as part-time employees, it also enables a division with the rest of the department and does not offer regular opportunities for collective engagement. As such, Moe identified that he is not able to develop relationships with his full-time colleagues that could contribute to his future career development.

\section{Career Stage Needs}

As an early career "hopeful full-timer," Moe described professional growth needs associated with his instructional role. Those needs included professional development, integration in the department, and equitable employment conditions. For professional development, Moe participates in workshops with the OAI and, on occasion, with unpaid 
course coordinator meetings in his department. Course coordinator meetings further his PD while also facilitating an opportunity for integration in the department through collaboration with other adjunct faculty and GTAs. However, an unmet desire he communicated was integration with full-time faculty in his academic unit. This integration is hindered due to the different office spaces for full- versus part-time faculty. Finally, he pursues equitable employment conditions for adjunct faculty through his work with PSUFA. The union was described by Moe as a learning experience, as a community, and as a job. His participation in PSUFA events is one way that he learned more about the adjunct role and the lived experiences of his part-time colleagues at PSU. It situated his adjunct work within a larger community of individuals. With PSUFA, his involvement advanced from participant, to volunteer, to employee and he continues to contribute to the union's efforts to advocate for equitable adjunct work experiences. As a learner, a professional, and an advocate for other part-time employees, Moe described his career stage needs as an evolution of a personal understanding of his role as an instructor, and at the time of our interviews, as an adjunct.

Moe's career stages at PSU include work as a GTA, as an adjunct, and as an active PSUFA member. Each stage ushered him through different levels of engagement and ownership with the department, the university, and his professional practice. For example, the initial hiring process for his adjunct position was informal and an extension of his GTA work. It happened that after two years as a GTA, he was told by his department that he could not work in the position for a third year; instead, they offered him a job as an adjunct. Once in his adjunct role, even the department orientation week 
was a shared experience facilitated for both new GTAs and adjuncts. As a result, Moe's professional identity as an adjunct is still rooted in his part-time GTA position, and he continues to pursue a better understanding of "his place" at PSU. This is an endeavor supported by his work with PSUFA. Moe described his role with the union as an extension of his adjunct work, and one in which he feels connected to shared goals with other adjuncts. In this stage of his adjunct work at PSU, he actively engages with the institution, as well as with the employment experiences of his colleagues. Engagement with the institution, alongside PSUFA, is an opportunity for Moe to continue to define his adjunct position and better understand this stage in his career.

Another stage within Moe's career as an adjunct at PSU was his participation in the professional evaluation, facilitated by his Department Chair. He discussed that process as an inconsequential milestone, yet one for which he can understand the originating purpose, based on his continued work at PSU and with PSUFA. When asked why he chose to participate in that experience, he shared,

I did it in part because it was offered and I feel like obliged to do things that are offered to me. And I knew it would give me a two-year contract, but I didn't really, I don't feel like I needed that, because I have confidence that my contracts will be renewed anyways. But I've since learned that it was good.

Moe engaged with the experience because it was offered, which was similar to why he originally became an adjunct at PSU. Furthermore, he described how his interpretation of the experience evolved from not thinking that it was necessary for continued employment, to understanding how it did impact his assignment rights. He described perceived benefits of participation in the evaluation experience as related to his employment and to his personal professional growth since the evaluation put him "higher 
on the pecking order" within the adjunct pool. The higher position in this pool resulted in a greater likelihood of being chosen to teach, perhaps on an annual basis. In addition, he received a positive written recommendation from his Chair that could be used for other employment purposes (whether at PSU or not). Moe also described how the required supplemental materials for his evaluation facilitated personal introspection about his work. Although he did not choose the classroom observation as one of his two supplemental items, due to limited time and shyness, he did share that "it would have been a good thing to have somebody come in and observe my class.” An area of ambiguity with the professional evaluation was the impact on his title. He shared that he was not familiar with the adjunct ranking system, and he did not perceive that the system was known by anyone. When asked if his professional evaluation impacted his title in any way, that same level of uncertainty and ambivalence was expressed: "It might have changed my name, title. I'm not certain about that because I don't understand how the titles work here." As such, the tangible or more observable benefits of a favorable evaluation had little impact on Moe. His identified benefits were personal learning experiences connected to the process. Even so, outside of the professional evaluation, Moe ascribed meaning to his adjunct role and to individual experiences within that role, based on personal values and needs.

Moe continues to exercise agency within his current career stage through pursuit of additional employment and professional development experiences, influenced by his dual student/adjunct identities, as well as his identified personal and professional needs. For example, he communicated a desire to continue to develop as an effective instructor, 
which he pursues through additional teaching experience and through PD which facilitates that learning. He also identified a personal need to generate an income each month, which is made possible through his multiple jobs. As previously described, Moe pursued additional work experiences at PCC and with PSUFA. In addition to earning money from each job, he also has the opportunity to contribute to his professional practice as an instructor in his field and to advocate for employment equity within the profession.

Moe's described career stage is as an adjunct who possesses the agency to pursue additional work and PD experiences; however, he is also an adjunct with identified unmet needs. As a result, a number of dichotomies exist that characterize his work with PSU, all which call out for the fundamental desire for greater integration in his department. For example, he is immersed in the adjunct community at PSU, yet he is disconnected from full-time faculty within his department. Moe's department facilitates an expectation of continued employment by hiring their adjunct faculty from their pipeline of GTAs. However, Moe does not perceive that his continued employment expands outside of an adjunct position. His current adjunct position continues to be similar to his work as a GTA, based on shared organizational experiences (e.g., onboarding week, department coordinator meetings, etc.). However, the defining difference for Moe is that his GTA role was intertwined with his student persona, whereas his adjunct role is solely an employee position. Moe perceives that his department would only ever hire a person with a $\mathrm{PhD}$, although he counters that belief with examples of full-time faculty in the department with master's degrees. To this end, he communicated uncertainty about his 
future opportunities in the department and he described limited options through which to build connections with full-time colleagues in order to better understand those options.

Career Stage Needs: Department Context. Department coordinator, Marc, identified that the department had previously hired former adjunct faculty into full-time non-tenure track faculty roles. He referenced an example of a full-time non-tenure track faculty appointment to which multiple adjuncts in the department applied. Less likely, however, would be the prospect of hiring a former adjunct into a full-time tenure-track role. Marc described how there had been a decrease in full-time tenure-track lines in the department and an increase in FTNTTF hires. For adjuncts in the department, this meant that access to full-time work likely equated to a FTNTTF opportunity yet, despite the potential for an adjunct to apply to a FTNTTF role, Marc shared that there were still limited avenues through which to engage adjunct faculty in the larger department. Moe defined this limitation as missed opportunities for socialization and career development and Marc agreed, sharing that an adjunct faculty member's connection to the department was commonly limited to the one or two courses that they teach. The adjunct office space is their only other connection to the department, outside of their communications with a course coordinator. An exception to this experience is with adjunct faculty who were previously students in the department. Marc shared, "some of them [adjuncts] interact more than others, because some of them are graduates, recently graduated from us, so they're more familiar with the faculty." Based on this example, familiarity between partand full-time faculty is limited to former students. Additionally, Marc situated the context for department engagement with part-time faculty within the guidelines of the CBA for 
adjuncts. In the contract, outside-of-class required activities need to be compensated. Therefore, there is little that can be required of an adjunct outside of their instructional work.

Within this department context, Moe's experience demonstrates how he has pursued personal goals and addressed career stage needs on his own. As a former student in the department, he possesses some familiarity with full-time faculty, however, those relationships were not defined as meeting his needs for integration in the department, in line with his professional growth goals.

\section{Moe: Summary}

As an adjunct and a student, Moe embodies two identities that define his professional experiences. He is interested in full-time instructional work, and chooses his desired forms of engagement with PSU based on that future goal. However, Moe does not express feeling supported toward that goal within his department. He perceives that he is meant to further the institution's mission of "stay[ing] afloat [since] their mission is to survive." As an adjunct, he explained how his role is financially efficient for his department and for the university because they have little obligation to him and because he is paid less than his full-time counterparts (both NTTF and TTF). It is clear from our conversation that Moe's professional growth journey is an evolution of his identity from student to instructor. As he continues to navigate that journey, Moe is refining his expectations for PSU, his department, and his outside experiences (e.g., PCC work, PSUFA work, etc.). 


\section{Bibi: Semi-Retired, Subject Matter Expert, Instructor}

This section of the findings focuses on the experiences of Bibi, an adjunct faculty member with developed subject matter expertise based on his former career as a practitioner in his field. He chooses to engage with his department and with PSU in opportunities that either have the potential to develop his social capital or that will add to students' learning experiences. His professional goals, in this phase two of his career, have evolved during his time at PSU. At the time of our interviews, he expressed an interest in continuing to teach, but hopefully being able to take-on more credits than the 0.49 FTE maximum allowed for adjunct faculty. He did not describe an aspiration for a full-time instructional role, but he values the interactions with his students and would enjoy the opportunity to teach more classes each year. The analysis of Bibi's responses begins with a focus on his professional identity and how that identity impacted his motivation to engage in specific opportunities to the advantage of his professional growth.

\section{Motivation and Professional Identity}

Bibi described himself as being in "phase two" of his career. In the classroom, he is a practitioner and a subject-matter expert who takes pride in "sharing knowledge and experience." The relevance and importance of his discipline, as it relates to the future for students in his classes, was a consistent point that emerged as Bibi discussed his motivation for teaching and the ways in which he chooses to engage with his department.

Bibi shared two different motivators for engaging with his department and the larger institution during his five years with the university. The first motivator was his 
desire to share practice-based knowledge and experience with his students. That motivation led him to engage with the department within the context of his instructional role by attending course coordinator meetings, serving as a mentor for one of the graduate programs, and volunteering his time to present for students during a weekly workshop/speaker series. Bibi previously taught one online class, but he preferred teaching in-person. He said, "I certainly get my, you know, joy of the interaction." When asked to describe what he meant about "the interaction," he specified that it is the inperson interactions with his students that are the source of his joy. He said, "because if not, then we're left to other reasons why you'd want to do it (teaching) and those other reasons are not that important to me." After retiring from a career of almost 18 years with a company, he transitioned to sharing his subject-matter expertise with students and individuals new to the field. Prior to his work at PSU, Bibi developed a curriculum for a community program at PCC in which local professionals could take classes. Now at PSU, he continues to contribute to the learning and development of his students to support them in effectively engaging with the industry following graduation. He referenced receiving comments from students that he was "not your usual professor" and he interpreted that as a positive description.

Bibi's second motivator for engaging with the department and the university at large was a desire for full-time employment as a staff member. He shared, "for a while I was trying to teach here and work here, or just work here. You know, as my next sort of career." In his first few years with the university, he referenced serving on the university's Diversity Council, attending monthly social gatherings sponsored by the 
Office of Academic Affairs, and engaging in informational interviews with department heads. However, after multiple failed applications to staff roles at PSU, he let go of that goal. In turn, his motivation to engage with social activities outside of the classroom dissipated as he reflected in the following way:

...so the motivation actually stopped to want to work here full-time after four attempts. I'm like, forget it, you know, and forget it. Thus, possibly the motivation to go to all those social events, sort of also waned a little bit.

This example demonstrates how Bibi's motivation to engage with the institution was externally influenced. As his employment goals continued to be unmet, his motivation to engage in superfluous and/or non-instructional activities decreased.

It is interesting to explore the ways in which Bibi engaged with his role as an adjunct at PSU, and how those experiences changed over time. Although his motivation to participate in committees or social activities outside of his department waned, Bibi's commitment to his subject matter was consistent. He expressed a connection to his adjunct work as an interest in teaching and sharing practical knowledge about his field.

Bibi shared,

I think there's a missing gap between here and in what's needed in the working world. I think educational institutions teach core basics, classes[...] and you know all that stuff, but they don't necessarily teach you how to be at work, how to navigate your career, how to build a career...there's this missing piece like, you're here now. Now what? There's not a lot of that. So I'm just trying to share knowledge and experience that I've had, so it gives the students something else to compare it to.

When asked about future goals for his ongoing work at PSU, he shared that he doesn't have any, other than wanting to teach more than five classes per academic year. He also does not expect the institution to support him in identifying a future path. Bibi said, 
There's not a lot of, here's your path. Because really, I think this role is not supposed to be that way. I think this role is, you know, it supplements. You're here and it's flexible. So there is no path by design, nor do I actually look for a path.

Although Bibi's initial goals at PSU included finding a full-time staff role, he no longer identified with that plan at the time of our interviews. Instead, he regards the institution as intentionally uninvolved with facilitating a professional path, beyond his current role as an adjunct.

Motivation and Professional Identity: Department Context. In his academic unit, Bibi fit the definition of an adjunct faculty member, as described by both department coordinators interviewed for this study ("Cleo" and "Swift"). Cleo shared that "adjunct faculty generally are experts in their field and we're bringing them in as practitioners to come into the classroom." Similarly, Swift described how adjunct faculty are valued by the department, including their students, for bringing relevancy to the curriculum. In combination with full-time faculty (NTTF or tenure-track faculty (TTF)) doing leading research, adjunct faculty are seen as providing applied knowledge that has been practiced in the workplace. In this way, the department echoes Bibi's values in what he brings to his role as a dedicated instructor. Swift stated, “...you're not just getting an academic's view on this. You actually are getting folks that actually do the work too." Although they do fulfill a budgetary need in the department (as the number of tenure lines decrease in the department, they are expected to fill them with adjunct instructors), there is an inherent appreciation for their subject matter expertise. This appreciation does not translate to increased compensation or other financial benefits, but it is present in the organizational structure of the unit. Specifically, Bibi's department employs a full-time 
faculty member with the responsibility of coordinating and supporting adjunct faculty onboarding and development (the faculty member in this position is NTTF). This role was uncommon in other academic units at PSU. In addition, the department utilizes course coordinators, who are another identified form of curricular support for adjunct faculty. The department endeavors to express investment in their adjunct faculty through each of these forms of support. As Bibi's motivation has remained focused on preparing students to succeed in the field, post-graduation, his engagement with the department occurs within the context of his teaching role. The faculty position dedicated to adjunct faculty onboarding and training was created after Bibi's hire, so he did not see a need to engage with that individual. He did, however, describe participation in course coordinator meetings and he spoke highly of each of his course coordinators.

\section{Respect}

For Bibi, respect is communicated from his department and from PSU through expressed value for his subject matter expertise as a practitioner (rather than as an academic). He described himself as being in his second career as an adjunct at PSU. Therefore, respect for the knowledge acquired throughout his first career was an important element bearing intrinsic value for Bibi. He identified feeling respected and valued by his department based on interactions with his course coordinators and other full-time faculty. That respect was described as being ongoing and consistent. From the larger university, he initially felt respected based on a friendship with a previous university President, but that respect was not ongoing and all-encompassing. Instead, it was temporary and limited to the period of time in which the President worked at PSU. It 
also did not mitigate the challenges that Bibi faced with the job search process outside of his department at PSU. As such, Bibi felt respected in his role as an adjunct within his department, but that same value was not communicated from the larger institution.

Within his academic unit, Bibi typically teaches three different classes throughout the academic year, so he works with three different course coordinators. Bibi identified his course coordinators as a main form of support and collegial interaction for him at PSU. He shared, "I don't really communicate with anybody else." Each coordinator is the content lead for a specific undergraduate course and they share resources throughout the quarter, as well as informal feedback on student evaluations at the end of the term. Bibi chooses to participate in optional group meetings scheduled by his course coordinator(s) and although they are unpaid, he described the meetings as a "form of support" that he appreciates. Bibi shared,

I think all three do a great job at least trying to make you feel valued...I think they really go out of their way to make sure you know, "hey you're really appreciated" and all that, which is great. I think that's what they're supposed to do. I think they generally mean that and yeah, I like it. You can tell I like all three of them. I think they're great.

The "support" provided that Bibi described is more than content-related information.

Each course coordinator makes him feel valued, which encourages his attendance at the optional meetings.

In addition to engagement with department coordinators, Bibi referenced times when he experienced feeling heard and valued as a subject matter expert. The first example was one in which he expressed an opinion outwardly to other faculty regarding the content of a student workshop. The workshop was focused on a topic that he did not 
find appropriate for the developmental levels of the students in attendance. He shared, "so I voiced my concern and another professor did too, and they (department leadership) said oh, why don't you guys do a counter presentation...I just wanted to offer another perspective on that topic." Bibi voiced his concern and his opinion was validated and given space through the counter presentation that he led. He shared another example of how his colleagues would contact him when they needed someone to teach a specific class and/or when they learned about an opportunity for a course that they thought might be of interest to him. He said, "I'm assuming that they think I'm worthy, or else why would you refer somebody?" For Bibi, this form of outreach and collegial interaction is a sign of trust and respect.

In terms of his title, the term "adjunct faculty" has a negative connotation for Bibi, so he refers to himself as an instructor. He described thinking of the idea of an adjunct instructor as "super low paid, and there's no security...so I just don't even call myself that." That picture of adjunct faculty is not one that Bibi aligns with, so he chooses not to own the title. In his department, he identifies a division between full-time (NTTF and TTF) and part-time faculty ("I don't think they quite see the adjuncts as on the same level"), but he is not bothered by that difference because he associates full-time faculty work with a terminal degree (a PhD), which he does not hold. The division or difference in faculty type is not one that he describes as a reflection of his value in the department. Based on his prior professional and academic experiences, Bibi identifies feeling valued and respected as an instructor by his colleagues. 
In addition to Bibi's collegial relationships and respect experienced within his department, his former friendship with a past PSU president was an important connection outside of his department. This relationship was referenced multiple times and it emerged as a pillar of connection with the university at large. Bibi did not go into great detail about the friendship, but its existence surfaced through discussion of why he values the field in which he works and teaches. As a respected subject matter expert, Bibi spoke of his classes with pride. The relationship with the former President was similarly discussed with an expression of gratification. The President was interested in Bibi's reason for teaching part-time at PSU, and he asked him about his motivation for doing so. As was referenced in the findings about Bibi's relationship with colleagues in the department, he shared that he perceives worthiness when opportunities are offered to him. The President shared an opportunity for engagement (the Diversity Council) and Bibi, in turn, discussed their relationship as connected to work at PSU with which he feels valued. Even so, Bibi's friendship with the former university President did not translate to additional employment opportunities. Specifically, he described multiple failed job applications for staff roles at PSU, which frustrated his motivation to engage with the institution in the manner that he had initially chosen (i.e., institution-wide social gatherings). This journey affirmed for Bibi that he is valued as a subject matter expert in his adjunct role, but not in other capacities at PSU. As a seasoned professional, Bibi does not choose to pursue opportunities in which he consistently fails. Because he did not experience consistent respect outside of his department, Bibi now concentrates his engagement on opportunities to serve students within his department. 
Respect: Department Context. Bibi is a faculty member within one of the schools/colleges at PSU that is defined as a professional school because the majors offered prepare students for careers in specific fields. The culture of the department, as described by Bibi and the two department coordinator participants, is one in which practitioners with subject-matter expertise are valued in high esteem. Cleo described faculty as being collegial and committed to the university's access mission and the kind of student that is served. She shared,

We have many faculty who could go on to a research one school, or adjuncts who work in really high-powered, high-paying jobs in the city and don't need to teach, but they're doing it to give back. So I think everyone coalesces around that.

Different organizational systems exist for full-time versus part-time faculty, however, shared dedication to shaping the educational experiences of students is a characteristic of the department culture. This shared values system resonates with Bibi's desire to teach courses that develop students' knowledge in areas that will translate into life after college. As such, the general department culture is one in which both department leadership and faculty (full- and part-time) value each other's unique experiences and skill-sets. For adjunct faculty, this manifests through inclusion in support systems that might otherwise only focus on the professional experiences of full-time faculty. For example, the adjunct faculty coordinator role in the department focuses on adjunct faculty onboarding and ongoing PD. It was created in response to an identified need to better serve the growing number of adjunct faculty in the academic unit. Bibi described feeling respected and valued by his colleagues, which resonates with the department's commitment to 
sustaining a positive faculty experience through collegial interactions and strategic support systems.

\section{Career Stage Needs}

Self-described as being in "phase two" of his career, Bibi's career stage needs are concentrated on his work at PSU. Specifically, he is interested in continuing his instructional role, at least at its current level. Experiences that contribute to and advance that goal are ones that Bibi will pursue. For example, Bibi chooses to attend optional, unpaid course coordinator meetings, he volunteers to facilitate workshops and/or talks for students in the department at-large, and he previously served as a graduate student mentor for multiple years. Each of these examples contribute to his engagement and presence in the department. Distinct from Moe, Poppy, and Sara, Bibi does not consistently supplement his PSU work with outside employment. He explained that this does not occur because he does not require supplemental income and, additionally, because it simply does not align with his current goals. As an adjunct at PSU, Bibi exercises agency by engaging with his instructional role in a manner that specifically fits his interests. He is not employed out of necessity, but rather, based on personal choice.

Bibi's agency and confidence were evident from his initial hire, which he approached without hesitation. He learned of and was offered the role eight days before the start of the quarter and he easily transitioned, leaning on his subject-matter expertise and the resources provided by colleagues in the department. Instructional experiences since that point were also described with the same ease. Bibi does not question whether he will be offered courses from year-to-year and when he is not interested in a specific 
class, he will decline the offer. Bibi described his adjunct role as a career that he has control over in ways that are important to him: course options and engagement with colleagues.

When asked if he is aware of opportunities for promotion, Bibi referenced his experience with the professional evaluation. Outside of that evaluation, he does not believe that other opportunities exist for adjunct promotions. Bibi shared, "I wouldn't call them promotions. I think you have the opportunity to look for jobs." At this point in his career at PSU, he is interested in teaching more than five courses per year (plus a summer class). This additional course load is not something that he wants to pursue in order to receive higher pay or benefits (e.g., healthcare). "I just want to teach more classes" he shared. His professional evaluation was a process that he chose to participate in when it was offered. He described it as something that he's thankful for and that was important to him at the time, as evidenced by the effort that he put into the application. However, he is uncertain how the process impacted his adjunct work and if the two-year contract is even still active for him. He reflected on it by saying, "I just don't know what it got...I don't even know if there was a bump in pay." Furthermore, Bibi was not sure what would have occurred had he declined to participate in the evaluation process. Whereas an increase in course assignments would have been a perceived benefit, the professional evaluation was not discussed by Bibi as a process that greatly shaped his experience or his career at PSU.

The career stage that Bibi inhabits is self-described as phase two of his larger career, yet in addition, it is also phase two of his PSU career. This current phase was arrived at based on changes in his goals over time. Bibi's career goals at PSU have 
evolved since his initial hire, based on opportunities offered, collegial relationships, and personal interests. Although a combination of all three components, he described this career evolution as being greatly impacted by the failed internal hiring processes that he navigated, when applying for other roles within the university. The cumulative experience of those negative hiring processes for Bibi shifted his goal away from the desire to work in a staff role, while also teaching a few courses. He shared, ...ideally what I wanted to do was work here, full-time or part-time at a nonteaching role. There are a couple roles I looked into and, again, with every one of them I spoke with somebody pretty up high and they're like yeah yeah, you'd be great. And then I could keep teaching my classes. You know, the ones I'm teaching. That would have been ideal. Just the mixture, you know. But yeah, I stopped pursuing those after the fifth time.

So, based on his adverse experiences, Bibi shifted his goal and is now in a career phase focused on his instruction as an adjunct. He shared, "I have no idea what would be after this role," however, he doesn't describe himself as aspiring to other faculty positions (e.g., associate professor, etc.), nor to the previous staff roles that were of interest to him.

Bibi describes the difference between goals and opportunities when sharing about his professional growth experiences. At this point in his career at PSU, he can identify opportunities that were offered and pursued, but he no longer describes those experiences as the pursuit of goals. For Bibi, a goal is more of a future trajectory for one's career as he explained, "a goal to me is like, I want to start as an adjunct. And then maybe become the course coordinator, and then maybe become this and...I don't really have those here." In phase two of his career at PSU, Bibi does not have career goals. Phase one career goals for Bibi during his initial years at the university changed, or really—waned, due to multiple failed job applications for staff roles. Now, he is presented with opportunities 
PROFESSIONAL GROWTH

and he discerns participation based on whether or not the experience aligns with his interests.

Career Stage Needs: Department Context. In Bibi's department, Cleo described three different groups of adjunct faculty: career adjuncts, altruistic adjuncts, and resumebuilding adjuncts. The career adjuncts work at multiple schools and they are deeply committed to their students. Cleo described them as "career adjuncts" because they are employed at multiple institutions in order to "piece together a full-time job" and earn a living wage. Altruistic adjuncts choose to teach part-time in order to "give back" and resume-building adjuncts want the position on their resume. She described this third category as the group who "insist[s] that the students call them Professor, or on their LinkedIn it's like, "Professor at Portland State"., Bibi best aligns with Cleo's description of the altruistic adjunct. He is invested in his students and his courses in order to give back and impart his knowledge gained from years of successful practice. The challenge for the altruistic adjunct is limited career development resources, because their needs are nebulous. Some altruistic adjuncts work full-time in another capacity, while others are similar to Bibi and are retired from another career and these different employment situations shape a diverse workforce with varying needs. As a way to combat this challenge, Cleo shared that an annual adjunct orientation meeting is meant to communicate the department's respect for their part-time faculty. This meeting includes information about department resources, but more importantly, it is intended as an opportunity to integrate adjunct faculty into the department culture. She shared that 
students, "love to hear from practitioners," so the orientation is an opportunity to "[help] the adjuncts to understand that we're a better school because they're there."

Bibi communicated that he feels valued and respected by his department, which is a theme that was previously discussed. What is interesting, however, is how Bibi's feelings of respect and value differ at PSU, based on the context. Within his department, he feels valued and his investment as an instructor is positively impacted based on feelings of belonging. Outside of his department, the experience is the opposite and, as a result, his chosen career path at PSU is now limited to work within his academic unit. For Bibi, his career stage needs have evolved, based on positive employment experiences within his department, and the lack of respect and opportunity experienced outside of it.

\section{Bibi: Summary}

Overall, Bibi's responses indicate that he feels valued and respected by his department. He is invested in impacting the learning experiences of his students, as well as furthering the advancement of knowledge in his field. He identifies as an educator, with 18 years of practiced subject matter expertise to inform his instruction. At PSU, Bibi's professional growth journey has been informed by prior experiences both positive and negative. He described positive experiences as those that involved in-person interactions with students or collaboration with his course coordinator(s). The application and interview process for multiple staff roles, for which he was not offered the job, are the negative experiences that he described. Interestingly, a recurring theme with Bibi was the impact of multiple contexts on his experience. His satisfaction as an instructor was shaped by a sense of belonging developed within his department. Even so, the external 
world outside of his department — the university — was a space in which he did not develop that belonging over time. As a result, his department's strong culture and respect for adjunct faculty sustained his satisfaction at the university. The importance and impact of a department's culture on adjunct faculty experiences cannot be underestimated.

\section{Poppy: Educator, Former NTTF, Hopeful Full-Timer}

The next section focuses on the professional experiences of Poppy. As an adjunct, she articulated a different, yet similar, theme to Bibi regarding a connection to her academic unit. Poppy is an early-to-mid career faculty member, with a long history of connection to PSU—-from student, to GTA, to full-time non-tenure track faculty (FTNTTF), to adjunct. Poppy is motivated by a desire to resume full-time employment as an instructor, yet her adjunct work on multiple campuses restricts available time with which to engage in non-instructional opportunities at PSU. Even so, when she is able to participate, she values professional development that supports her continued growth as an instructor and that enables interactions with colleagues. Additionally, she is committed to creating a positive learning environment for her students. The presentation of Poppy's experience begins with a focus on her professional identity and accompanying motivators for engagement. An analysis of her professional growth journey follows.

\section{Motivation and Professional Identity}

Poppy described herself as a teacher. Her pedagogy is guided by the goal of "creating community inside and outside of [the classroom]" because her class is where "the world comes together and where bridges can be built." Her instructional work at multiple institutions as well as her commitment to professional development and service 
to each institution, all demonstrate her dedication to the profession. Within her selfidentification as a teacher, Poppy embodies two spaces: as both an adjunct and FTNTTF. Although her current role at PSU is part-time, her previous full-time work continues to frame the ways in which she engages with the university and how she interprets her position. Specifically, Poppy referenced her FTNTTF work as a point of comparison when describing her current part-time work at PSU and her engagement in Department A. Similar to Moe, Poppy communicated a tension in her professional identity, which was described through the many differences that she identified in her FTNTTF and adjunct work.

Examples of engagement for Poppy at PSU include serving on the Diversity Action Council, attending workshops through the Office of Academic Innovation, volunteering for the annual undergraduate scholarship reading, and participating in campus-wide symposiums (e.g., the winter symposium). She identified an interest in opportunities for engagement that can further develop her practice in the classroom, facilitate collegial interactions, and serve the university. Poppy explained those interests in the following way:

I like to go to larger community events and those aren't necessarily related to developing in my field, but they're related to me as an instructor here. I also do things like I always volunteer for scholarship application reading. And I don't really think that that's a professional development. Like, I don't know that it would fit neatly in that category, but I do feel like it helps me be more of service to the university, and I'm more of a part to the university so I do try to seek out things that make me more connected. And in a lot of ways that is professional development.

In that example, Poppy referenced how attendance at larger community events is related to her work as an instructor. She also identified service to the institution and professional 
connection ("more of a part to the university") as outcomes of her engagement. These examples of personal impact are interesting because they call out an established pillar of tenure (service to the institution), as well as a desire for increased connection with the university. As a former FTNTTF member, Poppy's desired outcomes for engagement aligned with her internalized identity as a full-time faculty member. Although the focus of her role as FTNTTF was on instruction, engagement in various institutional opportunities (i.e., committees, scholarship review, etc.) were experiences that could be included on Poppy's curriculum vitae and/or submitted during contract reviews with Department A. Her continued participation and engagement with the institution as an adjunct is connected with a set of expectations about how to "grow your career." She reflected on the challenge of having limited expectations for engagement in her adjunct role in the following statement:

...because you're not required to sit on a committee, you no longer have that committee experience on your CV. Because you're not required to work on this project, it doesn't go on your CV, so your opportunities to grow are much smaller. And it's much more on you to make that happen.

In addition to wanting to grow her career, Poppy referenced engagement with colleagues as a source of motivation. Poppy's attitudes about her adjunct role at PSU are influenced by feelings of inclusion and support from colleagues in the department. She reflected,

I do think it makes you want to do a better job. If you know the team of people that you're working with. If you see the quality of instruction happening from your colleagues if you're talking about teaching, if you're having these little conversations and feeling included and supported, then, it definitely makes me feel much more engaged and like I want to do a much better job. 
Grounded in her identity as a teacher, the motivation derived from positive interactions with colleagues is described through a beneficial relationship with Poppy's instruction. Positive engagement and accountability from her colleagues motivated her to do a better job; however, although she finds value and motivation through engagement with colleagues, her ability to do so is less accessible as a part-time faculty member, than it was in her previous role as FTNTTF. Poppy has less available time on-campus, which limits her collegial interactions.

Motivation and Professional Identity: Department Context. The top faculty rank held by individuals employed in Department A is currently Senior Instructor 2. Faculty are either employed as FTNTTF or as adjuncts. "Noel," the department coordinator interviewed for this study, identified that the main focus of faculty in the department is on instruction. Since their primary focus is on instruction, their culture as a unit is collegial and dedicated to improving their craft. Noel shared,

I think we are all, you know, by nature, academics, so we like to, you know, find ways to do it better. You know, part of it is ease. It makes it easier if you're kind of talking to each other and being like, oh, okay, I never thought about that. How about if I do it this way instead? Maybe that might, you know, might be more effective. So I think, you know, personal desire. Just to grow in your own craft.

For the full-time instructors, there is limited turnover, other than when layoffs occurwhich is dependent on student enrollment. Poppy's identity as an educator is aligned with that of her colleagues in Department A. Therefore, her interest in engaging with professional development is supported by the department culture. The part-time nature of her role presents the challenge as resources (e.g., compensation and time) are more 
limited for adjunct faculty. These limitations are discussed in the next section about respect and professional growth.

\section{Respect}

In her adjunct role, Poppy described feeling respected by her colleagues based on positive interactions and relationships in Department A at PSU. Conversely, she identified a lack of respect based on limited resources, namely those that are financial (e.g., pay per credit/course and compensation for PD) as well as the time needed to engage with institution-sponsored professional development. As a resource with which Poppy desires more access, "time" was referenced as a consistent challenge and a commonly valued resource that, when absent, inhibited her access to opportunities that encouraged collegial interactions and professional growth. Poppy's reflection on her experiences was discussed as a series of contrasts (e.g., full-time non-tenure track faculty versus adjunct, PSU versus PCC, etc.). In contrast to her prior FTNTTF work at PSU, she sees her professional growth as an adjunct faculty member as static and/or largely out of her control, based on the time and financial limitations imposed by her current part-time status. As a hopeful full-timer (Tuckman, 1978), this is frustrating for Poppy. Her established social integration in Department A is a contributing element to feelings of belonging and respect, but limited financial and time resources temper her satisfaction and capacity to set and achieve professional goals.

"Super collaborative," and "tight-knit" are ways that Poppy discussed the culture of Department A at PSU. She described her colleagues as invested in her continued employment in the department, which communicates to Poppy that she is a respected part 
of the learning community, even though her employment status changed. She said, "people are like, we're waiting to see your name on the schedule, like, where is it? Are you going to get a class?" When she does see her name on the schedule for the quarter, Poppy's colleagues share in her relief and are quick to offer teaching resources (e.g., copies of books). When she is able, Poppy endeavors to spend time in the department suite. Her office space is one that she worked from as FTNTTF and was a space that she maintained after transitioning to an adjunct role, due to space availability and the decrease in both full- and part-time faculty. The effort to increase her presence in the department is due to positive collegial interactions and the instructional resources available for her in the department. She described how people are, "constantly dropping into offices" to say hello, to discuss a call, and to personally connect. Poppy recalled an example of a colleague dropping in to share a loaf of bread, just because she wanted to share it. Personal connection and physical presence in the department are both external motivators for Poppy and her engagement as an instructor. Through reflection, Poppy shared that she believes her inclusive experience is unique as a result of previous inhabited identities in the department. From a GTA, to FTNTTF, and then to an adjunct, Poppy feels like she is a part of the department and she receives that affirmation from colleagues. Poppy shared,

I think there's a lot of sympathy and people feel like, oh my gosh, you were one of us and you got laid off and now you're like, still here in this capacity and we feel bad for you. So, and we like you too, because you are a part of us, so we want to make you feel more included.

Colleagues see her as "one of [them]" and wronged, worthy of sympathy and intentional care. Interestingly, Poppy is not certain if this same experience would resonate with other 
adjunct faculty in the department who were not previously employed as FTNTTF. Nonetheless, she expresses feeling valued and respected by her colleagues, due to her previous full-time work in the department.

Outside of her collegial relationships that communicate respect and belonging in the department, Poppy described two persistent challenges that diminish feelings of respect and belonging. The first is her limited access to financial resources, including compensation for PD and committee work, as well as for her instructional duties. Poppy described how PCC pays part-time faculty for "every outside activity," but at PSU, she is not compensated for any work outside of her contracted classroom instruction. For Poppy, her personal contrast of the two experiences highlights the deficit at PSU. She shared, "that makes me view it very differently too, like, oh wow I really feel like my time is not as valued here." In this description, value is tied to Poppy's time. Because she is not compensated at PSU for engagement outside of her instructional responsibilities, she perceives a disconnect between what she values and what PSU values. Poppy shared, "I think I would say to PSU, yeah, provide more opportunity for adjuncts, but also make it so that it is worthwhile financially." As an educator, Poppy seeks out opportunities to engage in PD and to develop within her practice. However, her professional growth as an adjunct at PSU does not encourage those interests. In addition to not being compensated for PD, Poppy described the financial challenge of earning less money from PSU as an adjunct, due to the 0.49 FTE limit. Although she is technically part-time at PSU, she is now working more per quarter, than she was as NTTF. She shared,

So really, if adjunct means part-time, then that would mean okay, 0.49 as the definition. But right now, if you're a full-time faculty member, that's, you have to 
teach 12 credits. I currently have 16 credits. So I am, as I said, teaching way more. I'm doing way more work than I ever did before when I was full-time. And so the idea of it being this part-time job, is so not accurate for me. Now, maybe it is for some people who just really do teach part-time. And they teach one class and that's enough. But for me, it's like okay, I can be part-time here and meet that threshold and then I also though, I'm only making like 1,000 bucks a month, so then it's like, well, that's not gonna cut it. So I have to reach out elsewhere. So then actually, I'm beyond the full-time credit level. But still making less money.

As adjunct faculty at PSU, Poppy described how she is now working more across multiple institutions, yet she is still making less money than she did as FTNTTF. She describes that reality as frustrating because she is making less money, yet working more. And based on the increase to her course load, across multiple campuses, she has less available time with which to engage in PD and/or other professional advancement opportunities.

This leads to the second challenge that Poppy described: the limitation of time. She teaches at PSU, PCC, and at MHCC and she also works as a writing consultant at the University of Portland. Her time is spread across multiple campuses, which makes engagement in PD within or outside of her department a challenge. Moe described adjunct work at multiple institutions as another "spreading" of himself, which seems to resonate with Poppy's assessment of her current professional experience. As FTNTTF, she was not focused on money as the driver for engagement. Instead, Poppy's professional growth occurred at PSU and every activity was an extension of her FTNTTF role. Now, as an adjunct, she identified time as a commodity of which she has a limited supply. Poppy shared, "I can barely make a living wage. And so I don't have time. But why would I just give you my time?" Her available time is filled deliberately in order to make a living wage, yet she still expressed a desire and commitment to her own 
development as an instructor. Poppy shared experiences that she would like to participate in, if time permitted. Those experiences include meaningful engagement with PSU staff and faculty outside of her department, and "more opportunities for people to come together in a casual environment and get to know each other." Collegial interactions were identified as an element from which Poppy feels respect and support. She derives meaning from professional relationships which provide external motivation for her professional growth as an instructor. However, Poppy's limited supply of time hinders her ability to engage outside of the classroom in ways that are the most impactful for her, including engagement with colleagues. She described herself as being more busy as an adjunct, than she was as FTNTTF, which limits her ability to participate with the institution outside of her contracted duties.

When asked if she feels respected as an adjunct at PSU, Poppy shared that she does feel respected by her department (Department A). In addition, she perceives external respect from people outside of the PSU community, based on her work as faculty in higher education. The adjunct status is not something that she thinks folks outside of higher education would fully understand. And instead, there is a "small bit of prestige attached to being faculty...and so I do get satisfaction out of that." Outside of PSU and the field of higher education, the hierarchy of faculty roles is not as transparent. As such, Poppy feels a sense of belonging and pride within the term "faculty." That said, she described her ongoing professional growth experiences within higher education as shaped by feelings of respect, or a lack thereof, communicated through collegial relationships and her access to financial and time resources. Poppy's collegial relationships are a 
positive source of respect because she perceives that full-time instructors in Department A still see her as one of them. These relationships further her identity as FTNTTF in the department, even though her contractual assignment is now part-time. In contrast, Poppy's schedule as an adjunct at multiple campuses differs greatly from her FTNTTF responsibilities. As an adjunct, she has limited time with which to pursue PD or other outside-of-class professional growth experiences at PSU. She is also compensated at a lower rate, although she is now teaching more credit hours as an adjunct.

Respect: Department Context. Noel described the department culture in a similar way to Poppy. She shared, "we're pretty much a kind of knock on the door if you need anything culture." The department is the professional home to many instructors who have been with PSU for "quite a while," so there is a certain level of familiarity and connection. In addition to their work in the department, full-time faculty serve on university committees and are "out playing in the, in the rest of the university." As former FTNTTF in the department, Poppy served on university-wide committees (e.g., the Diversity Action Council) and volunteered in various ways (e.g., annual undergraduate scholarship reading). Those forms of engagement were customary for fulltime faculty in Poppy's unit. Her formative instructional experiences in the department were developed based on a culture of familiarity as well as engagement in the university at large. Professional growth within the department is predicated on a commitment to student learning and engagement in the practice of teaching. Poppy embodies and communicates both commitments, however, as an adjunct faculty member, she now has less available time with which to participate in service to the institution and PD for her 
professional practice. Within the department, she does not identify her limited time as an issue preventing future full-time employment (she attributes that to student enrollment). However, outside of the department, she does identify limited time as an issue (i.e., she cannot as easily participate in activities that could be added to her CV). At PCC, Poppy is paid for her participation in PD, which increases her likelihood of participating. Although Department A at PSU is a unit in which she feels collegial respect and support, she does not perceive that her time is valued because she is not compensated for anything outside of her classroom instruction. As a commodity, time is a limited resource for Poppy that she strategically allocates based on her personal values system, her professional goals, and practical decision-making (i.e., what is available, what works with her schedule, and what provides compensation).

\section{Career Stage Needs}

Poppy's career stage needs at PSU are not being met. Her position within Department $\mathrm{A}$ is unique from the other adjuncts interviewed for this study, based on her previous full-time role. Because her current career stage was imposed upon her, rather than pursued, department support and resources for adjunct faculty are less of a solution than they are a reminder of her former full-time role. Poppy desires a return to her fulltime teaching position, but her department is currently unable to satisfy that goal, so, as a result, she is left to navigate her adjunct role and the unintentional career stage in which she exists.

Poppy's hiring process for her adjunct role was more a forced transition than a deliberate choice. She did not pursue her adjunct role, but rather, was offered the 
opportunity when she lost her FTNTTF position due to decreases in student enrollment. That distinction remains relevant for Poppy as she navigates her adjunct work responsibilities across multiple institutions of higher education. This stage in her career is not one that she sought out, yet she continues to navigate it in order to pursue her goals. She identified two main goals of wanting to continue to develop as an effective studentcentered instructor in her field and also, to resume a full-time faculty role. Even so, Poppy also discussed how it is challenging to envision and maintain professional goals because everything is "term-to-term." She feels confined within the barrier of limited available time, which makes proactive career planning a low priority:

...it makes it really hard to create any kind of long-term future for yourself, or vision, or just like, where am I going to be next term? I have no idea, and that's in seven weeks. And so I don't currently, right now I feel like my goal is to still be an engaging instructor in the classroom. To still be the best I can be for my students, whoever they might be. And then just hold it together.

Despite the cyclical stress that occurs each quarter, Poppy continues to prioritize her students. Her intrinsic needs as an instructor are tied to her students' needs as learners. Therefore, effective professional support for Poppy within this adjunct stage of her career at PSU needs to include continued focus on how to provide quality instruction for her students, which could occur through PD and consistent collegial interactions.

At PSU, collaborative professional growth opportunities are of interest to Poppy. She is interested in engaging with colleagues from within her department, as well as from across campus, in order to broaden her professional network, develop social capital, and connect with the university, at large. Her FTNTTF role enabled ongoing professional integration at PSU, based on required committee work, attendance at faculty meetings, 
and consistent on-campus work hours. As an adjunct, Poppy has to intentionally make time for collegial interactions because they no longer exist in tandem with her instructional role. Even though it requires an extra effort, this element is important to Poppy, within her current career stage at PSU. She shared, "the more connected that I feel, the more excited I am to be here, and I can't help but think that makes me a better instructor." Poppy finds connection with her colleagues at PSU when she is able to work from her on-campus office, as well as through participation in faculty meetings, committees, and/or campus-wide symposia.

As an adjunct, non-instructional activities are optional for Poppy because they are not included in her contract. She does not pursue them with the expectation that they will lead to a promotion, but she is instead internally driven to connect with her colleagues. Even so, Poppy did express confusion as to why there is no clear pathway to promotion. She shared,

If you do participate in all of these, why is there no promotion for adjunct faculty? And there is none, I mean, so that would be another thing, is the more that you are participating, there should be room to move up like a step system of some kind. It would be nice.

In her current career stage, Poppy desires a pathway back to a full-time instructional role_-or, at the least, a role that will once again provide healthcare benefits. Since becoming an adjunct, Poppy has pursued two different staff roles at PSU, one that was full-time with benefits, and the other part-time with benefits (which she shared was a rare opportunity), but she was unsuccessful in acquiring either position. Not being able to connect with an administrative job on campus places her in a similar position to Bibi, 
albeit with very different responses to the dearth of opportunities at PSU. Poppy reflected on that growing frustration in the following way:

...the longer that I'm here, the more resentful I get, and those two interview experiences were really exhausting and sort of made me like, run out of steam a little bit. So I've seen a few more postings that I thought, "I could apply for that," but then I just kind of didn't, 'cus like, I don't have enough energy. And also I just, it takes so much out of you to go through that process.

Poppy feels resentment about losing her full-time job and being relegated to an adjunct role, while still pursuing job opportunities at PSU that, at minimum, provide healthcare benefits.

Poppy's career at PSU is in a place where her needs are less aligned with her adjunct position and more aligned with her goal to resume full-time employment. Meanwhile, she continues to prioritize quality instruction for her students and meaningful collegial interactions outside of the classroom, both priorities carried over from her FTNTTF days. As an adjunct at PSU, Poppy communicated to me a desire for a clear pathway to promotion and she is frustrated that there is not one. Like Bibi, outside of her department, she expresses similar frustration with the limited employment opportunities available to her campus-wide at PSU. Poppy's current career stage at PSU is one in which she finds it challenging to pursue and achieve her professional goals.

Career Stage Needs: Department Context. Noel described a department culture for full- and part-time faculty that is supportive and inclusive, in part because individuals have taught within the unit for many years (over 10 years for full-time faculty and between eight-10 for part-time). She shared, "everyone has been, you know, started as an adjunct and may or may not have gotten flipped up and may or may not gave gotten 
flipped back down." There seems to be an understanding of shared experience across the full- and part-time faculty roles within the unit. Even so, Noel highlighted how student enrollment impacts faculty employment, which can create organizational divisions between those who are employed full-time and those who are part-time. The divisions, while unintentional, occur based on opportunities that are available to full-time versus part-time faculty. For example, attendance at the spring faculty professional development day is required for FTNTTF, but optional for adjunct faculty. Adjunct faculty need to receive approval from the department Director in order to attend, due to limitations in the part-time employment contract for non-instructional activities (i.e., compensation for non-instructional work requires approval). Poppy described this professional development day as an enjoyable opportunity to learn from her colleagues both in and outside of her department. As FTNTTF in the unit, she worked for many years on the organizing committee for the event, which was "really rewarding." However, as an adjunct, she shared that she wasn't able to attend the event in 2019 because she was teaching elsewhere that day. In fact, Poppy described her adjunct work at multiple institutions as "a real barrier to participating" in her department at PSU.

The limitation of time and conflicting schedules is the consistent barrier for Poppy's professional needs in her adjunct career at PSU. Although she described her department as "tight knit," supportive, and collaborative, the divide between what she can and cannot accomplish as an adjunct is ever-present to Poppy. She desires a pathway for promotion within the unit, in order to move back into a full-time role. And, unfortunately, that pathway is not clearly available to her. 
PROFESSIONAL GROWTH

Poppy: Summary

Poppy's current role as an adjunct in Department A at PSU is a position that she did not desire, but that she felt the need to assume, based on the loss of her full-time appointment. This distinction is an important one because it questions thinking about professional growth as a traditional process with incremental advancement over time. For Poppy, the shift from FTNTTF to adjunct was out of sync with her goals, but she continues to respond and change her expectations to meet the new boundaries of her professional reality. Overall, our interviews confirm Poppy's identity as an educator who is dedicated to personal professional development, as well as the learning experiences of her students. Her dedication is regularly challenged in her part-time role, based on limited access to time and financial resources. However, her collegial relationships are sustaining and a point of connection to her work at PSU.

\section{Sara: Scholar, Advocate, Mentor}

The final sub-unit of analysis of this study is focused on the experiences of "Sara." With a PhD in her academic discipline, Sara is an adjunct at PSU with extensive published research and previous employment experiences in other institutions of higher education. The primary outlet for her non-instructional engagement at PSU is her work with PSUFA. The union facilitates her professional engagement in multiple forms - most notably, access to a professional community of support. Additional forms of outside engagement are focused on her students (e.g., faculty mentor for student research, out-ofclass supplemental learning opportunities). Her long-term goals can be most simply defined as an interest in a full-time faculty role however, she also expressed a desire for 
professional respect. The sections that follow explore her professional identity and motivators for engaging at PSU with an analysis of her professional growth experiences.

\section{Motivation and Professional Identity}

Sara described herself as a researcher, an educator, and a community organizer. She has experience in each space and sees the intersection of those identities as the basis for her teaching philosophy which is, "a pedagogy of action that links scholarship with activism." As an adjunct faculty member, Sara identified two motivators. The first is her students and the goal of supporting their learning and development while the second motivator is the need to earn an income, which she does through simultaneous employment at three institutions. Of the four adjunct faculty interviewed, Sara is the only one with a terminal degree in her discipline and extensive research experience. Those parts of her identity are in constant conflict with her adjunct role, which does not permit the time or financial resources in which to pursue a research agenda.

When asked why she continues to work at PSU as adjunct faculty, she shared, "I work here because I want to support students' learning. And there continue to be opportunities to support their research or engage with them in the classroom." Sara mentioned examples of ways that she supports student learning through serving as a faculty mentor with the undergraduate research program for first-generation, low income, and under-represented students and engaging students in optional experiences outside of the classroom. Sara's drive to teach is found in her students, and the affirmation of their appreciation and respect sustains that drive. She described intentionally developing syllabi and classrooms that "decolonize the space" and remove barriers to learning 
through a flexibility for accessibility. She is invested in her students' individual development in order to support them in "grow[ing] in ways that provides them with social and economic mobility" that they can then take "wherever they end up working or living." As a source of pride and value, Sara's motivation to support student learning is affirmed through positive outreach from students. For example, she described her motivation for working as an adjunct as being rooted in contributing to students' positive educational experiences. She stated,

I'm doing it for the students, so, as soon as I open up my email and read an email from a student that says, I really respect the work you're doing. You're inspiring. You made me think of something in a different way. Thank you for letting me, you know, share my ideas and I can see where we differ, but I respect yours...whenever I get that feedback, it just is like, means more than anything, you know. Really awesome. Really why I'm here.

Student descriptions of how Sara has impacted their world view and aided their academic development hold great meaning for her.

The second of Sara's motivators for working as adjunct faculty and engaging with the institution is the need for financial resources as pursued in her contracted adjunct role, as well as through involvement with PSUFA. Her union colleagues provide social and emotional support as they collectively advocate for improved working conditions, including pay parity. Sara's union involvement in PSUFA was also described as the source of her collegial interactions and social capital at PSU. In terms of her motivation for engaging with the union and in the efforts championed by the group, Sara discussed how adjunct faculty share the common goal of wanting to develop into better teachers, however, that goal is not attainable without financial compensation. She explained that: 
...we want to be better teachers and we know to do that we all have to have some basic standard of living to survive. And it's so bad right now that many of us just are barely surviving.

Engagement with the union is pursued with the goal of impacting the working conditions of adjunct faculty at PSU who, without a living wage, cannot spend the time or mental labor to develop as instructors.

Sara's motivation to support student learning while also earning enough money to provide for her family should not be goals in conflict. These are reasonable goals of many educators that function as a mirror image: a dedication to students paired with the physiological need to earn enough money to sustain a modest, comfortable life. However, quite often for Sara, engagement with her students is not always linked with financial compensation, as this work could be construed as pro-bono. For example, her mentorship work with an undergraduate research program for first-generation, low income, and under-represented students earns about $\$ 300$ for an entire summer, yet she reports dedicating roughly 80 hours, which works out to less than $\$ 4.00$ per hour. In addition, out-of-class engagement with students who take her courses is considered an "optional out-of-class learning experience" and therefore, unpaid time. While out-of-class experiences could still be grouped within her role as an instructor, they are appropriately described as uncompensated hours because her teaching contract does not require them. Sara's time is fully occupied with adjunct responsibilities across three campuses, out-ofclass engagement with students at all three schools, and with her full engagement in PSUFA. Any additions to that workload are either in support of student learning or in pursuit of additional income. Sara continues to engage with opportunities to support 
student learning, if she finds them meaningful, even if the experience is not attached to adequate compensation. This reality is frustrating for Sara as the pursuit of a living wage competes with her continued dedication to the students she cares so deeply about. All of the time she spends with students does not result in additional income, yet she continues to commit herself to that work.

\section{Motivation and Professional Identity: Department Context. Department} coordinator, "Doug," described two groups of adjunct faculty in the department: 1) those who are full-time adjuncts across multiple campuses and who are interested in a full-time teaching role, and 2) those who are full-time professionals who teach one class each term because they love to teach. A difference between the two groups is that the "career" adjuncts are dedicated to the undergraduate program and the full-time practitioners typically teach the upper division undergraduate or graduate courses. This group wants to give back to the profession and, "make sure that the next generation have their knowledge." Doug connects the full-time adjunct group with the "national narrative around adjuncting," which includes working at multiple institutions in order to "create enough salary to survive." By his definition, Sara's experience aligns with that group. Doug described a precarious situation in their department in which the adjunct faculty are revered for their subject-matter expertise and "teaching prowess," however, if budgets have to be cut significantly, the majority of the adjunct faculty employed would be let go. They are described as valuable, yet disposable, based on department needs. Sara's motivation to engage with the learning experiences of her students, while also trying to maintain a living wage, echoes the anxiety inherent in the role of adjuncts in the 
department. Because she is interested in a full-time instructional role, the precarious situation within the department greatly impacts her satisfaction; she connects her adjunct experiences with the "disposable" definition that does not engender feelings of respect from her academic unit, as explained in our next section.

\section{Respect}

The essential element of respect, specifically the lack of, defines all of Sara's experiences as an adjunct. Specifically, Sara does not feel respected as an adjunct in her department at PSU. She defines the role of an adjunct as being "undervalued, invisible, and isolated." For Sara, these adjectives connote the lack of connection and professional respect she experiences as an adjunct. These experiences include limited access to financial resources, no provided healthcare benefits, and a department culture that defines her adjunct position as "temporary." Her experience as a temporary adjunct has been consistent at each of the institutions where she has been employed and as a result, Sara navigates and survives her adjunct role by setting boundaries with her employers. She shared, "the onus is on us to be really clear about our boundaries about how poorly we will be treated and I've learned how to set those boundaries." Sara's work with the adjunct union at PSU is one space in which she can advocate for professional boundaries for herself and her colleagues.

Sara described her work with PSUFA as the professional community at PSU in which she feels supported and respected. When she is teaching an online class, she does not choose to work from the adjunct offices in her department, but she does still come to campus at least once per week for union meetings and other organizational purposes. 
Other than Sara's students, PSUFA is the professional community at PSU to which she communicates the highest levels of engagement and accountability. They share common goals as a group and organize around improving adjunct faculty working conditions in order to also impact students' learning conditions. She reflected,

The union has provided me with everything I've needed that my department, my chair, my colleagues, have not even been aware to give me. I've had health emergencies, the PSU faculty fund helped me, you know, literally not lose the roof over my head. Um they've provided me with emotional support. They've provided me with resources, like I had my computer die and you know, was able to get a shitty used computer to work on to keep teaching.

PSUFA fills the gaps for Sara's unmet safety (i.e., financial resources, housing, etc.) and belongingness (i.e., emotional support) needs (Maslow, 1970). They facilitate an ongoing meaningful exchange that positively contributes to her work as an educator as well as her retention at PSU.

Sara's work in her department at PSU is absent of the elements that PSUFA provides for her. She does not feel respected for her educational background nor for her years of research and teaching experience. Whereas PSUFA is a space in which Sara shares common goals and lived experiences with her colleagues, interestingly, she does not reference similar feelings of belonging in her academic unit. She shared,

I don't feel valued because I'm not recognized for the work that I do in a way that helps me do better. And I don't feel valued because every time I've reached out to ask for a potential opportunity, not only has that opportunity not been given to me, but I feel like I've been stabbed in the back.

Based on this example, Sara identified two missed avenues for engagement: recognition for efforts in the department, as well as support with internal job aspirations. Sara described recognition as being multifaceted and encompassing more than the receipt of a 
teaching award. She explained that recognition includes integration into a professional community that collectively invests in professional growth. Genuine recognition commits to organizational processes that incorporate her adjunct role in decision-making spaces (e.g., in department meetings, on committees, etc.). However, Sara described how adjuncts at PSU are currently "invisible everywhere," so they are not recognized for contributing to the learning experiences of students nor to the daily mission of the institution.

Sara's access to resources, namely financial resources, is another barrier to feeling respected and having agency within her professional growth journey at PSU. She discussed a direct connection between the compensation paid, per credit, for her courses versus the amount of work that she is able to invest in a course. An integral component to her courses is the inclusion of external resources and community members, in order to enhance the learning process for students. Sara provided an example of how she was asked to teach a course online that was initially designed as an in-person course. In order to do so and still align with the same learning objectives, the course would need to be redesigned. Initially, additional pay was not offered for the redesign, but she set a clear boundary and advocated for a $\$ 500$ stipend. Inadequate pay, to be sure, as PSU empowers its OAI to partner with full-time tenure-track faculty to design or redesign courses through the Flexible Degree Program and, if a grant is available, may pay the instructor a stipend for around $\$ 4,000$ per quarter, plus the assistance of an in-house instructional designer. This instance was an experience that highlighted the inadequate 
financial compensation available for the instruction that Sara wanted to provide for her students. She shared,

I can't bridge those social capital networks, using online resources and a couple months prep for $\$ 4,000$ a quarter with no health insurance, and no retirement benefits. I'm this close to just saying, I can't survive in this industry anymore. I can't be an educator. It's horrible.

In her work with PSUFA, they invested time into calculating the disparity in pay between adjunct faculty and FTNTTF teaching the same course (i.e., about $\$ 200$ per credit). Cumulatively, the difference adds up and Sara believes that it likely has an effect on her future research opportunities. At PSU, she is earning an income each quarter that necessitates instruction across multiple institutions in order to provide for her family, which doesn't allow adequate time for outside engagement (i.e., committee work, research, etc.) that could be added to her CV. Poppy shared a similar reflection about how limited available time for outside engagement hindered development of her CV. Sara directly linked the limitation of time to compensation, and until her compensation matches the quality of her work — or at least reaches pay parity with FTNTTF—Sara will continue to feel "undervalued, invisible, and isolated."

Respect: Department Context. Although Sara does not derive feelings of respect and connection with her academic unit at PSU, she did provide examples of how she engages with other adjunct faculty in the department. Her collegial relationships in the department are ones that she initiated and that have commonly focused on course development. When she was initially hired, she met with a former faculty member who originated the design for a course that she would be teaching. And in prior terms, Sara would bring a small group of adjuncts together who were also teaching undergraduate 
courses in the department. These conversations focused on course design, continuity, and students. Although development of social capital, along with economic resources, was identified as a priority for Sara, it did not surface as an intended outcome of these interactions with adjuncts in her unit. Whether that changed over time was not discussed.

Within the physical department space, Sara discussed how the adjunct offices can organically facilitate interaction with a few other adjuncts throughout the term. In addition, Sara referenced the designated adjunct office space as a benefit to her role when she is teaching an in-person class, and as the "only little bit of prestige" associated with her employment at PSU. The office space facilitates interactions with adjunct faculty, access to resources, and a designated space that is her own on-campus. She shared,

It's a great space. It's got a big beautiful window and, you know, it's got really great computers that work well and I can print for free and I can scan to PDF. It's got just what I need! And I can go there and not be interrupted, but, I mean, in some ways it's sort of the prestige...I have an office with a window in downtown Portland.

The adjunct office space provides Sara with a dedicated office in downtown Portland. However, the existence of this space does not eclipse Sara's feelings of invisibility and disrespect in the department. For example, when she does not have a reason to be physically in the department (e.g., during quarters when she is teaching online) Sara instead chooses to spend time in the PSUFA office alongside colleagues with whom she shares a close connection.

Sara's experience of existing on the periphery of the department is interesting in contrast with how Doug, the department coordinator, described a portion of their adjunct faculty. He offered another way to understand the adjuncts employed in their department. 
Adjunct faculty in the department are either: 1) graduates of the program and/or the spouse of a full-time faculty member in the department, 2) full-time professionals, or 3) adjuncts who have been with the department for a long period of time (e.g., more than 40 years). Of the three definitions, the first group of adjuncts is described as being the most present and a "part of the department." Doug shared that the second group does not contribute to the culture of the department directly, based on their limited time oncampus. Finally, he described the third group as not contributing to the culture, but existing as a part of the "[imagination] of the department." Sara does not fall into any of Doug's identified categories. She is an adjunct who has been with the department for a few years, who was not a former student, and who is not the partner of a full-time faculty member. Sara communicates feeling "invisible" in the department, which resonates with her omission from the main adjunct groups identified by her department coordinator.

\section{Career Stage Needs}

As an adjunct, Sara described herself as being invisible and as existing on the periphery of her department at PSU. She desires a full-time faculty position, however, because she is unseen in her current role, she does not perceive a pathway to full-time employment at PSU. This perception has been affirmed through unsuccessful internal job applications, the professional evaluation, and her term-to-term employment. Sara is wellinto her career as a researcher, an educator, and a community organizer. She is not a novice in any part of her career, but rather, she has extensive experience that she draws upon in her adjunct position at PSU. Even so, her career stage at PSU is more precarious. She described herself as a temporary employee whose status and teaching assignments 
change and are unpredictable from term-to-term. As a result, Sara is gaining experience as an adjunct who is able to navigate a temporary position, but she does not describe herself as being on a pathway to a full-time role. Similar to Poppy, Sara's career stage at PSU is not in alignment with her professional goals. Her adjunct work facilitates the opportunity to positively support student learning, but it has not yet delineated a career pathway to a full-time faculty position.

Sara was initially offered a part-time position in her department because a fulltime tenure-track faculty member was on leave. That entry into the department was a precursor for her future opportunities. She now describes herself as being on the "leave lottery," as she is asked to teach classes each quarter to fill-in for other faculty. Although her two-year contract projects being able to offer her a specific number of courses each quarter, it does not specify the course numbers. And when her contract previously included specific course assignments, those assignments changed. As a result, she has no expectations about her employment within her department. Support offered has lacked follow-through in meaningful ways that would impact Sara's experience. At this point in her career at PSU, Sara is interested in recognition that acknowledges her experience. One example, or opportunity, that she referenced is a professional evaluation during which constructive feedback is offered. When she was previously offered a professional evaluation in the department, she was excited about the opportunity in order to receive constructive feedback. This experience followed an unsuccessful application process for a FTNTTF appointment in the department, so the evaluation offered the opportunity to 
receive feedback for continued PD. However, constructive feedback was not offered and

instead, she concluded the evaluation feeling less valued and more invisible. She shared,

My evaluation was basically, well, your scores are above average. Looks like you're doing everything okay. I spent a little bit of time asking questions about the hiring process and what other jobs would be available to me in the future and that interview or that meeting, the evaluation meeting, ended with my chair saying, well congratulations. You're promoted. And I said, what do you mean I'm promoted? And he said well, you're a senior instructor now! And I said, so, doesn't that mean it's just a title change? And he basically confirmed that.

Sara was optimistic about the opportunity to receive feedback in order to continue to develop within the department. However, that optimism was not met with the desired outcome and, instead, her questions remained unanswered about how to progress professionally in the department.

Sara's professional evaluation is one example of how she lacks mentoring or support within her department at PSU. She desires professional recognition that elevates her experience and voice and she communicated that this could occur through organizational hiring practices and promotional opportunities that prioritize the quality of someone's teaching, rather than just rewarding seniority or titles. She shared,

If we're trying to build some kind of mobility, you know, within our educator pool, it feels like what should be rewarded isn't just seniority, or the fact that someone got hired with this label or that you know, like non-tenure-track faculty or senior instructor. To me what I think matters is like what we're teaching and how we're teaching it, the quality of that teaching.

Here she describes a system of values that prioritize "the student experience," and as such, Sara places great emphasis on her instruction and her interactions with students. Given the congruence between her values and the department culture you would think that these elements would nourish a space in which Sara could likely thrive. However, 
she described her adjunct experience as a temporary position and one that is not evaluated with rigor or high professional standards. Again, Sara described the professional evaluation as a missed opportunity for meaningful engagement. She expressed the desire for something more than a logistical contract milestone: "I should get something out of it besides, I'll keep you around for two years." As it functions, Sara described the professional evaluation as a logistical hurdle, rather than a professional growth experience that contributed to her current career stage.

For Sara, her career at PSU is in conflict with her overall career aspirations because her employment continues to be temporary from term-to-term. She feels unseen as a contributing professional in the department and a pathway to full-time employment is not evident. An opportunity to recognize her experience and contributions would be through meaningful, constructive feedback. However, the avenues available to provide such feedback (i.e., the professional evaluation) have not been available or existent. As a result of these incongruent goals, Sara does not feel valued for her professional experience, which greatly limits her ability to envision future opportunities and/or a longterm career at PSU.

Career Stage Needs: Department Context. Although Sara communicated frustration with her department and the lack of transparency around professional pathways for promotion, her department does not share an awareness of the impact of that experience. Doug discussed how the department follows the guidelines in the CBA for the professional evaluation. He identified that the evaluation is the promotional opportunity available to adjuncts in the department, and at PSU in general, but based on 
Sara's experience, this reality is a limitation to her desired career pathway at PSU. The idea of "promotion" for Sara does not equate to changing her title (e.g., from instructor to senior instructor) or extending her part-time position with a two-year contract that lacks certainty of employment. She desires promotional experiences that lead to full-time employment, or at the least, guaranteed part-time work. That desire is out of sync with her department's intention for their adjunct workforce. In the department, Doug described how adjunct faculty are hired to, "add teaching capacity, but only when we can afford it." He shared that adjunct faculty are hired at will and even the senior adjuncts can be let go if the department is in financial duress. As such, they are employed as temporary additions, rather than as faculty with whom they intend to invest. This reality places Sara's career goals at odds with the situation available to her. Even so, the opportunity remains for the professional evaluation to become an experience during which adjunct faculty receive constructive feedback. While the feedback would not result in future opportunities, it could communicate career value and career investment in Sara (and other adjuncts) as professionals. Although Sara and the department are not in alignment with her intentions and goals, the opportunity remains for change to current practices.

\section{Sara: Summary}

Sara's interviews, as well as others, suggest that for adjunct faculty at PSU, professional growth experiences are heavily influenced by collegial relationships and feelings of respect. Further, when either element is lacking within an academic department, the adjunct faculty member might seek one or both in an outside environment. For Sara, PSUFA is the source of her professional connection to PSU. Her 
community within the union provides just that - community. As a community organizer, a scholar, and an educator who, in her own words, seeks to decolonize learning spaces for her students, Sara's professional identity values the collective support generated within the union. Her professional growth journey exists often in conflict with her adjunct work at PSU, but her engagement with the union and with her students is not deterred.

\section{Chapter Summary}

The purpose of this exploratory case study was to better understand the professional growth experiences of four adjunct faculty at a large, urban, commuter fouryear public university. The two guiding research questions asked: 1) What motivators influence adjunct faculty engagement at PSU? And 2) How does institutional engagement shape an adjunct faculty member's professional growth at PSU? The findings from this chapter indicate that adjunct faculty motivation for institutional engagement is rooted in individual professional identities, which are informed by academic and professional histories, as well as long-term goals. Additionally, professional growth experiences differ for all adjunct faculty, but common themes that connect them are the elements of respect and career stage needs. Faculty commonly perceive respect, or a lack thereof, based on access to information and resources (i.e., time and compensation) and collegial interactions. Adjunct faculty career stages vary and their accompanying needs shape feelings of agency and satisfaction, depending on how the university and the department make space for them. These findings suggest that adjunct faculty benefit from communities of practice; and further, that engagement with colleagues with whom adjunct faculty share a common experience has the opportunity to positively impact their 
work as instructors. Chapter V discusses the key themes from the findings, in response to the guiding research questions. Implications for future practice and recommendations for additional research are provided. 


\section{CHAPTER V DISCUSSION}

This study explores adjunct faculty experiences with professional growth, and how those experiences were shaped by institutional engagement in its many forms. Findings suggest that professional identity served as a driver for adjunct faculty participants' decisions regarding institutional engagement, and their satisfaction with the opportunities available. Through the lens of Thirolf's (2017) Inclusive Faculty Engagement Model and the essential element of professional growth from Gappa et al.'s (2007) Framework for Rethinking Faculty Work, two central research questions guided this study:

1. What motivators influence adjunct faculty engagement at Portland State University?

2. How does institutional engagement shape an adjunct faculty member's professional growth at Portland State University?

This qualitative, embedded single case study interviewed four adjunct faculty from four different academic units at PSU, a large, urban, commuter four-year public university. From each of their academic units, a total of six department coordinators were interviewed, with a minimum of one department coordinator representing each unit. Department coordinators were identified by adjunct faculty as providing professional support and/or oversight for part-time faculty in their individual department. Finally, documents detailing elements of adjunct faculty professional growth experiences were analyzed from each of the adjunct faculty, their academic units, as well as from the university-at-large. Documents included employment contracts, handbooks, and teaching 
philosophies. This study investigated the relationship between adjunct faculty members' professional motivation and their institutional engagement. It considered how that relationship manifests in professional growth experiences for the four adjunct participants.

The findings of this study include two descriptive themes of the adjunct faculty participants' employment experiences: 1) professional identity drives motivation, and 2) professional growth experiences differ, based on the elements of respect and career stage needs. This chapter fully explains both themes, in response to the research questions. It discusses and analyzes the emergent findings for each theme, in connection with the research literature on faculty professional growth. Additionally, implications and recommendations for future research and practice are provided.

\section{Motivation that Influences Adjunct Faculty Engagement}

Professional identity emerged as a driving motivator for institutional engagement amongst the four adjunct faculty participants in this study. My participants shared components of professional identity that include prior academic and work experiences, current outside employment, and future professional goals. Both extrinsic and intrinsic motivators emerged from descriptions of adjunct faculty members' professional identities, including what Maslow (1970) would describe as intersections of personal and professional self-conceptions of their needs. Identified needs include increased compensation; additional time with which to engage with students, colleagues, and career planning; and finally, respect or esteem from colleagues. All three needs influenced adjunct faculty members' willingness and ability to engage with their academic unit, 
outside of defined classroom duties. Engagement was described by adjunct faculty as participation in out-of-class experiences with other colleagues at PSU (e.g., faculty meetings, professional development (PD), collegial interactions within the department), as well as meaningful engagement with students both in and out of the classroom. These two types of engagement, collegial-based and student-based, were salient examples of motivation for institutional engagement and the ways in which these participant adjunct faculty chose to engage. Thirolf (2017) defines faculty engagement as "activity-based" (p.305) and comprised of "the actions and behaviors that faculty and institutions take to facilitate and support faculty professional growth" (p.305). These definitions tell us that faculty engagement is a shared experience between the faculty member and the institution, based on an assumption of goal alignment focused on professional growth. The experiences of Moe, Bibi, Poppy, and Sara do not fully negate this definition, but they do highlight misalignment between their professional growth needs and institutional priorities. Specifically, the desire for a pathway to full-time employment was communicated by Moe, Poppy, and Sara, however, they did not perceive the existence of such a pathway, based on their PSU experiences within their respective departments. Although Bibi's career stage differed, he did previously express interest in full-time employment, yet that goal was adjusted based on multiple negative hiring experiences. While not every participant sought full-time employment as an instructor at PSU, each was unsuccessful in gaining employment beyond their adjunct work. Each of the adjuncts interviewed expressed different motivators, both intrinsic and extrinsic, for their chosen 
forms of engagement, yet they all identified misalignment between their intended goals and the institution.

\section{Intrinsic Motivation: Professional Values and Pathways to Promotion}

Intrinsic motivation emerged in two main ways for adjunct faculty in this study.

The first was that professional values guided decision-making as they discerned

opportunities for engagement at PSU. The participants described their values as a desire to contribute to their field of study and, in doing so, to impact the learning experiences of their students. Nakamura and Csikszentmihalyi (2005) describe these values as being associated with a "calling" or a "vocation," rather than solely with a job. In their analysis of faculty engagement in the profession of undergraduate teaching, they identify four “enjoyable challenges” (Nakamura \& Csikszentmihalyi, 2005, p.62) that drive faculty engagement. They are 1) educating students, 2) preserving and advancing knowledge, 3) serving the needs of the institution, and 4) serving the needs of the broader society. These challenges resonate with the experiences of adjunct faculty in this study. Specifically, the desire to educate students while advancing knowledge in their fields.

Bibi described his previous professional experiences as a practitioner in the field as framing his motivation for what and how he now teaches. He shared, "I'm just trying to share knowledge and experience that I've had, so it gives the students something else to compare it to." For Bibi, the act of sharing prior knowledge is also a way of shaping and advancing knowledge within the profession. He describes himself as seeking to fill the gaps in what students do/do not know, based on what academia deems is a high priority. 18 years of experience as a practitioner informs his instructional priorities. 
Outside of the classroom, his priorities lead him to engage with the department through optional volunteer-led workshops for students. Sara and Poppy describe a similar commitment to supporting student learning, with a desire to develop community within their respective classrooms. Both participants link community development as an imperative for student learning. Sara describes her role with students as a partnership, rather than viewing her position as one of solely "a gatekeeper and a point counter." As a growth process, students' development of knowledge aligns with her pedagogy that seeks to "decolonize the space in ways that remove impediments that aren't the person, the student's choice." Her commitment to students drives her pedagogy and her engagement as an instructor. She shared,

I think my role as an educator is to help students develop knowledge and grow in ways that provides them with social and economic mobility. So it kind of depends on where you start, what resources you're given. But I really try to help that knowledge build the city from people taking the knowledge they learned through the community at PSU and take it wherever they end up working or living.

Similarly, in her teaching philosophy, Poppy describes her dedication to "creating community inside and outside of [the classroom]" because her class is where "the world comes together and where bridges can be built." She perceives that student learning in her classes can improve both the student's life, as well as the community at large. Poppy endeavors to "empower learners" and to create a welcoming environment that is inclusive to all. Both Poppy and Sara communicated examples of how their internal commitment to students shaped their engagement as adjunct faculty. Examples include meeting with groups of students out-of-class for supplemental learning experiences, staying late after class to support students, and serving in mentoring roles. 
Internal motivation to support student learning was shaped by prior experiences for most adjunct participants in this study. As former PSU graduate students, Poppy and Moe discuss a commitment to student learning that is framed by their individual academic journeys at the university. Bibi's commitment to students derives from his previous career and his practiced subject matter expertise regarding what it takes to thrive in his field. Prior experiences, whether professional or academic, framed the participants' values and their motivation to positively contribute to student learning at PSU.

The second way that intrinsic motivation emerged in this study, as a contributing factor to faculty engagement, was in regard to future goals. Each adjunct's individual professional goals impacted the choices they made in their roles at PSU. Specifically, opportunities for institutional engagement, outside of their contracted duties, were often considered based on alignment with individual future goals. Each adjunct faculty member in this study determined opportunities that best aligned with their values and professional goals. Common themes across experiences were referenced, including PD and student mentoring. There is some alignment across individual goals for each faculty member (e.g., an interest in full-time teaching work), however, individual pathways in pursuit of those goals are largely dependent on each adjunct's academic department and their individual preferences.

In terms of future professional goals, the adjunct faculty in this study can be understood in two ways: 1) those who aspire to a full-time instructional role, and 2) those who do not. Both groups have minor overlap with the other-for example, Bibi doesn't aspire to a full-time faculty role, but he is interested in teaching more than the $0.49 \mathrm{FTE}$ 
course load permitted for adjuncts. On the opposite side, both Moe and Poppy are open to and have applied for non-instructional positions, but they continue to more actively pursue and/or prepare for full-time instructional work. Interestingly, although professional goals differ, adjunct faculty reference similar examples of ways that they choose to engage with PSU. Professional development through OAI, course coordinator meetings within their department, union work with the Portland State University Faculty Association (PSUFA), student mentoring, and department engagement are a few examples of common engagement experiences. This overlap is interesting and significant because all non-instructional activities for adjunct faculty are optional. As such, any choice to engage is just that - a choice. It is up to each individual to discern what opportunities align with their goals and what they can prioritize, within their daily schedule.

The development of social capital at the university is a valued element of engagement for adjunct faculty, whether they are interested in a full-time instructional role or not. Frequently, participation in non-instructional activities is pursued if there is an opportunity for connection with other colleagues at PSU. Adjunct participants in this study referenced a desire to find and develop community if it is not provided in their department. They seek out experiences that facilitate connection with other faculty, both full- and part-time at PSU. In addition, intentional networking is referenced as a way to develop social capital and to learn about new opportunities, namely employment opportunities, at the university. For example, engagement with PSUFA is a grounding experience for Moe and Sara at PSU. They describe it as an empowering experience that 
facilitates community and that advocates for their working conditions. An undeniable sense of belonging is communicated. Sara shared that, "the union has provided me with everything I've needed that my department, my chair, my colleagues, have not even been aware to give me." She references examples of support from PSUFA in the form of emotional, financial, and professional resources. There is a clear contrast in the level of understanding offered by the union and from her department. Sara describes collegial relationships in the union built on shared lived-experience and an empathy of understanding, based on those experiences. Whereas she feels out-of-place within her academic unit, PSUFA is her place at PSU.

Another example of the impact of developed social capital is from Bibi, who initially participated in cross-campus networking events during his first few years as an adjunct at PSU. During that period of time, he was interested in pursuing a full-time staff role on-campus, so opportunities for engagement with other faculty and staff were of high priority. For example, his friendship with a former PSU president was a strategic acquisition of social capital, although it proved to be fruitless in his pursuit of nonadjunct work at the university. Although professional relationships were fostered, his job aspirations (i.e., for a full- or part-time staff role) were not realized. As a result, Bibi's chosen experiences for engagement were adjusted. Whereas participation in PSUFA strengthened Moe and Sara's sense of belonging through the development of social capital with other adjuncts, Bibi's attendance at cross-campus social opportunities did not achieve his desired end, so he stopped attending. 


\section{Extrinsic Motivation: Compensation}

Intrinsic motivation emerged in this study as a guiding force for decision making involving engagement opportunities. Professional values and future goals shaped adjunct faculty choices regarding institutional engagement and the development of social capital was a desired residual of participation for most adjuncts in this study. That said, intrinsic motivation was only one contributing factor to adjunct faculty engagement. As an extrinsic motivator, compensation played a unique role for each participant and their decisions to/not to engage with the institution. This element of the adjunct experience was discussed in different ways for each faculty member, but two examples resonated across the group. The first was that compensation is inherently tied to work, as an incentive and an expectation. In this sense, "work" could be defined as any form of engagement or interaction with PSU, in structured and/or planned settings. For example, weekly class sessions, course coordinator meetings, office hours, department meetings, professional development workshops, and committee meetings were referenced as common work experiences for the adjuncts in this study. In this way, the adjunct role is analyzed strictly by its functional parts and the relationship between PSU and each faculty member is transactional. Even so, this shared definition leads to the second way that compensation was discussed, which is from a deficit perspective. Specifically, that there is an absence of compensation offered for adjunct participation in uncontracted, non-instructional activities at PSU.

As an expected reward or outcome of work, compensation for participation in institution sponsored activities is discussed by adjunct faculty as a byproduct of their 
value, or lack thereof, to the institution. Adjunct faculty describe feelings of value as synonymous with respect, which Gappa et al. (2007) define as “...a fundamental entitlement for every faculty member[...] at the core of any reciprocal relationship between faculty members and their institutions" (Gappa et al., 2007, p.139). This definition prioritizes a relationship that is a dynamic see-saw of giving and taking between the participants, their departments, and PSU. However, this definition does not fully account for the power dynamic between adjunct faculty and their employing institution. A reciprocal relationship assumes equitable or comparable experiences, yet this dynamic does not exist within the adjuncts of this study and PSU. Adjunct faculty fulfill many needs for PSU, including providing subject matter expertise and satisfying hiring gaps, based on fluctuations in full-time appointments and sabbatical leave. PSU provides adjunct faculty with part-time employment and compensation for that employment, yet additional benefits, arguably justified and well-earned, vary for each participant. For example, having access to an office with a window in downtown Portland, as referenced by Sara, or identifying with the prestige of teaching at a university, as desired by Poppy. As a result, the relationship with PSU, according to this group of part-time instructors, was not reciprocal. The institution wields complete control over faculty working conditions, which compensates adjuncts for total credits taught each quarter. Whereas a full-time faculty role is accompanied by a combination of teaching, service, and research (depending on tenure or NTTF status), adjunct instructors are expected to teach and are contracted solely for that responsibility. 
As a former full-time faculty member, Poppy's perspective about compensation is an interesting one. She shared that she never previously questioned her compensation as FTNTTF, including for time directed to volunteer work, professional development, or service to the institution. However, as an adjunct at PSU, that consideration is now a priority and at the forefront of her decision-making. When considering her motivation to engage or not to engage in out-of-class opportunities she shared, "I can barely make a living wage. And so I don't have time. But why would I just give you my time?" Poppy is open to participation in professional development and committee work, but her part-time status necessitates a more transactional approach to those experiences. She reflected, "so I think I would say to PSU, yeah, provide more opportunity for adjuncts, but also make it so that it is worthwhile financially."

Similar to Poppy, both Moe and Sara teach part-time at multiple institutions in order to make more money. Moe describes this experience as a "spreading" of himself, most likely "thin" if the thought were carried to its fullest expression and consistent with the tone he possessed during our discussion. They each reference a term-to-term uncertainty within the employment cycle, although the experience was slightly different for each. Organizational culture and commitment to one's workplace is directly tied to a sense of belonging and purpose, which enables the capacity for engagement. However, the findings of this study highlight the challenges of part-time employment on employee engagement. In the case of adjunct faculty who teach at more than one organization, as they are "spread" across multiple roles, time is a commodity and the limitation of that resource frames most other decisions that they encounter. If an experience is not 
compensated, for example - attendance at faculty meetings, service on a department committee, or participation in professional development, there is no other external motivator encouraging engagement. As this study found, there is an absence of compensation for participation in out-of-class activities and as a result, engagement by the adjunct participants was inconsistent.

\section{Summary}

In this study, engagement is discussed as an action and/or an active process that connotes participation in specific experiences. It is shaped by internal and external forces that impact adjunct faculty willingness to participate in activities that are not required in their employment contract. Faculty interviewed referenced professional values and future goals as two common intrinsic motivators and a main extrinsic motivator was compensation for work in its many forms, such as service and professional development. The original guiding research question asked, "what motivators influence adjunct faculty engagement at PSU?" The participants' answer to that question encompasses both internal and external motivators and their impact on individual faculty circumstances. When adjunct faculty choose to engage in extra-curricular activities at PSU, they do so with an understanding of what they will be paid for that time (if at all). Their participation is guided by a strategic pursuit of professional goals, as well as practical consideration of how that engagement will benefit them. Personal benefits are not exclusive to compensation, because they do encompass faculty values, but also include their commitment to students and their commitment to advancing knowledge in their academic field. Professional values, long-term goals, and compensation represent 
elemental functions that motivated this group of four adjunct faculty and their decisions regarding how they choose to engage with PSU.

\section{Institutional Engagement and Adjunct Faculty Professional Growth}

The second question in this study focused on the relationship between institutional engagement and faculty professional growth. While the first research question highlighted reasons why adjunct faculty choose to engage with PSU, the second question shifts our focus to an analysis of the reciprocal benefits of engagement or the repercussions of disengagement. To review, engagement was described by adjunct faculty as participation in out-of-class experiences with other colleagues at PSU (e.g., faculty meetings, professional development, collegial interactions within the department), as well as meaningful engagement with students both in and out of the classroom.

Through collegial- and student-based experiences, adjunct faculty choose to engage with PSU in myriad ways. The impact of that engagement on their professional growth is just as varied, depending on their individual context.

Based on what I learned from the participants of this study, a reframing of adjunct faculty professional growth is required. Whereas Gappa et al. (2007) accounted for professional growth as an essential element impacted by institutional characteristics and programming, O'Meara et al. (2008) prioritize professional growth as a personal change process. As the employment experiences of these adjunct faculty encounter persistent change, the definition of professional growth asserted by O'Meara et al. (2008) seems to describe the process in a more accurate way. They define professional growth as a, "...change that occurs in a person through the course of her or his academic career or 
personal life and that allows her or him to bring new and diverse knowledge, skills, values, and professional orientations to her or his work" (p.25). This definition leads with the idea of a change process situated across both personal and professional spaces. Furthermore, professional growth "is ongoing and in a constant state of becoming, as opposed to being fixed" (p.25). Based on this definition, professional growth is a malleable process with symbiotic influences from faculty members' identities, roles, and work. O'Meara et al. (2008) argue that this growth occurs in a specific sociocultural and personal context relative to each faculty member. Adjunct faculty experiences are conceptualized within the context of individual environments, and this study focuses on engagement in the following three spaces that shape professional growth: the university, the department, the outside non-PSU instructional environment (i.e., personal and professional non-PSU spaces).

\section{The University}

The university is the first of the three environments that will be reviewed. As it was described by adjunct faculty, it exists as a physical space as well as a set of shared expectations based on history, institutional sagas, mythology, and a cumulative collection of shared experiences and perceptions. As a physical space, it is comprised of an urban campus with buildings nestled in a medium-sized American city, while as a digital space it includes an invisible online learning community. Regardless of the setting in both spaces, instruction occurs and the two spaces facilitate the formal employment relationship and define the parameters for adjunct faculty working conditions at the university. 
The adjunct faculty interviewed for this study describe the university, as a whole, through points of disconnection. For example, when asked about their current title at PSU, none of the adjunct faculty interviewed responded with certainty. Their responses expressed a general lack of awareness and confusion about their individual titles, as well as an ambivalence to the adjunct ranking system at this university. Moe's response best encompasses the general sentiment expressed by the group when he shared, "no idea [what my title is]. I would have thought that there would be a two there or potentially a senior. But I have no idea what the ranking system means. And as far as I understand, nobody knows." This response demonstrates a lack of connection to a title, which connotes a similar lack of connection to the university as an employer. That lack of connection is based on two assumptions. The first is that an employee's title carries with it an identity. That identity can be one that the employee does or does not align with and/or that communicates feelings of pride or shame. Secondly, a title ranks an employee within a tiered organizational structure, and within higher education, faculty titles are even further stratified and revered, based on the tenure system. For adjunct faculty, all titles are perceived as less than their full-time counterparts because they connote a contingent relationship between the individual and the university. Bibi shared,

I think the connotation is kind of negative, adjunct faculty. To me, I always call myself an instructor here on things I complete. I'm an instructor here. Adjunct is, I just tune to those stories of people who were super low paid and there's no security, so I just don't even call myself that.

Even for Bibi, who does not express a long-term professional aspiration to assume a fulltime instructional role, the term "adjunct" is not one that he wants to identify. Titles and 
the ranking system for adjunct faculty are not prioritized as professional identities with which the participants in this study align.

Another example of an expressed disconnect for adjunct faculty is with the university's mission. "Let knowledge serve the city" is displayed on a sky bridge in the middle of PSU's campus and it encompasses the mission and values of the university (Portland State University, 2021). Gappa et al. (2007) identify connection to an institutional mission as an integral component of faculty professional growth. Interestingly, the adjunct faculty in this study were able to reference elements of the mission, but they did not express a connection to that mission. Moe truthfully shared his personal perception regarding the mission of PSU, as he sees it realized:

Their mission is to like, stay afloat. Their mission is to survive...I mean, like, obviously secondary, well primarily in their mind, secondary in my mind, is to just follow the mission statement, let knowledge serve the city. Which I do believe they believe, but like, what's their number one priority? Keep in the black. And the way they're doing that is not with athletics, it's with keeping enrollment...and then like, yeah, maybe attracting some people who are going to get some good grants.

This response reflects a perception of the institutional mission, based on Moe's lived experience as a former PSU student and now as an adjunct faculty member. He referenced "let knowledge serve the city," yet his overarching statement described an institution struggling to maintain its financial solvency. For faculty, the institutional mission is a concept that can guide instructional approaches in the classroom and that can impact an understanding of how one's values align with that of their employer. That said, for adjunct faculty, it can also highlight the disconnect between what the university espouses, and what is lived in the day-to-day. As I asked the adjunct participants about 
the university's mission, the perceived response was confusion as to how that information was relevant for their experience. If a mission is asserted as a guiding standard by which decisions are made and by which employees align their priorities, it could be argued that it is not being effectively enacted within an organizational culture if the mere mention of it prompts confusion or even revulsion.

The points of disconnection with the university, expressed by adjunct faculty, differ from the relationship that Thirolf (2017) asserts exists for true faculty engagement. She defines faculty engagement as, "the actions and behaviors that faculty and institutions take to facilitate and support faculty professional growth" (p.305). There is a shared responsibility in her definition that places ownership on both the institution and the faculty member. Thirolf (2017) describes that shared ownership as the institution offering different opportunities for engagement (e.g., professional development, social learning experiences) and the faculty member taking advantage of offered opportunities. If professional growth is to occur, it assumes a willingness on the part of the faculty member to engage with the institution.

Just as there are different environments for adjunct faculty experiences (i.e., the university, the department, and the outside non-PSU instructional environment), there are also different worlds nested within each environment (Bronfenbrenner, 1979). Those nested worlds are subject to change, as adjunct faculty choices adjust their experiences; over time, the process of adjunct faculty professional growth is consistently fluctuating and moving in and out of focus. For example, both Moe and Poppy embody multiple professional identities within the university as former students and current faculty. Poppy 
is also accompanied by a third identity as a former full-time non-tenure track faculty (FTNTTF), yet for each of them, their previous experiences are not identities that departed when they transitioned into their adjunct role. Instead, they continue to be present and impact their professional decisions regarding instructional choices and expectations for their work at the university. Moe chooses to engage with the Office of Academic Innovation (OAI) because he previously participated as a graduate teaching assistant and he now continues to receive their correspondence, based on that prior participation. Poppy volunteers as a reader for the annual undergraduate scholarship review because that is a service activity that she previously engaged in as FTNTTF. She also tries to attend PSU's annual Winter Symposium because that is a PD experience that she previously valued and engaged in. Poppy and Moe both carry institutional knowledge that reflects their prior lived experiences on this campus, as they currently relate to their adjunct role. As O'Meara et al. (2008) state, the "change" that occurs for them, based on engagement in their previous and current experiences, is a shift in their professional orientation to their individual work. As a student and/or as FTNTTF, participation in each activity was typically a required component of their role. However, as adjunct faculty, that choice is squarely their own. For Moe, development as an effective instructor is a value that he expresses, so PD with OAI aligns with that goal. For Poppy, service to students and socialization with colleagues from across campus are important components to her professional practice. As such, her chosen examples of engagement are in pursuit of both components. 
The university is a space where each adjunct embodies at least one identity and in which they change their personal conception of their role, based on their chosen forms of engagement. Connection to the university is not derived from titles or ranking systems, nor is it found within the university mission. For the adjunct faculty in this study, professional growth within the university is based on individual choices and introspection about what it means to be a part-time faculty member. The challenge is that introspection for adjunct faculty can highlight more disconnection, rather than connection, with the university.

\section{The Department}

The department is the second of the three environments. It is described as the professional community in which each adjunct teaches and gains or loses satisfaction based upon feelings of professional belonging. Departments differ from one another and essentially are individual, distinct learning communities based on their academic subject matter and their expressed culture of scholarship. For example, many of the department coordinators interviewed for this study described their department culture as collegial and their collective focus on instruction, research, and the student experience. The department is a microcosm of the university, so it embodies both the institutional mission and its own set of values, which may or may not be in alignment with that of the larger university. As a smaller learning community, it is the environment in which the adjunct faculty member most intimately interfaces as an instructor. However, that smaller community does not necessarily connote professional integration, which is an element of engagement that directly shapes professional growth. 
In the inclusive faculty engagement model, Thirolf (2017) differentiates

integration from engagement by defining the former as perception-based, whereas the latter is action- or activity-based. She defines faculty integration as,

...a state of being whereby a faculty member feels a sense of belonging to their academic department and college. More specifically, faculty academic integration is a sense of feeling intellectually and professionally connected to a department or campus. Faculty social integration can be defined as a perception of fit or collective affiliation among faculty colleagues and a connection to students and other colleagues overall. (2017, p.306)

Holistically, faculty integration connotes an intellectual and professional connection to a department whereas faculty social integration refers specifically to a person's "fit or collective affiliation" (Thirolf, 2017, p.306). The experience of integration is deeply personal, as it relates to individual feelings of belonging and connection. The adjunct participants of this study discuss their department(s) in a dichotomous way with a similar level of personal connection, by either expressing feelings of professional respect or disrespect. By describing feelings of a sense of belonging being seen and heard, or as disconnection by being utterly invisible, there is a clear strongly bipolar dichotomy of experience.

An example of this dichotomy exists in the example of Bibi and Sara; one in an academic unit that prioritizes subject-matter-expertise and practical experience from the workplace (Bibi), and one whose academic unit emphasizes scholarship and terminal degrees amongst their faculty (Sara). As an adjunct faculty in his self-pronounced second career phase, Bibi described 18 years of professional experience for which he was valued in his department, and he assumed this was the reason that he was offered the teaching role. Within his department, he expresses feeling respected by his colleagues and he 
provides examples of when his professional discretion was heard and incorporated into the curriculum (e.g., when he expressed concern over the topic of a student workshop, he was asked to lead a "counter" presentation). Conversely, Sara does not feel respected by her department. She has a $\mathrm{PhD}$ with years of instructional and research experience, but she has not been prioritized during hiring processes for full-time faculty roles. Sara's department is one with espoused values that align with her prior professional experiences (e.g., terminal degrees, active scholarship, etc.), however, she has not experienced academic or social integration within that community. As a result, Sara is eager to pursue opportunities outside of her department, whereas Bibi does not feel the need to embrace that goal.

Faculty integration within one's department is an essential element of professional growth, which echoes the definition of respect discussed by Gappa et al. (2007) in their framework for rethinking faculty work. Within the framework as a whole, respect is the element on which all other essential elements depend; without respect, faculty professional growth cannot be facilitated by the institution and it cannot be pursued or realized by the faculty. Gappa et al. (2007) argue that "until all faculty members (in fact, all employees) feel that they are respected, they are less likely to place much importance on other elements or to benefit from them" (p.139). Therefore, if respect and faculty integration are lacking in a department, adjunct faculty will not prioritize engagement experiences that might impact their professional growth. If respect and faculty integration occur, professional growth will be a process in which the faculty member(s) engage and, as a result, foster the agency over their experience. 


\section{The Outside Non-PSU Instructional Environment}

The third space that shapes adjunct faculty experiences is the outside non-PSU instructional environment. It looks different for each adjunct faculty member and is comprised of personal and professional elements. Outside work experiences, family obligations, professional organizations, and personal relationships comprise some elements of this environment. The adjunct faculty in this study add to their university and department experiences with an individual outside environment that often shapes their expectations and goals for their part-time role. This is a nebulous space that looks different for each of the four adjunct faculty members. Even so, it is one of the contexts that impacts their professional growth.

In order to understand the eclectic outside environments of the four adjunct faculty, a lens focused on career stage needs will be employed. These career stage needs emerged as a central theme for faculty professional growth in this study, especially when analyzing the connections between engagement and professional growth with the looming context of each participant's disparate outside world. In this study, career stages include those that could be described as early-career and middle-career stages. Gappa et al. (2007) define faculty career stages based on the tenure-track, which leaves no room for adjunct faculty stages. As such, this study will define adjunct faculty career stages based on the experiences of the four adjunct faculty participants. Bibi and Moe could be described as early-career adjuncts because they have been teaching for less than five years, while Sara and Poppy could be described as mid-career adjuncts because they have been teaching for more than five years. However, none of the participants describe 
themselves as nearing the end of their instructional careers. That said, for both groups, the definition of a "career" can be understood in myriad ways, so, for this discussion of faculty career stages, the specific career under consideration is their instructional career (whether full- or part-time). Each adjunct in this study chose to disclose different elements of their outside environments, with some disclosing more than others.

For Sara, Poppy, and Moe, outside teaching obligations emerged as elements of their outside non-PSU instructional environment. Each taught at different institutions (with overlap at PCC for Poppy and Moe) and they described how that outside engagement shaped their professional growth as an adjunct. Specifically, descriptions are discussed as comparisons. For example, the experience of teaching at more than one institution facilitates more diverse professional development offerings across each school. And further, there are different benefits for participation in PD at each school. These differences increased their awareness of institutional priorities and opportunities contained therein. For example, Moe referenced the difference in his experience with PD at PSU and PCC. At PSU, his participation in PD within his department was unpaid, but at PCC, it was paid. His outside non-PSU instructional environment (PCC) compensates him for institutional engagement in learning experiences, and communicates to him that, for PCC, those experiences are worth his time. By contrast, at PSU, Moe isn't compensated for attendance at course coordinator meetings, which are optional for adjunct faculty. He shared that he now often chooses not to engage with those meetings because they are unpaid, which is very different from when he was a GTA and required to participate. For all four adjuncts, the instructional environment beyond PSU provides 
the opportunity to compare their experiences, which can raise consciousness about employment inequalities and inspire changes within an adjunct faculty member's professional practice.

\section{Change and Professional Growth}

O’Meara et al. (2008) define professional growth as a change process. Through their definition of professional growth, they assert three questions: 1) How does change, in the form of growth, occur and by what means, and in what contexts?; 2) How is such change made manifest?; and 3) What specifically about the individual changes? (O’Meara et al., 2008). This study examines each question through three change processes that adjunct faculty experience. Those processes are role and/or job changes, practice-based developmental changes, and resilience-based changes.

The first change process, a role and/or job change, forces a shift in identity for the individual undergoing the change. For example, Poppy involuntarily changed from a fulltime to a part-time faculty member, which prompted different forms of engagement for her with the university, with her department, and with her non-PSU instructional environment. As professional growth is set in a "specific sociocultural and personal context relative to faculty members' identities, roles, and work" (O’Meara et al., 2008, p.25), if one element changes — for example, a faculty member's job — their professional growth will be altered based on that new context. For Poppy, this change was manifested in her personal identity and the feelings of belonging that she felt with her department and with the university as a whole. As part-time faculty at PSU, her available time was more limited after she pursued other outside roles. This changed her presence in the 
department (e.g., she was in the office suite less), as well as her ability to engage in PD and network with colleagues from across the university. The change in her FTE status altered multiple aspects of her instructional identity: 1) her relationship with PSU; 2) her awareness of employment challenges for part-time faculty; and 3) her professional goals. In terms of her goals, rather than aspiring to more senior full-time positions within her department and/or working to develop elements of her teaching craft, she is now interested in resuming a full-time position and/or simply ensuring that she has enough income from her multiple instructional positions (across each institution). The change process incurred from a job change, even if that change is simply a change in responsibilities (e.g., new course assignment, teaching in a new academic department, etc.), is one that forces a shift in identity for adjunct faculty.

The second change process, a practice-based developmental change, is more gradual than the first, yet it also facilitates a shift in professional identity. This change is one that occurs over time, based on new learning experiences that prompt personal development. It is practice-based and subject to consistent change because one's practice as an adjunct instructor persistently evolves. One example of this change is with Bibi and his transition from practitioner to teacher. Bibi referenced his first career many times throughout our interviews, but he did so in connection with how that experience positively impacts his courses and his teaching. His primary instructional identity, after multiple years in the classroom, is now as an instructor, versus as a practitioner who casually teaches. Over time, he developed preferences for courses that he did or did not enjoy teaching, based on his continued practice in the classroom. For example, whenever 
possible, he preferred in-person and upper division classes, rather than online, hybrid, and lower-division courses. The practice of teaching each course developed a new awareness and identity for Bibi as an instructor who is also an experienced SME. This gradual change process is unique for each individual and will likely involve a shift in a professional identity, depending on the specific developmental change.

The third change process is a resilience-based process that emerges as adjunct faculty encounter adversity and change their behaviors and/or professional identity as a result. One example of this change process, born of resilience, is evident in Sara and the professional boundaries that she sets as an adjunct. The way she reflects upon her experiences as an "invisible" adjunct at multiple institutions has taught the lesson that no one will advocate for her individual needs. In order to persist within the field as a parttime instructor, she needed to set boundaries with her department and with the university. Resilience requires contemplation and time, through which the individual will shift their behaviors and mindsets. The resilience-based change is manifest through Sara's command of her individual experience. Further, this change is ongoing as the professional adversity that she experienced took new forms in the way of new work environments, changes to institutional policies, and budgetary challenges. Both Sara and Moe work to impact institutional change for all adjunct faculty at PSU, which is another example of resilience-based change. As they find new ways to resist and persist through the inequities within their work space, they endeavor to raise awareness around their individual experiences with PSUFA. Similar to job-based and practice-based change, 
change born of resilience is deeply personal and is immensely impacted by adjunct faculty professional identities, roles, and work.

Across each of the described change processes (job-based, practice-based, and resilience-based), awareness is raised, which shapes the adjunct faculty member's professional growth journey. Whether the new awareness is concerning their day-to-day work, their department's values, institutional priorities, or personal goals, job satisfaction is likely changed and as a result, professional growth and personal goals are altered over time. This study found that adjunct faculty expressed their new awareness, and their altered goals, through different dimensions of dissatisfaction. Based on their individual dimension of dissatisfaction, from active frustration to passive ambivalence, a change response was triggered in order to move towards more positively-associated feelings of satisfaction. The change response was a form of personal ownership and it endeavored to create control for the individual adjunct. For Moe and Sara, union involvement communicated a commitment to equitable employment experiences for adjunct faculty. Bibi re-focused his professional goals on improving his instruction and contributing to the learning environment for students in his department. Poppy is still in self-discovery, but she continues to engage with her department and the university with the intention of securing another full-time faculty role. Her change, while subtle, demonstrates a resilience response focused on her goal-oriented solution of regaining full-time employment. Dissatisfaction expressed by each adjunct fell along a dimension, and is not static. Change is gradual and as awareness increases over time, dissatisfaction about specific elements of the adjunct role emerge. Professional growth is impacted by 
institutional engagement in myriad ways that are individual to the adjunct faculty member and their specific context. Most importantly, professional growth is a persistent change process as it is ongoing, individual, and malleable. As a result, universities and departments have ample opportunities to impact positive change and shift adjunct faculty experiences from a dimension of dissatisfaction to one of satisfaction.

\section{Implications for Practice and Future Research}

The findings of this analysis identify many implications for professional practice and opportunities for future research. To review, adjunct faculty report multiple motivators for engaging with their employing institution, based on their professional goals to or not to pursue full-time instructional work. Examples from the responses of my four adjunct faculty participants include: 1) the desire to impact student learning and the advancement of knowledge in their field, 2) to secure adequate compensation, and 3) the development of social capital through networking with collegial interactions. Adjunct faculty experience professional growth as different change processes in unique environments (i.e., the university, their department, the non-PSU instructional environment). As such, implications for professional practice are grouped into two spaces: the university and the department. Opportunities for future research are discussed using Thirolf (2017), Gappa et al. (2007), and O’Meara et al. (2008) as grounding analyses from which to build.

\section{Implications for Practice: Universities and Departments}

The diverse taxonomy of adjunct roles (Tuckman, 1978), along with the other faculty typologies discussed in this study (Gappa \& Leslie, 1993; CCSE, 2014), consider 
the individual intentions that are driving part-time employment. The faculty-type frameworks are further understood through analysis of individual adjunct faculty, across academic units, at one institution. As this study highlighted, adjunct faculty are professionals with unique academic and professional histories that shape their intentions for working part-time. Those intentions guide their expectations for their university, their department, and their satisfaction over time. As such, universities and departments have the opportunity to acknowledge those varied groups during faculty hiring planning and decision-making. When this awareness and acknowledgement informs policy, it can facilitate professional opportunities that create a healthy working culture for adjunct faculty, as well as an effective learning environment for students.

At the university-level, this study suggests a clear implication for adjunct faculty employment contracts. Pathways to promotion and transparency regarding opportunities for advancement were identified by adjunct faculty as imperatives in their professional growth journeys. Promotion and advancement are described by adjunct faculty as experiences that lead to new opportunity (e.g., increased course assignments) and that also provide an increase in compensation. Therefore, universities are encouraged to create employment contracts and internal policies for adjunct faculty that clearly define available opportunities for advancement. And if opportunities for advancement are offered, they should tangibly benefit the adjunct faculty member who pursues them. For example, if contracts for continuous employment are available for adjunct faculty, they should guarantee assignment rights or compensation if the contract is broken. Without 
such assurance, adjunct faculty will not benefit and will not attribute much meaning to the experience of acquiring such a contract.

At the department-level, clear implications exist for faculty culture. If adjunct faculty identify an interest in developing social capital with colleagues in their department in order to increase their sense of belonging and potentially gain access to additional employment opportunities, the department should include these as a form of compensation. To do so, academic departments should create opportunities to engage adjunct faculty and encourage an inclusive environment in the conduct of typical faculty gatherings. Faculty meetings and course-specific professional development are two examples of ways to facilitate that engagement. In addition, if departments will be offering opportunities for adjunct faculty to engage with colleagues from across the department, they should consider the accessibility of the experiences. For example, at what time of day and in what format is the meeting or the training offered? Are those options varied from month-to-month? Finally, compensation is another consideration that must be prioritized since the facilitation of experiences that can increase social capital is only a first step. Ultimately, adjunct faculty are professionals, and their engagement with the institution is work, so this work should be compensated.

Within both environments, universities and academic departments have the opportunity to consider how they are contributing to the professional growth experiences of their adjunct faculty. They can do this through creating equitable employment contracts, transparent pathways to promotion, and through facilitation of an engaging and inclusive organizational culture. That said, institutional decisions are ongoing regarding 
policies and practices that have implications for adjunct faculty; these decisions are not isolated to contract negotiations or professional development. As such, intentional decision-making should thoughtfully consider how adjunct faculty are impacted by institutional changes. Similar to an equity lens approach to decision-making, this study encourages institutions of higher education to ask similar questions with adjunct faculty in mind. For example, four guiding questions could be: 1) who does this policy/change/etc. benefit?; 2) who does not benefit from this policy/change/etc.?; 3) what are the implications for those who do not benefit?; and 4) how do those implications impact students? Adjunct faculty are just one group within an institution's employee base, and this study does not assert that they should be prioritized over all others. However, this study does recommend that they should be offered a seat at the table as well as consideration for how their professional growth can be better supported.

\section{Implications and Recommendations for Future Research}

As a whole, recommendations for future research from this study include continued reexamination of faculty professional growth models and frameworks, specifically for the adjunct population. Through application of Thirolf's (2017) inclusive faculty engagement model and the research on faculty professional growth from Gappa et al. (2007) and O'Meara et al. (2008), it is evident that part-time faculty are a distinctly different workforce than full-time faculty. Their experiences don't mimic those of their full-time counterparts, so current models leave room for reconceptualization. Research from Thirolf (2017), Gappa et al. (2007), and O’Meara et al. (2008) informed this study’s analysis and discussion of adjunct faculty engagement and professional growth. As such, 
implications and recommendations for future research are offered within the context of each framework.

Thirolf's (2017) model for including and engaging part-time faculty was developed within a community college context. That said, the asserted inclusive faculty engagement model offers suggestions with practical application within a four-year setting, specifically, at Master's and R3-designated colleges and universities with large adjunct faculty populations (AAUP, 2018a). This study employed Thirolf's (2017) model as a lens from which to understand institutional data, but a recommendation for future study would be to examine how this model functions at a four-year institution and what differences emerge in that space. Within that study, detailed examination of the "positive outcomes" portion of the model could yield actionable recommendations for institutions and departments.

As professional growth frameworks, research from both Gappa et al. (2007) and O’Meara et al. (2008) prioritize the full-time faculty identity and experience within their analyses. Although some elements resonate with the adjunct experience (e.g., the element of respect from Gappa et al. (2007) is paramount for adjunct faculty satisfaction), there is room for further analysis of the frameworks' application for part-time instructors. For example, this exploratory study prioritized faculty professional growth, based on the framework for rethinking faculty work from Gappa et al. (2007). Findings highlighted the relevance of the other essential elements as fairly symbiotic, so a recommendation would be to conduct additional qualitative analysis of adjunct faculty experiences with collegiality, employment equity, academic freedom \& autonomy, and flexibility. 
Additionally, Kezar (2012b) offers policy recommendations for each element within the framework, so an action research study could evaluate and consider the implications for adjunct faculty when the recommended institutional policies and programs are implemented.

This study examined the professional growth experiences of four undergraduate adjunct faculty at PSU, which is a small sample from within the larger part-time faculty community at the university. Additional research opportunities at this site are myriad, but one recommendation is to analyze adjunct experiences, by academic discipline. This study highlighted the variety in experience, based on department culture, but I would like to examine the assumption that academic discipline is an influential factor within that variety. For example, what are the professional growth experiences of adjunct faculty within an academic unit focused on pre-professional degree preparation (e.g., accounting, pre-health, etc.), versus one focused on the social sciences? Based on that research, recommendations for institutional practice could be offered in order to tailor employment best practices for adjunct faculty, by academic discipline.

As an adjunct faculty member, Bibi offers a poignant reflection that should guide the implications of this study: "We all just kind of think, okay, that's the way it is. I'm like, why does that have to be the way it is?" Through examination of the findings from this study and available research about faculty in institutions of higher education, it is evident that there is still much to learn about adjunct faculty. Their presence and role on two- and four-year campuses continues to evolve, but institutions are not always as nimble with reevaluating how to create equitable work experiences. Even so, "that's the 
way it is" does not have to be a default response. Our institutions of higher education bear the responsibility of creativity, to let knowledge serve and to not neglect a community of educators contributing to that service. This study highlights the many opportunities that universities have available to engage and partner with their adjunct faculty population.

\section{Concluding Thoughts}

Institutions of higher education continue to face challenges - from limited institutional funding, to student affordability, to curricular relevancy, to pandemics. These challenges force innovation in order to sustain a desirable learning environment for students, staff, and faculty alike. Unfortunately, innovations within institutions of higher education have largely overlooked and/or downplayed the professional growth needs of adjunct faculty. This omission can be attributed to a number of reasons. The adjunct role originated in the 1970s, with two-year and then four-year institutions hiring adjunct faculty due to their subject matter expertise. They were valued as practitioners who could add relevant, practiced insight into the academic landscape. As practitioners, their identity exists outside of the respected tenure-track role and assumptions-sometimes accurately — could assume disinterest from the part-time instructor in professional growth at the university. Additionally, institutions have turned to adjunct faculty hires as temporary solutions to decreases in state funding and increases in operational costs (Kezar, 2012a). Temporary solutions do not necessitate integration or engagement from the university. However, both reasons fall short in capturing the adjunct experience. Adjunct faculty have not evolved as a temporary solution, and they are not all 
practitioners with outside full-time jobs. The one-size-fits-all approach to adjunct faculty employment, as an underpaid, under-resourced, contingent faculty workforce, overlooks the diversity in adjunct professional identities (i.e., the typology of adjunct types). This research highlights the diverse professional growth experiences of adjunct faculty who communicate professional identities and goals that largely fall outside of the original understanding of an adjunct from the 1970s.

This exploratory study interviewed four adjunct faculty from different academic units at PSU, a large, urban, commuter research university that employs over $40 \%$ of their instructional faculty part-time. Adjunct participant experiences were explored in connection with data from six department coordinators and institutional documents from human resources, PSUFA, individual departments, and the adjunct faculty themselves. Findings demonstrate that professional growth experiences differ and change over time for adjunct faculty. Originating motivators for working part-time, professional goals, collegial interactions, and access to resources (e.g., time and compensation) impact the evolution of professional growth journeys for adjunct faculty. Across their three environments of influence - the university, the department, and the outside non-PSU instructional space — adjunct faculty encounter affirmation and adversity, which contributes to the change process of faculty professional growth. The findings of this study encourage a more holistic and creative consideration about how institutions can work with adjunct faculty, with the individual person in mind.

Change, of any scale, in higher education is challenging to invoke (Birnbaum, 1992; O'Meara et al., 2008). Even so, the pursuit of meaningful change is a challenge 
worth attempting - especially with student outcomes as an intended positive result. Parttime instructors are faculty members on college campuses, and although their specific roles and responsibilities differ from full-time tenure-track and/or non-tenure track faculty, they are still charged with the task of educating students. That charge is a shared endeavor within institutions of higher education, yet it is often lost amongst the hierarchy of faculty roles and the myriad organizational challenges that dictate priorities. Nevertheless, adjunct faculty continue to commit to the task of educating students in institutions of higher education, and institutions continue to hire them for that task. Throughout my interviews with the adjunct participants in this study, a sincere commitment to student learning was a salient theme shared by all—despite the professional challenges faced in their part-time roles. In order to develop institutional support for that dedicated work and the learning experiences of students, analysis of adjunct faculty members' unique journeys is an imperative. Findings from this study contribute to that analysis and can be used to inform future organizational changes regarding the work experiences of adjunct faculty. 


\section{References}

1940 Statement of Principles on Academic Freedom and Tenure. (n.d.). American Association of University Professors. Retrieved from https://www.aaup.org/file/1940\%20Statement.pdf

Alderfer, C.P. (1972). Existence, relatedness and growth: Human needs in organizational settings. New York, NY: Free Press.

Altheide, D.L., \& Schneider, C.J. (2013). Qualitative media analysis ( $2^{\text {nd }}$ ed.). Thousand Oaks, CA: Sage.

American Association of University Professors. (2017). Trends in the academic labor force, 1975-2015 [Data file]. Retrieved from https://www.aaup.org/sites/default/files/Academic_Labor_Force_Trends_19752015.pdf

American Association of University Professors. (2018a). Data snapshot: Contingent faculty in US higher ed. Retrieved from https://www.aaup.org/sites/default/files/10112018\%20Data\%20Snapshot\%20Ten ure.pdf

American Association of University Professors. (2018b). The annual report on the economic status of the profession, 2017-18. Academe. Retrieved from https://www.aaup.org/sites/default/files/ARES_2017-18.pdf

American Association of University Professors. (2019). The annual report on the economic status of the profession, 2018-19. Retrieved from https://www.aaup.org/sites/default/files/2018-19_ARES_Final_0.pdf 
Astin, A.W. (2016). Are you smart enough? How colleges' obsession with smartness shortchanges students. Sterling, VA: Stylus Publishing, LLC.

Baldwin, R. G., \& Wawrzynski, M.R. (2011). Contingent faculty as teachers: What we know; What we need to know. American Behavioral Sciences, 55(11), 1485-1509. doi: 10.1177/0002764211409194

Bates, A.W., \& Sangra, A. (2011). Managing technology in higher education: Strategies for transforming teaching and learning. San Francisco, CA: Jossey-Bass.

Bergquist, W.H., \& Phillips, S.R. (1975). A handbook for faculty development. Retrieved from https://files.eric.ed.gov/fulltext/ED115174.pdf

Bernstein, D., \& Bass, R. (2005). The scholarship of teaching and learning. Academe, 91(4), 37-43.

Berrett, D. (2011). Separate and unequal. Inside Higher Ed. Retrieved from https://www.insidehighered.com/news/2011/04/13/adjunct_college_professors_e mbody_troubling_disparities

Bertaux, D. (1981). Biography and society: The life history approach in the social sciences. Beverly Hills, CA: Sage Publications.

Birnbaum, R. (1992). How academic leadership works: Understanding success and failure in the college presidency. San Francisco: Jossey-Bass

Bolman, L.G., \& Deal, T.E. (2013). Reframing organizations: Artistry, choice, and leadership. San Francisco, CA: Jossey-Bass. 
Bourdeaux, R., \& Schoenack, L. (2016). Adult student expectations and experiences in an online learning environment. The Journal of Continuing Higher Education, 64, 152-161. doi:10.1080/07377363.2016.1229072

Boyer, E.L. (1990). Scholarship reconsidered: Priorities of the professoriate. San Francisco, CA: Jossey-Bass Inc.

Bronfenbrenner, U. (1979). The ecology of human development: Experiments by nature and design. Cambridge, MA: Harvard University Press.

Byse, C., \& Joughin, L. (1959). Tenure in American higher education: Plans, practices, and the law. Ithaca, NY: Cornell University Press.

Cameron, M. (2010). Faculty tenure in academe: The evolution, benefits, and implications of an important tradition. Journal of Student Affairs at New York University, VI, 1-11. Retrieved from https://steinhardt.nyu.edu/scmsAdmin/media/users/lh62/CameronJoSA_.pdf

The Carnegie Classification of Institutions of Higher Education. (2017). Institution lookup: Portland State University. Retrieved from https://carnegieclassifications.iu.edu/lookup/lookup.php

Case, P., Chun, E.B., Evans, A., Kelly, R., Kezar, A., Liebhaber, K.P., Mandernach, J., Marble, T., Lorenzetti, J.P., Offerman, D., Trotta, N., Weiss, D.R., \& Widen, J. Managing adjunct faculty. (2016). Madison, WI: Magna Publications.

Center for Community College Student Engagement. (2014). Contingent commitments: Bringing part-time faculty into focus. Retrieved from http://www.ccsse.org/docs/PTF_Special_Report.pdf 
Centra, J.A. (1976). Faculty development practices in U.S. colleges and universities.

Princeton, NJ: Educational Testing Service. Retrieved from

https://files.eric.ed.gov/fulltext/ED141382.pdf

Charfauros, K.H., \& Tierney, W.G. (1999). Part-time faculty in colleges and universities:

Trends and challenges in a turbulent environment. Journal of Personnel

Evaluation in Education, 13(2), 141-151.

Chronicle Data. (2018). 4-year public. Retrieved from

https://ata.chronicle.com/salaries/methodology/

Coalition on the Academic Workforce. (2012). A portrait of part-time faculty members: A summary of findings on part-time faculty respondents to the coalition on the academic workforce survey of contingent faculty members and instructors.

Retrieved from http://www.academicworkforce.org/CAW_portrait_2012.pdf

Cohen, A.M., \& Brawer, F.B. (2008). The community college (5th ed.). San Francisco, CA: Jossey-Bass.

Contingent Faculty. (2017). National Education Association. Retrieved from http://www.nea.org/home/34762.htm

Creswell, J.W. (2013). Qualitative inquiry \& research design (3rd ed.). Thousand Oaks, CA: Sage Publications.

Creswell, J.W., \& Creswell, J.D. (2018). Research design: Qualitative, quantitative, and mixed methods approaches (5th ed.). Thousand Oaks, CA: SAGE Publications, inc. 
PROFESSIONAL GROWTH

Diamond, R.M. (2002). Faculty, instructional, and organizational development: Options and choices. In K. Gillespie, L. Hilsen, \& E. Wadsworth (Eds.), A guide to faculty development: Practical advice, examples, and resources (pp.2-8). Bolton, MA: Jossey Bass.

Emerson, R.M., Fretz, R.I., \& Shaw, L.L. (2011). Writing ethnographic fieldnotes (2nd ed.). Chicago, IL: The University of Chicago Press.

Feldman, D., \& Turnley, W. (2011). A field study of adjunct faculty: The impact of career stage on reactions to non-tenure-track jobs. Journal of Career Development, 28(1), 1-16.

Flaherty, C. (2015). More than adjuncts: U. of Denver moves to new titles, a career path and multiyear contracts for those off the tenure track. Could this be a model for other institutions? Inside Higher Ed. Retrieved from https://www.insidehighered.com/news/2015/02/17/new-faculty-model-u-denvercould-be-prototype-reform

Flaherty, C. (2016). Big gains for adjuncts: Northeastern is latest university where first contract with adjunct union has included substantial salary increases and other key benefits—-such as payments for classes that colleges cancel. Inside Higher Ed. Retrieved from https://www.insidehighered.com/news/2016/01/15/does-newcrop-first-adjunct-union-contracts-include-meaningful-gains

Francis, J.B. (1975). How do we get there from here?: Program design for faculty development. The Journal of Higher Education, 46(6), 719-732. 
Frey, S. (2012). Faculty members' perceptions of community college centers for teaching and learning: A qualitative study. Retrieved from ProQuest Dissertations Publishing. (UMI 3552318)

Gaff, J.G., \& Simpson, R.D. (1994). Faculty development in the United States. Innovative Higher Education, 18(3), 167-176.

Gappa, J. (2000). The new faculty majority: Somewhat satisfied but not eligible for tenure. New Directions for Institutional Research, 105, 77-86.

Gappa, J.M., \& Austin, A. E. (2010). Rethinking academic traditions for twenty-firstcentury faculty. AAUP Journal of Academic Freedom, 1, 1-20. Retrieved from https://www.aaup.org/sites/default/files/files/JAF/2010\%20JAF/Gappa.pdf

Gappa, J.M., \& Leslie, D.W. (1993). The invisible faculty: Improving the status of parttimers in higher education. San Francisco, CA: Jossey-Bass Inc.

Gappa, J.M., Austin, A.E., \& Trice, A.G. (2007). Rethinking faculty work: Higher education's strategic imperative. San Francisco, CA: Jossey-Bass.

Glaser, B.G., \& Strauss, A. (1967). The discovery of grounded theory: Strategies for qualitative research. Chicago, IL: Aldine Publishing.

Green, K.C. (2018). 2018 Campus computing: The 29th national survey of computing and information technology in American higher education. Retrieved from https://static1.squarespace.com/static/5757372f8a65e295305044dc/t/5bd70c94f4e 1fc4181923249/1540820120742/CAMPUS+COMPUTING++2018+REPORT.pdf 
Handy, C. (1993). Understanding organizations: How understanding the ways organizations actually work can be used to manage them better. New York, NY: Oxford University Press.

Herzberg, F. (1966). Work and the nature of man. Cleveland, OH: World.

Hoikala, P. (2012). Lecturers anonymous: Moving contingent faculty to visibility at a master's institution. In A. Kezar (Ed.), Embracing non-tenure track faculty: Changing campuses for the new faculty majority (pp. 130-146). New York, NY: Routledge.

Keast, W.R., \& Macy, J.W. (1973). Faculty tenure: A report and recommendations. San Francisco, CA: Jossey-Bass.

Kelly, R. (2016). Adjunct professional development improves teaching, builds community. In Managing adjunct faculty: A resource collection for administrators (pp.46-48). Madison, WI: Magna Publications.

Kezar, A. (2012a). Preface. In A. Kezar (Ed.), Embracing non-tenure track faculty: Changing campuses for the new faculty majority (pp.X-xxiv). New York, NY: Routledge.

Kezar, A. (2012b). Needed policies, practices and values: Creating a culture to support and professionalize non-tenure track faculty. In A. Kezar (Ed.), Embracing nontenure track faculty: Changing campuses for the new faculty majority (pp.2-27). New York, NY: Routledge.

Kezar, A. (2013). Examining non-tenure track faculty perceptions of how departmental policies and practices shape their performance and ability to create student 
learning at four-year institutions. Research in Higher Education, 54(5), 571-598. doi:10.1007/s11162-013-9288-5

Kezar, A. (2016). The adjunct crisis: How poor work conditions for adjuncts are affecting student outcomes. In Managing adjunct faculty: A resource collection for administrators (pp. 5-8). Madison, WI: Magna Publications.

Kezar, A., \& Maxey, D. (2013). The changing academic workforce. Association of Governing Boards of Universities and Colleges. Retrieved from https://www.agb.org/trusteeship/2013/5/changing-academic-workforce

Kezar, A., \& Sam, C. (2010). Special issue: Non-tenure-track faculty in higher education - theories and tensions. ASHE Higher Education Report, 36(5), 1-91.

Kezar, A., \& Sam, C. (2011). Understanding non-tenure track faculty: New assumptions and theories for conceptualizing behavior. American Behavioral Scientist, 55(11), 1419-1442. doi:10.1177/0002764211408879

Krippendorff, K.H. (2004). Content analysis: An introduction to its methodology (2nd ed.). Thousand Oaks, CA: Sage Publications.

Kuhlenschmidt, S. (2010). Issues in technology and faculty development. In K.J.

Gillespie \& D.L. Robertson (Eds.), A guide to faculty development (pp.259-274). San Francisco, CA: Jossey-Bass.

Lewin, K. (1947) Frontiers in group dynamics. Human Relations, 1(1), 5-41.

Lewis, K.G. (1996). Faculty development in the United States: A brief history. International Journal for Academic Development, 1(2), 26-33. doi: $10.1080 / 1360144960010204$ 
Lieberman, D. (2005). Beyond faculty development: How centers for teaching and learning can be laboratories for learning. New Directions for Higher Education, 131, 87-98.

Louziotis, D. (2000). The role of adjuncts: Bridging the dark side and ivory tower. Review of Business, 21(3), 47-52.

Lyons, R.E. (Ed.). (2007). Best practices for supporting adjunct faculty. Bolton, MA: Anker.

Maisto, M. (2012). Taking heart, taking part: New faculty majority and the praxis of contingent faculty activism. In A. Kezar (Ed.), Embracing non-tenure track faculty: Changing campuses for the new faculty majority (pp. 190-204). New York, NY: Routledge.

Marion, R., \& Gonzales, L.D. (2014). Leadership in education: Organizational theory for the practitioner (2nd ed.). Long Grove, IL: Waveland Press, Inc.

Maslach, C., \& Leiter, M.P. (1997). The truth about burnout: How organizations cause personal stress and what to do about it. San Francisco, CA: Jossey-Bass.

Maslow, A.H. (1970). Motivation and personality (2nd ed.). New York: Harper Collins. Maxwell, J.A. (2013). Qualitative research design: An interactive approach. Los Angeles, CA: SAGE Publications, Inc.

McKee, C.W., Johnson, M., Ritchie, W.F., \& Tew, M. (2013). Professional development of the faculty: Past and present. In C.W. McKee, M. Johnson, W.F. Ritchie, \& W.M. Tew (Eds.), The breadth of current faculty development: Practitioners' perspectives (pp.15-20). San Francisco, CA: Jossey Bass. 
Merriam, S.B., \& Bierema, L.L. (2013). Adult learning: Linking theory and practice. San Francisco, CA: Jossey-Bass.

Merriam, S.B., \& Tisdell,E.J. (2016). Qualitative research: A guide to design and implementation (4th ed.). San Francisco, CA: Jossey-Bass.

Messina, L.S. (2011). Examining an adjunct faculty professional development program model for a community college. ProQuest Dissertations Publishing. Retrieved from https://search-proquest-com.proxy.lib.pdx.edu/docview/879634649

Musu-Gillette, L., de Brey, C., McFarland, J., Hussar, W., Sonnenberg, W., \& Wilkinson-Flicker, S. (2017). Status and trends in education of racial and ethnic groups 2017. National Center for Education Statistics. Retrieved from https://nces.ed.gov/pubs2017/2017051.pdf

National Center for Education Statistics. (2018). Number of faculty in degree-granting postsecondary institutions, by employment status, sex, control, and level of institution: Selected years, fall 1970 through fall 2017. Digest of Education Statistics. Retrieved from https://nces.ed.gov/programs/digest/d18/tables/dt18_315.10.asp

O’Meara, K., Terosky, A. L., \& Neumann, A. (2008). Faculty careers and work lives: A professional growth perspective. ASHE Higher Education Report, 34(3), 1-221.

Office of Institutional Research and Planning. (n.d.). Common data set 2018-2019. Retrieved from https://www.pdx.edu/researchplanning/sites/g/files/znldhr2096/files/2020-12/CDS_2018-2019_UPDATED.pdf 
Office of Institutional Research and Planning. (2018). Instructional and non-instructional faculty. Portland State University. Retrieved from http://tableau.services.pdx.edu/Personnel/Instructional\%20and\%20NonInstructional\%20Faculty.html

Office of Institutional Research and Planning. (2021). Total End of Fall Term Enrollment Profile. Portland State University. https://www.pdx.edu/research-planning/totalenrollment-trends

Ouellett, M.L. (2010). Overview of faculty development: History and choices. In K.J. Gillespie \& D.L. Robertson (Eds.), A guide to faculty development (2nd ed.) (pp 3-20). San Francisco, CA: Jossey Bass.

Perez, A.M., McShannon, J., \& Hynes, P. (2012). Community college faculty development program and student achievement. Community College Journal of Research and Practice, 36(5), 379-385. doi:10.1080/10668920902813469

Portland State University. (2015). Collective bargaining agreement between Portland State University Faculty Association, local 3571 American Federation of Teachers, AFL-CIO and Portland State University, Portland, Oregon for the period July 1, 2015 through June 30, 2020. Retrieved from https://www.pdx.edu/hr/sites/www.pdx.edu.hr/files/AFTCBA-CBA-9-1216_Formatted_no\%20signatures.pdf

Portland State University. (2017). Policies and procedures for the evaluation of faculty for tenure, promotion, and merit increases. Retrieved from https://www.pdx.edu/academic-affairs/sites/www.pdx.edu.academic- 
PROFESSIONAL GROWTH

affairs/files/2017\%20P\%26T\%20Guidelines\%20and\%202017\%20PTR\%20Guide lines\%20FINAL.pdf

Portland State University. (2018). Adjunct Teaching Multi-Year Letter of Offer. Portland State University: Letters of Offer. Retrieved from https://drive.google.com/file/d/1-QW69Pc9-9by0DRyqFh5iIJ83nCv2ZZT/view

Portland State University. (2021). Mission. https://www.pdx.edu/portland-stateuniversity-mission

Portland State University Faculty Association (2019). [PSUFA 2020 Bargaining Survey]. Unpublished raw data.

Portland State University Faculty Association. (2020). Public comment submissions to the board of trustees for the April 9, 2020 meeting: The adjunct experience, letters to the PSU board of trustees. Retrieved April 9, 2020, from https://drive.google.com/file/d/1YltbuNvkzfIBC0Rng_uqUWXzHfU-FJ-w/view

Roueche, J.E., Roueche, S.D., Milliron, M.D. (1995). Strangers in their own land: Parttime faculty in American community colleges. Washington, D.C.: Community College Press.

Roueche, J.E., Roueche, S.D., \& Milliron, M.D. (1996). Identifying the strangers: Exploring part-time faculty integration in American community colleges. Community College Review, 23(4).

Saldaña, J. (2009). The coding manual for qualitative researchers. Los Angeles, CA: Sage Publications. 
Schein, E.H. (2010). Organizational culture and leadership ( $4^{\text {th }}$ ed.). San Francisco, CA: Jossey-Bass.

Schmidt, P. (2012). Accreditation eyed as a means to aid adjuncts. Chronicle of Higher Education, 58(30), A1-A10.

Schreier, M. (2012). Qualitative content analysis in practice. London, England: SAGE Publications Ltd.

Schreier, M. (2014). Qualitative content analysis. In U. Flick (Ed.), The SAGE Handbook of qualitative data analysis (pp. 170-183). London, England: SAGE Publications Ltd.

Seidman, I. (2013). Interviewing as qualitative research: A guide for researchers in education and the social sciences. New York, NY: Teachers College Press.

Smith, M., \& Wright, D. (2000). Orientation of adjunct and part-time faculty: Exemplary models. In D.E. Greive \& C.A Worden (Eds.), Managing adjunct and part-time faculty for the new millenium (pp.45-69). Elyria, OH: Info-Tec.

Snyder, T.D., de Brey, C., \& Dillow, S.A. (2016a). Digest of education statistics 2014. National Center for Education Statistics. Retrieved from https://nces.ed.gov/pubs2016/2016006.pdf

Snyder, T.D., de Brey, C., \& Dillow, S.A. (2016b). Digest of Education Statistics 2015. National Center for Education Statistics. Retrieved from https://nces.ed.gov/pubs2016/2016014.pdf 
Snyder, T.D., de Brey, C., \& Dillow, S.A. (2018). Digest of education statistics 2016. National Center for Education Statistics. Retrieved from https://nces.ed.gov/pubs2017/2017094.pdf

Sorcinelli, M.D., Austin, A.E., Eddy, P.L., \& Beach, A.L. (2006). Creating the future of faculty development: Learning from the past, understanding the present. Bolton, MA: Anker Publishing Company.

Strauss, A.L. (1987). Qualitative analysis for social scientists. Cambridge, UK: Cambridge University Press.

Street, S., Maisto, M. Merves, E., \& Rhoades, G. (2012). Center for the Future of Higher Education Policy Report \#2: Who is professor "staff" and how can this person teach so many classes?. Center for the Future of Higher Education. Retrieved from http://www.nfmfoundation.org/ProfStaffFinal.pdf

Tarr, T. (2010). Working with adjunct faculty members. In K.J. Gillespie \& D.L. Robertson (Eds.), A guide to faculty development (2nd. ed.). (pp.347-362). San Francisco, CA: Jossey-Bass.

Thirolf, K.Q. (2017). Reconceptualizing a more inclusive faculty engagement model: Including and engaging part-time faculty at community colleges. Community College Journal of Research and Practice, 41(4-5), 303-310. doi:10.1080/10668926.2016.1251357

Tierney, W. G. (1988). Organizational culture in higher education: Defining the essentials. Journal of Higher Education, 59(1), 2-21. 
Tierney, W.G. (2004). Academic freedom and tenure: Between fiction and reality. The Journal of Higher Education, 75(2), 161-177.

Tierney, W.G. (2011). The impact of culture on organizational decision-making: Theory and practice in higher education. Sterling, VA: Stylus Publishing.

Tinto, V. (1993). Leaving college: Rethinking the causes and cures of student attrition (2nd ed.). Chicago, IL: University of Chicago Press.

Tuckman, H.P. (1978). Who is part-time in academe? American Association of University Professors, 64(4), 305-315.

Tyree, L.W., Grunder, P., O’Connell, A. (2000). Mending the rift between full and parttime faculty. Community College Journal, 70(4), 24-28.

Umbach, P. (2007). How effective are they? Exploring the impact of contingent faculty on undergraduate education. Review of Higher Education, 30(2), 91-123.

Valentine, J.C., Konstantopoulos, S., \& Goldrick-Rab, S. (2017). What happens to students placed into developmental education? A meta-analysis of regression discontinuity studies. Review of Educational Research, 87(4), 806-833. doi:10.3102/0034654317709237

West, E. (2010). Managing adjunct professors: Strategies for improved performance. Academy of Educational Leadership Journal, 14(4), 21-36.

Yin, R.K. (2018). Case study research and applications: Design and methods. Thousand Oaks, CA: SAGE Publications, Inc. 
Appendix A: Case Study Graphic

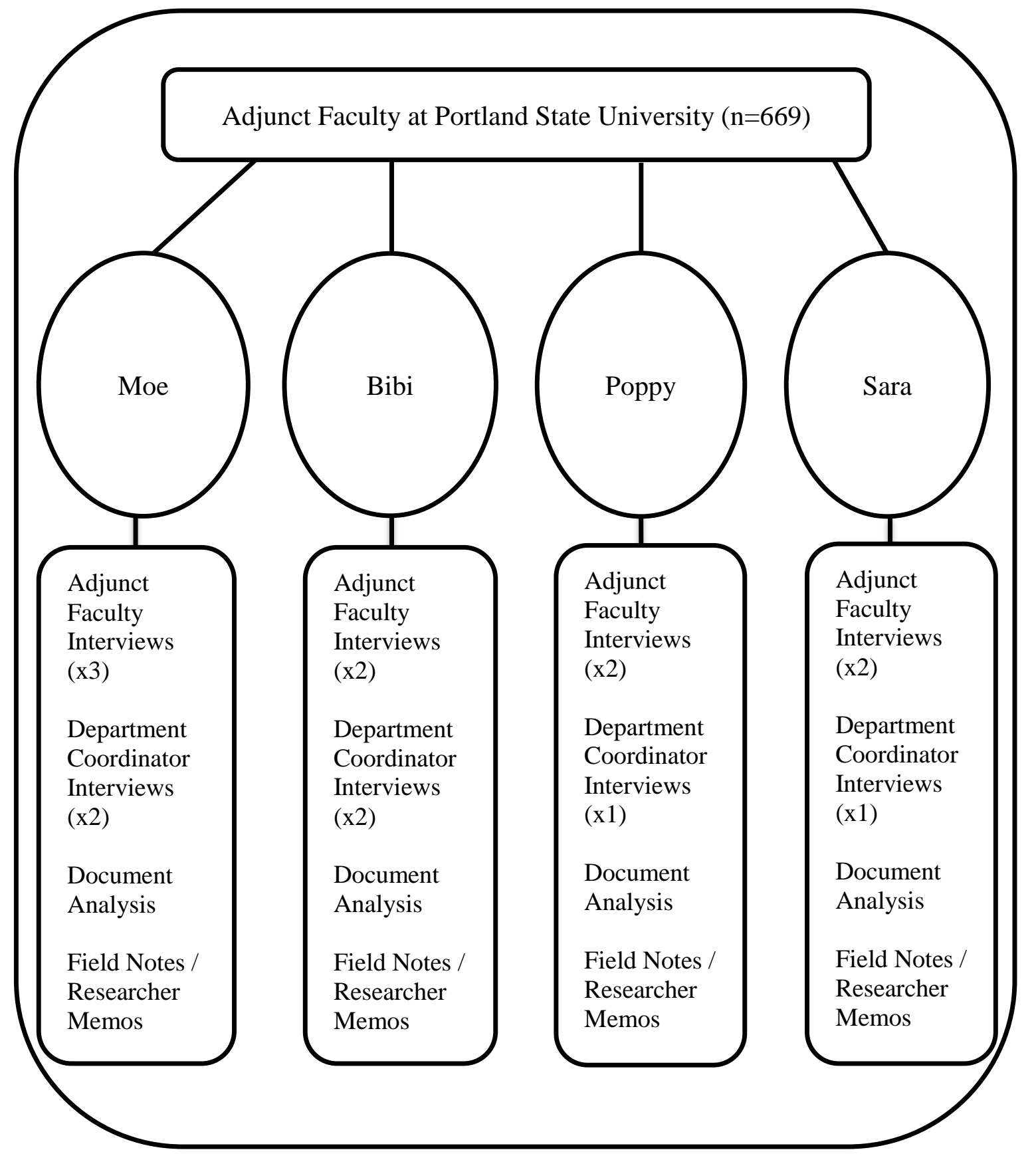


Appendix B: Data Collection/Analysis Timeline

\begin{tabular}{|c|c|}
\hline Dates & Associated Items \\
\hline $\begin{array}{l}\text { November/December } \\
2019\end{array}$ & $\begin{array}{l}\text { - Participant Recruitment } \\
\text { - Pilot Interviews (x2) }\end{array}$ \\
\hline $\begin{array}{l}\text { Winter Quarter } 2020 \\
\text { (January-March) }\end{array}$ & $\begin{array}{l}\text { - } \text { Adjunct faculty In-Person Interviews (x9) } \\
\text { - } \text { Department Coordinator In-Person Interviews (x3) } \\
\text { - } \text { Adjunct Faculty Outreach/Recruitment } \\
\text { - Ongoing: Document gathering (from both adjunct } \\
\text { faculty and department coordinators); Create } \\
\text { interview transcriptions; data analysis of interview } \\
\text { transcripts; field notes; memos }\end{array}$ \\
\hline $\begin{array}{l}\text { Spring Quarter } 2020 \\
\text { (late-March-June) }\end{array}$ & $\begin{array}{l}\text { - IRB Amendment (for online interviews due to } \\
\text { COVID-19) } \\
\text { - Department Coordinator Zoom Interview (x1) } \\
\text { Ongoing: Document gathering (from both adjunct } \\
\text { faculty and department coordinators); Create } \\
\text { interview transcription; data analysis of interview } \\
\text { transcript; field notes; memos }\end{array}$ \\
\hline $\begin{array}{l}\text { Summer Quarter } 2020 \\
\text { (June-September) }\end{array}$ & $\begin{array}{l}\text { - Department Coordinator Zoom Interviews (x2) } \\
\text { - Department Coordinator Outreach/Recruitment } \\
\text { Ongoing: Document gathering (from both adjunct } \\
\text { faculty and department coordinators); Create } \\
\text { interview transcriptions; data analysis of interview } \\
\text { transcripts; field notes; memos }\end{array}$ \\
\hline $\begin{array}{l}\text { Fall Quarter 2020 } \\
\text { (September 2020) }\end{array}$ & $\begin{array}{l}\text { - Document gathering \& Analysis (QCA) } \\
\text { Data analysis of all interviews (adjuncts \& department } \\
\text { coordinators) }\end{array}$ \\
\hline $\begin{array}{l}\text { Winter Quarter } 2021 \\
\text { (January-March 2021) }\end{array}$ & $\begin{array}{l}\text { - Data analysis (interviews \& QCA) } \\
\text { - Writing (Findings) }\end{array}$ \\
\hline $\begin{array}{l}\text { Spring Quarter } 2021 \\
\text { (late-March-June) }\end{array}$ & $\begin{array}{l}\text { - Writing (Findings \& Discussion) } \\
\text { - End of Study }\end{array}$ \\
\hline
\end{tabular}




\section{Appendix C: Emails to Participants}

\section{Email Invitation to Adjunct Faculty for Participation in In-Person Interviews:}

Hi [Adjunct Faculty Name],

My name is Bethany Potts and I am a doctoral candidate studying Postsecondary Educational Leadership at Portland State University in the College of Education.

As an adjunct faculty member at PSU, I am writing to ask you to consider participating in my doctoral research study titled, "An Exploratory Study of how Institution-Facilitated Professional Development Shapes the Adjunct Experience." I am interested in exploring how adjunct faculty at Portland State University experience institution-facilitated professional development and instructional support, including motivators for participation and subsequent implications of participation. In order to explore this area of inquiry, I will conduct individual interviews with adjunct faculty members, interviews with department coordinators, as well as document analysis of institutional policies.

As part of my research, I would like to invite you to participate in a series of two individual 60 minute in-person interviews during which we will discuss your past and current experiences as an adjunct faculty member at Portland State University. A focus on your experiences with institution-facilitated professional development and instructional support will be prioritized. The interviews will take place during the winter 2020 quarter, with specific scheduling dependent on your individual availability.

Your participation in this study will be kept confidential and will not affect your work or be reported back to your supervisor or any other individuals within your academic department or at this institution. Participation is completely voluntary and responses will be recorded without identifying information. A pseudonym will be used in place of your name in all interview transcripts, researcher memos, data analysis, the final report, and any subsequent papers or presentations. As thanks for your participation, you will be compensated with a $\$ 40$ Visa gift card following the second interview (\$20 per interview).

If you are willing to participate in this study through two in-person 60-minute interviews, please complete [GOOGLE FORM LINK] with your availability by [DATE]. If you have any questions, don't hesitate to contact me at [my email address] or by phone at (xxx) $\mathrm{xxX}-\mathrm{Xxxx}$.

Thank you!

Best, Bethany Potts 
Email Invitation to Department Coordinators for Participation:

Dear [Department Coordinator Name],

My name is Bethany Potts and I am a doctoral candidate studying Postsecondary Educational Leadership at Portland State University in the College of Education. I hope this message finds you safe and well.

I am writing to ask you to consider participating in my doctoral research study titled, "An Exploratory Study of how Institution-Facilitated Professional Development Shapes the Adjunct Experience." I am interested in exploring how adjunct faculty at Portland State University experience institution-facilitated professional development and instructional support, including motivators for engagement. In order to explore this area of inquiry, I am conducting individual interviews with adjunct faculty members, interviews with department administrators (i.e. individuals who support faculty work and/or who are identified as key contacts by the interviewed adjunct faculty), as well as document analysis of institutional policies.

As part of my research, I would like to ask you about your work as the [TITLE] in the [ACADEMIC UNIT NAME] through one 60-minute interview. Your name was identified by at least one adjunct faculty participant in this study as a key individual who supports adjunct work in the department, including connection to information and resources. Based on that role, you will provide valuable insight into past and current policies and procedures that shape the adjunct faculty experience at this university.

Your participation in this study will be kept confidential and will not affect your work or be reported back to any individuals at this institution. Participation is completely voluntary and responses will be recorded without identifying information. A pseudonym will be used in place of your name in all interview transcripts, researcher memos, data analysis, the final report, and any subsequent papers or presentations. As thanks for your participation, you will be compensated with a $\$ 20$ Visa gift card at the conclusion of our interview.

If you are willing to participate through one 60-minute interview, please complete [GOOGLE FORM LINK] with your availability. If you have any questions, don't hesitate to contact me at [my email address] or by phone at $(\mathrm{xxx}) \mathrm{xxx}-\mathrm{xxxx}$..

Thank you for your consideration and I hope to speak with you soon.

Best, Bethany Potts 


\section{Appendix D: Adjunct Faculty Interview Protocol}

Note: Interview protocol is included below for two interviews with adjunct faculty. As semi-structured interviews, the questions provide a potential structure around identified themes. The researcher will ask additional questions, as needed, in line with the guiding research questions for the study.

\section{Interview \#1 - Demographic Data}

Interview Sequence:

- Thank the adjunct faculty member for participating in the study.

- Say: Your participation in this study is voluntary and you are able to withdraw at any point. I'm going to start with an overview of this study and then I will provide you with an informed consent form.

- Review the focus, design, and rationale for the study

- Informed consent form review

- Say: I will be recording our conversation today in order to better support my analysis of your information provided. I will be using two devices, to ensure that the information is captured: Otter.ai and this manual recorder.

- Review key definitions: Adjunct faculty, professional growth, professional development

- Questions

\begin{tabular}{|l|l|}
\hline $\begin{array}{l}\text { Potential Anchor } \\
\text { Question(s) }\end{array}$ & Potential Follow-Up Questions \\
\hline
\end{tabular}

Focus: Context for professional capacity at PSU; typology of adjunct roles

1. How long have you been a. IF LESS THAN 2 YEARS: During that time, have you an instructor at Portland State?

taught at least 8 credits?

b. IF AT LEAST THREE YEARS: Following completion of your third year (or 20 credits), were you offered an evaluation by your Department chair in order to establish a multi-year (2 yr) appointment?

b1. If Yes: Please tell me more about that evaluation process. How were the expectations of that process communicated to you?

b2. If you were offered a multi-year appointment, how has that impacted your work within the department? 


\begin{tabular}{|c|c|c|}
\hline & \multicolumn{2}{|c|}{$\begin{array}{l}\text { c. Have you taught undergraduate courses, graduate } \\
\text { courses, or a combination of the two? } \\
\text { d. What is your title at PSU? }\end{array}$} \\
\hline $\begin{array}{l}\text { 2. Please tell me about } \\
\text { your prior academic } \\
\text { experiences. }\end{array}$ & \multicolumn{2}{|c|}{$\begin{array}{l}\text { a. In what field(s) have you previously earned degrees? } \\
\text { b. What is your highest degree earned? } \\
\text { c. Do you have any specialized certificates? }\end{array}$} \\
\hline $\begin{array}{l}\text { 3. During your time at } \\
\text { PSU, in which } \\
\text { departments have you } \\
\text { taught? }\end{array}$ & \multicolumn{2}{|c|}{$\begin{array}{l}\text { a. Are there any key differences that you would identify } \\
\text { between your work as an adjunct faculty member in each } \\
\text { department? }\end{array}$} \\
\hline $\begin{array}{l}\text { 4. Of the classes that you } \\
\text { have taught, were any } \\
\text { hybrid or fully online } \\
\text { classes? }\end{array}$ & $\begin{array}{l}\text { IF YES: } \\
\text { a1. Please tell me a little } \\
\text { more about that. Were } \\
\text { you previously familiar } \\
\text { with teaching hybrid or } \\
\text { online classes? } \\
\text { a2. What support or } \\
\text { training was provided in } \\
\text { preparation for that/those } \\
\text { class(es)? }\end{array}$ & $\begin{array}{l}\text { IF NO: } \\
\text { b1. Have you taught hybrid or } \\
\text { online classes at other } \\
\text { institutions? } \\
\text { b2. What is your level of } \\
\text { familiarity with the learning } \\
\text { management system, D2L, at } \\
\text { PSU? } \\
\text { b3. What support was offered } \\
\text { on D2L when you were hired? }\end{array}$ \\
\hline $\begin{array}{l}\text { 5. Do you currently or have } \\
\text { you previously served in } \\
\text { any other professional } \\
\text { capacities at PSU (for } \\
\text { example, as a staff } \\
\text { member)? }\end{array}$ & $\begin{array}{l}\text { a. IF YES: } \\
\text { What impact did that role } \\
\text { have on your experience } \\
\text { as an instructor at PSU? }\end{array}$ & $\begin{array}{l}\text { b. IF NO: } \\
\text { Have you pursued employment } \\
\text { in other capacities at PSU } \\
\text { and/or are you interested in } \\
\text { serving in other professional } \\
\text { capacities at PSU (i.e., as a } \\
\text { staff member, administrator, } \\
\text { full-time faculty, etc.)? }\end{array}$ \\
\hline $\begin{array}{l}\text { 6. While an instructor at } \\
\text { PSU, have you also } \\
\text { taught at other 2- or 4- } \\
\text { year } \\
\text { colleges/universities? }\end{array}$ & \multicolumn{2}{|c|}{$\begin{array}{l}\text { IF YES: } \\
\text { a. Where? } \\
\text { b. At which institution did you teach the largest credit } \\
\text { load? }\end{array}$} \\
\hline
\end{tabular}




\begin{tabular}{|l|l|}
\hline & $\begin{array}{l}\text { c. How did/does teaching on multiple campuses impact } \\
\text { your instruction at PSU? (i.e., benefits, challenges, etc.) }\end{array}$ \\
\hline $\begin{array}{l}\text { 7. While an instructor at } \\
\text { PSU, have you been/are } \\
\text { you employed in another } \\
\text { capacity outside of the } \\
\text { university? }\end{array}$ & $\begin{array}{l}\text { IF YES: } \\
\text { a. In what capacity/where? }\end{array}$ \\
$\begin{array}{l}\text { b. What would you identify as your primary profession } \\
\text { (i.e., in what role do you spend the majority of your } \\
\text { professional time?)? }\end{array}$ \\
$\begin{array}{l}\text { c. How does your work outside of PSU impact your } \\
\text { instruction at PSU? (i.e., benefits, challenges, etc.) }\end{array}$ \\
\hline
\end{tabular}

Focus: Onboarding; professional integration; professional support

8. Describe your onboarding experience for me. a. What training was provided on institutional processes, including: expectations for faculty, contact information for on-campus resources, course dates? Who provided that information?

a1. What institutional resources were you connected with?

b. What training was provided on technical processes and procedures, including: how to access the LMS, how to access email, how to order books, how to submit final grades? Who provided that information?

c. Part of my study includes document analysis of written institutional policies and documented resources for adjunct faculty. Do you have copies of any written expectations and/or resources that were provided (emails, etc.) that you would be willing to share with me?

IF YES: Thank you! Please bring any documents to our next interview and/or feel free to email them to me in advance.

9. Who are your main points of contact at PSU (i.e. with which employees do you interact with most)? a. How did you meet that/those individual(s)?

b. Describe your relationship. Under what circumstances do you most commonly interact?

c. Is there someone who you most commonly turn to in order to access information? Who are they? What is their role? Why do you turn to them? 


\begin{tabular}{|c|c|c|}
\hline $\begin{array}{l}\text { 10. What opportunities do } \\
\text { you have for connection } \\
\text { with other faculty at } \\
\text { PSU (in/outside of your } \\
\text { department)? }\end{array}$ & \multicolumn{2}{|c|}{$\begin{array}{l}\text { a. I would like to know more about that opportunity. Why } \\
\text { would you choose to participate in that experience? Is it a } \\
\text { required part of your role? } \\
\text { b. What impact does interaction or a lack of interaction } \\
\text { with other faculty have on your work as an instructor } \\
\text { at PSU? }\end{array}$} \\
\hline $\begin{array}{l}\text { 11. Have you previously } \\
\text { attended department } \\
\text { meetings within your } \\
\text { unit? }\end{array}$ & $\begin{array}{l}\text { IF YES: } \\
\text { a1. What prompted your } \\
\text { attendance? (i.e., was it } \\
\text { mandatory, paid, etc.) } \\
\text { a2. Would you describe your } \\
\text { attendance at department } \\
\text { meetings as impactful for } \\
\text { your role as an instructor? If } \\
\text { so, why? If not, why not? }\end{array}$ & $\begin{array}{l}\text { IF NO: } \\
\text { b1. Are you invited to } \\
\text { department meetings? If so, } \\
\text { why didn't you attend? }\end{array}$ \\
\hline $\begin{array}{l}\text { 12. Have you previously } \\
\text { served on a committee at } \\
\text { PSU? }\end{array}$ & $\begin{array}{l}\text { IF YES: } \\
\text { a1. What prompted your } \\
\text { participation? } \\
\text { a2. What impact, if any, has } \\
\text { that experience had on your } \\
\text { role as an instructor at PSU? }\end{array}$ & $\begin{array}{l}\text { IF NO: } \\
\text { b1. Have you been invited to } \\
\text { participate on a committee } \\
\text { and/or are you aware of } \\
\text { opportunities to participate? } \\
\text { b2. Would you be interested } \\
\text { in serving on a committee at } \\
\text { PSU, if the opportunity } \\
\text { arose? If not, why not? }\end{array}$ \\
\hline $\begin{array}{l}\text { 13. Do you have access to a } \\
\text { physical office space on } \\
\text { campus at PSU where } \\
\text { you can work? }\end{array}$ & $\begin{array}{l}\text { IF YES: } \\
\text { a1. If so, please describe that } \\
\text { space. } \\
\text { a2. How often do you work } \\
\text { from that space? } \\
\text { a3. What work do you do in } \\
\text { that space? }\end{array}$ & $\begin{array}{l}\text { IF NO: } \\
\text { b1. If a space was provided, } \\
\text { would you choose to work } \\
\text { from it? } \\
\text { b2. Do you have a specific } \\
\text { space on campus at PSU } \\
\text { where you prefer to meet } \\
\text { with students, grade, plan, } \\
\text { etc. (i.e., the library, a } \\
\text { classroom, etc.)? }\end{array}$ \\
\hline
\end{tabular}




\begin{tabular}{|c|c|}
\hline $\begin{array}{l}\text { 14. Describe your } \\
\text { experience with } \\
\text { professional } \\
\text { development at PSU. }\end{array}$ & \begin{tabular}{|l} 
a. How do you learn about PD opportunities at PSU? \\
b. Have you participated in any in-person professional \\
development experiences, facilitated by PSU? \\
b1. If so, what were those experiences? \\
b2. Why did you participate in that/those PD \\
experience(s)? \\
b3. What impact did your participation have on \\
your practice as an adjunct faculty member? \\
b3. Were you compensated for your time? \\
c. Have you participated in any online professional \\
development experiences, facilitated by PSU? \\
c1. If so, what were those experiences? \\
c2. Why did you participate in those experiences? \\
c3. What impact did your participation have on \\
your practice as an adjunct faculty member? \\
c3. Were you compensated for your time? \\
d. Yes or No: The professional development and training \\
available to me at PSU fits my needs as an adjunct faculty \\
member. Why/why not?
\end{tabular} \\
\hline $\begin{array}{l}\text { 15. Please describe the } \\
\text { experience that you } \\
\text { would identify as the } \\
\text { most impactful learning } \\
\text { opportunity for your } \\
\text { practice as an instructor. }\end{array}$ & $\begin{array}{l}\text { a. What was the focus of that learning experience? } \\
\text { b. Who facilitated the experience (i.e., what department } \\
\text { and/or office on campus)? } \\
\text { c. How did you hear about it? } \\
\text { d. What was your motivation for attending? } \\
\text { e. What was the format? } \\
\text { f. IF RELEVANT: What other faculty were participating } \\
\text { in the experience? } \\
\text { g. Why do you identify that experience as the most } \\
\text { impactful? } \\
\text { h. What impact did that experience have on your work as } \\
\text { an adjunct faculty member at PSU? }\end{array}$ \\
\hline
\end{tabular}




\begin{tabular}{|c|c|}
\hline & $\begin{array}{l}\text { i. If the opportunity should arise, would you choose to } \\
\text { participate in a similar experience again? Why/why not? }\end{array}$ \\
\hline $\begin{array}{l}\text { 16. Do you have a preferred } \\
\text { format when engaging in } \\
\text { PD (i.e. in-person, } \\
\text { online synchronous vs } \\
\text { asynchronous, etc.)? If } \\
\text { so, why do you prefer } \\
\text { that format? }\end{array}$ & $\begin{array}{l}\text { a. In what format is PD within your department most } \\
\text { commonly offered? } \\
\text { b. In what format is PD outside of your department (i.e., } \\
\text { through OAI, HR, etc.) most commonly offered? } \\
\text { c. In your experience, what topic(s) should be prioritized } \\
\text { for adjunct faculty professional development and training } \\
\text { experiences? } \\
\text { c1. Why did you choose that topic? }\end{array}$ \\
\hline $\begin{array}{l}\text { 17. Yes or No: In my role as } \\
\text { an adjunct faculty } \\
\text { member at PSU, I feel } \\
\text { supported and valued by } \\
\text { my department. }\end{array}$ & $\begin{array}{l}\text { a. Tell me more. What examples support that response. } \\
\text { b. What impact does that level of value and support have } \\
\text { on your work as a faculty member? } \\
\text { IF NO: } \\
\text { c. What changes would be needed in order to make you } \\
\text { feel supported and valued by your department. }\end{array}$ \\
\hline
\end{tabular}

- Thank you again for taking the time to share with me about your experiences.

- Our second interview will be on [INSERT DATE HERE] and during that time, we will focus on the essential element of Professional Growth that I defined at the start of our interview. This will include your individual goals as an instructor and specific experiences and expectations at the university that support you in pursuit of those goals.

- Finally, if you do have any documents that you would like to share that better help to illustrate your experience, including onboarding materials or other expectations from your department, please feel free to bring them to our second interview OR email them to me in advance.

Interview \#2 - Professional Development and Professional Growth Experiences Interview structure:

- Recap focus from the first interview

- Provide a topical overview for this second interview

- Say: Our interview today will focus more closely on your Professional Growth as an adjunct faculty member. This will include your individual goals as an instructor and specific experiences and expectations at the university that impact your pursuit of those goals. 
- Refreshing definitions: adjunct faculty; professional development; professional growth, pedagogy (new term for interview 2)

- Questions

\section{Potential Question(s)}

Focus: Professional Growth; Institutional Mission; Teaching Philosophy; Collegial Interactions; Commendations

18. How would you describe the mission of PSU? a. As an adjunct faculty member, how has this mission been communicated to you?

b. In your experience, how is this mission enacted? c. As an adjunct faculty member, what is your role within the mission of PSU (i.e., how do you contribute to that mission)?

19. What is your pedagogy as a teacher?

a. What do you think has informed and impacted that pedagogy (i.e., prior experiences, external expectations, etc.)?

20. In your role at PSU, what expectations does your department have for you (i.e., instructional choices, syllabi, participation in specific PD, etc.)?

21. Describe your process of planning for a course at the start of the term. What does that look like for you? a. How are those expectations communicated to you?

b. If you have questions about departmental expectations, how do you access that information?

a. Do you most commonly work alone or with others? Why?

b. Follow-up: What resources are provided to you from your department?

b1. How did you learn about those resources?

b2. Do you use those resources? b2a. If so, how and why? b2b. If no: Why don't you use the provided resources?

c. What resources are provided to you at PSU, outside of your department?

c1. How did you learn about those resources?

c2. Do you use those resources? c2a. If so, how and why? 


\begin{tabular}{|c|c|c|}
\hline & \multicolumn{2}{|c|}{$\begin{array}{l}\text { c2b. If no: Please tell me more about that. } \\
\text { Why don't you use the provided resources? }\end{array}$} \\
\hline $\begin{array}{l}\text { 22. Throughout the term, what } \\
\text { interactions do you have with } \\
\text { other individuals in and } \\
\text { outside of your department at } \\
\text { PSU? }\end{array}$ & \multicolumn{2}{|c|}{$\begin{array}{l}\text { a. How do those interactions impact your work as an } \\
\text { instructor? } \\
\text { b. Are there other ways in which you would prefer to } \\
\text { interact with colleagues at PSU? If so, how/why? }\end{array}$} \\
\hline $\begin{array}{l}\text { 23. In our first interview, you } \\
\text { mentioned that you } \\
\text { participated in the review } \\
\text { process for a multi-year } \\
\text { contract. I'd like to talk a little } \\
\text { more about that. }\end{array}$ & \multicolumn{2}{|c|}{$\begin{array}{l}\text { a. As an adjunct faculty member with a multi-year } \\
\text { fixed-term contract, what differences, if any, exist for } \\
\text { you professionally with this new contract? } \\
\text { b. How does this contract impact your work as an } \\
\text { adjunct instructor? } \\
\text { c. Are there any changes that you would make to the } \\
\text { process? If so, what are they? Why would you suggest } \\
\text { those changes? } \\
\text { d. As an adjunct faculty member, what other } \\
\text { opportunities are you aware of for promotion within } \\
\text { your department? Would you be interested in pursuing } \\
\text { those opportunities? Why/why not? }\end{array}$} \\
\hline $\begin{array}{l}\text { 24. Have you received any } \\
\text { awards in acknowledgement } \\
\text { of your instruction and/or } \\
\text { your research while an adjunct } \\
\text { faculty member at PSU? }\end{array}$ & $\begin{array}{l}\text { IF YES: } \\
\text { a1. What awards have you } \\
\text { received? Have new opportunities } \\
\text { emerged as a result of receiving } \\
\text { that award? If so, what? } \\
\text { a2. FOR ADJUNCT } \\
\text { EXCELLENCE AWARD } \\
\text { RECIPIENTS: As a prior } \\
\text { recipient of an adjunct faculty } \\
\text { excellence award, I'm curious to } \\
\text { know more about your } \\
\text { experience. Why were you } \\
\text { nominated for the award? Were } \\
\text { you publicly honored? }\end{array}$ & $\begin{array}{l}\text { IF NO: } \\
\text { b1. Are you familiar } \\
\text { with any awards or } \\
\text { commendations at } \\
\text { PSU for adjunct } \\
\text { faculty? }\end{array}$ \\
\hline \multicolumn{3}{|c|}{ Focus: Professional Goals; Career Planning } \\
\hline $\begin{array}{l}25 . \text { We briefly discussed this } \\
\text { in our first interview, but }\end{array}$ & & \\
\hline
\end{tabular}




\begin{tabular}{|c|c|}
\hline $\begin{array}{l}\text { please describe your prior } \\
\text { professional experiences to } \\
\text { me (i.e. what did you do, } \\
\text { professionally, prior to } \\
\text { pursuing employment as an } \\
\text { adjunct at PSU)? }\end{array}$ & \\
\hline $\begin{array}{l}\text { 26. Why did you choose to } \\
\text { pursue employment as a part- } \\
\text { time instructor at PSU? }\end{array}$ & $\begin{array}{l}\text { Follow-up here with additional questions, based on their } \\
\text { response. } \\
\text { Example: } \\
\text { If they share that they are interested in full-time faculty } \\
\text { work: Tell me more about your interest in pursuing full- } \\
\text { time work. What steps are you taking to pursue that } \\
\text { goal? }\end{array}$ \\
\hline $\begin{array}{l}27 . \text { What does being an } \\
\text { adjunct faculty member mean } \\
\text { to you? }\end{array}$ & $\begin{array}{l}\text { a. Within that description that you provided, what do } \\
\text { you most resonate with and what would you prefer to } \\
\text { change? } \\
\text { b. Why do you continue to work as an adjunct faculty } \\
\text { member? }\end{array}$ \\
\hline $\begin{array}{l}\text { 28. In your experience at } \\
\text { PSU, what is the role of } \\
\text { adjunct faculty? }\end{array}$ & $\begin{array}{l}\text { a. What is an example from your experience that } \\
\text { supports that? } \\
\text { b. How is that role communicated to you? } \\
\text { b. Is this a role that is malleable? For example, in your } \\
\text { experience, what opportunities are provided to further } \\
\text { develop your role, whether that is beyond the classroom } \\
\text { or beyond a part-time capacity? } \\
\text { c. Does this role that you've identified serve or hinder } \\
\text { the work of the individuals who work as adjunct } \\
\text { faculty? }\end{array}$ \\
\hline $\begin{array}{l}29 . \text { What are your } \\
\text { professional goals as an } \\
\text { adjunct faculty member at } \\
\text { PSU? }\end{array}$ & $\begin{array}{l}\text { a. What impacts those goals? } \\
\text { b. At PSU, in what ways are you supported in pursuing } \\
\text { those goals? } \\
\text { c. Do you discuss your professional goals/interests } \\
\text { with anyone at PSU (i.e., department chair, faculty }\end{array}$ \\
\hline
\end{tabular}


mentor, colleague, staff member, etc.)? If so, who? Why?

- Thank you again for sharing about your experiences as an adjunct faculty member at PSU. I know that these conversations only provided a glimpse into your work and your experiences but it is my hope that your insights and this study will impact future experiences of adjunct faculty at PSU.

- As thanks for your participation, here is a $\$ 40$ (or \$60) Visa gift card. Please sign here to confirm that you received the card.

- Finally, if you do come across any documentation that you think might provide greater context for your experiences as an adjunct faculty member, please don't hesitate to send them my way.

- Thank you again for your participation. 


\section{Appendix E: Department Coordinator Interview Protocol}

Note: Interview protocol is included below for one interview with each department coordinator (titles vary). As semi-structured interviews, the questions provide a potential structure around identified themes. The researcher will ask additional questions, as needed, in line with the guiding research questions for the study. The department coordinator interview will take place after the first interview with the adjunct faculty member in the same academic unit.

Interview Sequence:

- Thank the department coordinator for participating in the study.

- Say: Your participation in this study is voluntary and you are able to withdraw at any point. I'm going to start with an overview of this study and then I will provide you with an informed consent form.

- Review the focus, design, and rationale for the study

- Informed consent form review

- Say: I will be recording our conversation today in order to better support my analysis of your information provided. I will be using two devices, to ensure that the information is captured: Otter.ai and this manual recorder.

- Review key definitions: Adjunct faculty, professional development

- Questions

\begin{tabular}{|c|l|}
\hline Potential Anchor Question(s) & Potential Follow-Up Questions \\
\hline Focus: Defining their role; department culture \\
\hline $\begin{array}{l}\text { 1. How long have you worked } \\
\text { as a [INSERT TITLE } \\
\text { HERE] at PSU? }\end{array}$ & $\begin{array}{l}\text { a. Have you been employed in other capacities } \\
\text { at PSU? If so, in what capacity(ies)? }\end{array}$ \\
\hline $\begin{array}{l}\text { 2. Please describe the key } \\
\text { responsibilities of your role. }\end{array}$ & $\begin{array}{l}\text { a. I'm interested in knowing more about that } \\
\text { the day to day? }\end{array}$ \\
& $\begin{array}{l}\text { b. Are there specific documents that formalize } \\
\text { those responsibilities for you and/or for the } \\
\text { faculty with whom you work? }\end{array}$ \\
\hline $\begin{array}{l}\text { How would you describe the } \\
\text { faculty culture of your } \\
\text { department? }\end{array}$ & $\begin{array}{l}\text { a. What are some examples of that culture? } \\
\text { b. What do you perceive as high priorities for } \\
\text { faculty in your department (i.e., research, } \\
\text { instruction, service, personal development, } \\
\text { etc.)? }\end{array}$ \\
\hline
\end{tabular}




\begin{tabular}{|c|c|}
\hline & $\begin{array}{l}\text { c. Are there any formalized policies around } \\
\text { faculty mentors for new faculty? }\end{array}$ \\
\hline \multicolumn{2}{|c|}{ Focus: Faculty Support; Onboarding; Professional Development } \\
\hline $\begin{array}{l}\text { 4. When a new faculty member } \\
\text { is hired in your department, } \\
\text { what is their onboarding } \\
\text { process? }\end{array}$ & $\begin{array}{l}\text { a. What does this process look like for full } \\
\text { versus part-time faculty? } \\
\text { b. What are the key priorities for your } \\
\text { department during the onboarding process? }\end{array}$ \\
\hline $\begin{array}{l}\text { 5. How do faculty in your } \\
\text { department most commonly } \\
\text { engage with training on } \\
\text { technologies for teaching } \\
\text { and learning? }\end{array}$ & $\begin{array}{l}\text { a. What resources are available in your } \\
\text { department (i.e., specific person, online } \\
\text { resources, etc.)? } \\
\text { b. Are faculty encouraged to access centralized } \\
\text { resources, including those offered through OAI? } \\
\text { Do faculty access these resources? Why/why } \\
\text { not? How do you think that this is the case? }\end{array}$ \\
\hline $\begin{array}{l}\text { 6. How do faculty in your } \\
\text { department most commonly } \\
\text { engage with professional } \\
\text { development opportunities at } \\
\text { PSU? }\end{array}$ & $\begin{array}{l}\text { a. For those external conferences and } \\
\text { workshops, are faculty reimbursed for } \\
\text { participation? Is this benefit available and/or } \\
\text { communicated with adjunct faculty? } \\
\text { b. How common is it for faculty to engage in PD } \\
\text { facilitated by PSU? How do faculty learn about } \\
\text { those experiences? } \\
\text { c. What is your perception of faculty motivators } \\
\text { for participating in PD in general? Is your } \\
\text { perception different for faculty participation in } \\
\text { PD specifically facilitated at/by PSU? }\end{array}$ \\
\hline $\begin{array}{l}\text { 7. How do faculty in your } \\
\text { department most commonly } \\
\text { access information about on- } \\
\text { campus resources for } \\
\text { students? }\end{array}$ & \\
\hline $\begin{array}{l}\text { 8. I heard that your department } \\
\text { offers [INSERT SPECIFIC } \\
\text { PD EXPERIENCE HERE] } \\
\text { for faculty. I'm curious to }\end{array}$ & $\begin{array}{l}\text { a. What faculty most commonly participate? } \\
\text { b. Is there any incentive for faculty to participate } \\
\text { in this experience? }\end{array}$ \\
\hline
\end{tabular}




\begin{tabular}{|c|c|}
\hline $\begin{array}{l}\text { know more about that } \\
\text { opportunity. }\end{array}$ & c. How do faculty learn about this experience? \\
\hline $\begin{array}{l}\text { 9. What opportunities exist in } \\
\text { your department for faculty } \\
\text { to interact with one another? }\end{array}$ & $\begin{array}{l}\text { a. Are department meetings open to all faculty? } \\
\text { If not, why not? }\end{array}$ \\
\hline $\begin{array}{l}\text { 10. Where are faculty offices } \\
\text { located in your department? }\end{array}$ & $\begin{array}{l}\text { a. Is there physical office space available for } \\
\text { adjunct faculty in your department? If so, where } \\
\text { is it located? }\end{array}$ \\
\hline \multicolumn{2}{|l|}{ Focus: Adjunct Faculty } \\
\hline $\begin{array}{l}\text { 11. What is your relationship } \\
\text { with the adjunct faculty in } \\
\text { your department? }\end{array}$ & $\begin{array}{l}\text { a. What interactions do you have with adjunct } \\
\text { faculty, in your role? How frequent are those } \\
\text { interactions? }\end{array}$ \\
\hline $\begin{array}{l}\text { 12. To your knowledge, is the } \\
\text { number of adjunct faculty } \\
\text { employed in your } \\
\text { department consistent with } \\
\text { prior years or has it } \\
\text { experienced an } \\
\text { increase/decrease? }\end{array}$ & $\begin{array}{l}\text { a. What is your perception of adjunct faculty } \\
\text { retention term-to-term or year-to-year? }\end{array}$ \\
\hline $\begin{array}{l}\text { 13. Are there specific } \\
\text { documented policies or } \\
\text { procedures within your } \\
\text { department for adjunct } \\
\text { faculty regarding training or } \\
\text { course planning? }\end{array}$ & \\
\hline $\begin{array}{l}\text { 14. What instructional resources } \\
\text { are available for adjunct } \\
\text { faculty in your department? }\end{array}$ & \\
\hline $\begin{array}{l}\text { 15. Are there specific meetings } \\
\text { within your department that } \\
\text { adjunct faculty are invited or } \\
\text { required to attend? If so, } \\
\text { what are they? }\end{array}$ & \\
\hline $\begin{array}{l}\text { 16. What is your perception of } \\
\text { adjunct faculty motivators }\end{array}$ & $\begin{array}{l}\text { a. What are some examples that support that } \\
\text { perception? }\end{array}$ \\
\hline
\end{tabular}




\begin{tabular}{|c|l|}
\hline $\begin{array}{l}\text { for working in your } \\
\text { department part-time? }\end{array}$ & \\
\hline $\begin{array}{l}\text { 17. How would you describe the } \\
\text { culture for adjunct faculty in } \\
\text { your department? }\end{array}$ & $\begin{array}{l}\text { a. Why would you describe it in that way? What } \\
\text { examples demonstrate that culture? }\end{array}$ \\
$\begin{array}{l}\text { b. What is the role of adjunct faculty in your } \\
\text { department? What is their purpose, within the } \\
\text { larger organizational culture of your } \\
\text { department? }\end{array}$ \\
\hline
\end{tabular}

- As thanks for your participation, here is a \$20 Visa gift card. Please sign here to confirm that you received the card.

- Finally, if you do come across any documentation that you think might provide greater context for your work with adjunct faculty, please don't hesitate to send them my way.

- Thank you again for your participation. 


\section{Appendix F: Document Inventory}

\begin{tabular}{|l|l|}
\hline Document Name & Origin \\
\hline Adjunct Responsibilities \#1 & Moe \\
\hline Adjunct Responsibilities \#2 & Moe \\
\hline First year GTA and Adjunct letter & Moe \\
\hline Adjunct Professional Evaluation Letter from Chair & Moe \\
\hline Notice of Passing Email & Moe \\
\hline Faculty/Staff Website & Moe \\
\hline Teaching Statement & Moe \\
\hline Teaching Philosophy & Moe \\
\hline Professional Development Log & Moe \\
\hline Course Coordinator Scope of Work Document & Bibi \\
\hline Faculty/Staff Website & Bibi \\
\hline Faculty/Staff Directory & Bibi \\
\hline Teaching Philosophy Email & Bibi \\
\hline Adjunct Handbook & Bibi \\
\hline Adjunct General Information Resource & Poppy \\
\hline Faculty/Staff Website \#1 & Poppy \\
\hline Faculty/Staff Website \#2 & Poppy \\
\hline Onboarding Email & Poppy \\
\hline Faculty Intranet & Poppy \\
\hline Teaching Statement/Philosophy & Poppy \\
\hline Adjunct Faculty Survey for Course Adaptation Help & Sara \\
\hline Adjunct Faculty Needs Assessment (Email) & Sara \\
\hline $\begin{array}{l}\text { Syllabus Language Requirements and Recommendations } \\
\text { (Email) }\end{array}$ & Sara \\
\hline Online Teaching Changes (Email) & \\
\hline Adjunct Information Guide (Handbook) & Sara \\
\hline Adjunct Faculty Contract & Sara \\
\hline Hiring Process (Email) & Sara \\
\hline Information from the Department (Email x3) & Sara \\
\hline Promotion Opportunities (Email x2) & Sara \\
\hline Professional Evaluation Letter & Sara \\
\hline Award Recognition (Email) & Sara \\
\hline Faculty/Staff Website & Sara \\
\hline Teaching Statement/Philosophy & Sara \\
\hline Adjunct Orientation Invitation & Sara \\
\hline Adjunct Resources Website & University: General \\
\hline New Adjunct Onboarding Checklist & University: General \\
\hline Collective Bargaining Agreement Training Slides & University: General \\
\hline Summer Professional Development Email & University: General \\
\hline Certificate of Innovation in College Teaching Website & University: OAI \\
\hline Flexible Degree Program & University: OAI \\
\hline & University: OAI \\
\hline
\end{tabular}




\begin{tabular}{|l|l|}
\hline Adjuncts at Work Poster & University: PSUFA \\
\hline May 2019 Member Meeting Presentation & University: PSUFA \\
\hline COVID Challenges (Email) & University: PSUFA \\
\hline Public Comment Submissions to the Board of Trustees & University: PSUFA \\
\hline PSUFA 2020 Bargaining Survey & University: PSUFA \\
\hline PSUFA 2020 Bargaining Survey Response Summaries & University: PSUFA \\
\hline $\begin{array}{l}\text { PSUFA 2020 Bargaining Survey: General Experience } \\
\text { Question }\end{array}$ & University: PSUFA \\
\hline Collective Bargaining Agreement & University: PSUFA \\
\hline Portland State University Faculty Association Website & University: PSUFA \\
\hline
\end{tabular}


Appendix G: Provisional Code Book

\begin{tabular}{|c|c|c|}
\hline Organizational Culture & Motivation & Professional Growth \\
\hline Inclusion & Intrinsic motivation & $\begin{array}{l}\text { Access to information and } \\
\text { resources }\end{array}$ \\
\hline Faculty engagement & Extrinsic motivation & Faculty needs \\
\hline Documented policies & Professional ambition & Institutional needs \\
\hline $\begin{array}{l}\text { Unspoken perceptions of } \\
\text { performance }\end{array}$ & Self-reflection & $\begin{array}{l}\text { Job-embedded professional } \\
\text { development }\end{array}$ \\
\hline Conflict & Institutional investment & Work-related assignments \\
\hline Environment & Rewards structures & Committee work \\
\hline Mission & Incentives for participation & Flexibility \\
\hline Socialization & $\begin{array}{l}\text { Recognition from } \\
\text { colleagues }\end{array}$ & Collaborative relationships \\
\hline Information & Need-driven motivation & Collegial interactions \\
\hline Strategy & Cognitive motivators & Mentoring relationship \\
\hline Leadership & & Growth plan \\
\hline $\begin{array}{l}\text { Social construction of } \\
\text { culture }\end{array}$ & & Teaching portfolios \\
\hline Faculty behaviors & & Goal-setting \\
\hline Departmental climate & & Teaching strategies \\
\hline Institutional climate & & Classroom management \\
\hline Group norms & & Onboarding \\
\hline Symbolic values & & Intentional programming \\
\hline Embedded skills & & Respect \\
\hline \multicolumn{3}{|l|}{ Academic integration } \\
\hline Social integration & & \\
\hline
\end{tabular}


Appendix H: Qualitative Content Analysis Coding Frame

\begin{tabular}{|c|c|c|c|}
\hline $\begin{array}{l}\text { Institutional } \\
\text { Culture }\end{array}$ & $\begin{array}{l}\text { Department } \\
\text { Culture }\end{array}$ & $\begin{array}{l}\text { Professional } \\
\text { Development }\end{array}$ & $\begin{array}{l}\text { Professional } \\
\text { Growth }\end{array}$ \\
\hline & & $\begin{array}{l}\text { PSU-sponsored } \\
\text { Formal Learning } \\
\text { Informal Learning }\end{array}$ & $\begin{array}{l}\text { Collegial } \\
\text { Interactions }\end{array}$ \\
\hline & & $\begin{array}{l}\text { External Learning } \\
\text { Opportunities }\end{array}$ & $\begin{array}{l}\text { Access to } \\
\text { Information and } \\
\text { Resources }\end{array}$ \\
\hline & & Onboarding & $\begin{array}{l}\text { Career Stage Needs } \\
\text { Taxonomy of } \\
\text { Adjunct Types }\end{array}$ \\
\hline & & $\begin{array}{l}\text { Course Coordinator } \\
\text { Meetings }\end{array}$ & $\begin{array}{l}\text { Work-Related } \\
\text { Assignments }\end{array}$ \\
\hline & & $\begin{array}{l}\text { Teaching } \\
\text { Observations }\end{array}$ & $\begin{array}{l}\text { Flexible Unit } \\
\text { Planning }\end{array}$ \\
\hline & & $\begin{array}{l}\text { Online } \\
\text { Asynchronous } \\
\text { Learning }\end{array}$ & $\begin{array}{l}\text { Individualized } \\
\text { Growth Plans }\end{array}$ \\
\hline & & $\begin{array}{l}\text { Online } \\
\text { Synchronous } \\
\text { Learning } \\
\end{array}$ & $\begin{array}{l}\text { Addressing } \\
\text { Institutional } \\
\text { Mission } \\
\end{array}$ \\
\hline & & $\begin{array}{l}\text { Motivation } \\
\text { Intrinsic Desire } \\
\text { Financial } \\
\text { Students } \\
\text { Requirement of } \\
\text { Employment } \\
\text { Individual Belief } \\
\text { System }\end{array}$ & \\
\hline
\end{tabular}




\section{Appendix I: Informed Consent Form for Adjunct Faculty Interviews}

Project Title:

Researcher:
An Exploratory Study of How Institution-Facilitated Professional Development Shapes the Adjunct Experience

Bethany Potts, College of Education

Portland State University

Researcher Contact: [Bethany's email address] / [Bethany's phone number]

You are being asked to take part in a research study. The box below highlights key information about this research for you to consider when making a decision whether or not to participate. Carefully review the information provided on this form. Please ask questions about any of the information you do not understand before you decide to participate.

\section{Key Information for You to Consider}

- Voluntary Consent. You are being asked to volunteer for a research study. It is up to you whether you choose to participate or not. There is no penalty if you choose not to participate or discontinue participation.

- Purpose. The purpose of this study is to explore adjunct faculty experiences with institution-facilitated professional development. Motivators for faculty participation is one factor that will be prioritized in the inquiry. The way in which adjunct faculty professional growth is shaped, as a result of participation, will also be explored.

- Duration. It is expected that your participation will last for two to three separate in-person or virtual (via Zoom) interviews that are 45-60 minutes in length. The interviews will take place during the 2019/2020 and/or the 2020/2021 academic school year.

- Procedures and Activities. You will be asked to verbally share about your experiences as an adjunct faculty member at Portland State University as well as at other institutions. This verbal exchange will take place over the course of two to three in-person or virtual interviews. The interviews will be one-on-one between you and the interviewer.

- Risks. Some of the foreseeable risks or discomforts of your participation include sharing information about adverse personal experiences. The most probably magnitude of harm is minimal, but could cause personal discomfort or distress during the interview.

- Benefits. A direct benefit is that the you will receive a $\$ 40$ to $\$ 60$ Visa gift card for participation in the two to three interviews (\$20 per interview). The gift card will be provided at the conclusion of the final interview. In addition, an indirect benefit is that the researcher hopes to learn more about adjunct 
faculty experiences with institution-facilitated professional development in order to influence institutional planning, including intentional policies and procedures that consider the large adjunct faculty body.

- Alternatives. Participation is voluntary and the only alternative is to not participate.

\section{What happens to the information collected?}

Information collected for this research will be used to write the researcher's dissertation for the Educational Leadership EdD program at Portland State University. No identifiable information will be included.

\section{How will my privacy and data confidentiality be protected?}

We will take measures to protect your privacy including excluding all identifiable information from interview transcripts and by saving all gathered information, including informed consent forms and interview transcripts, on a password protected external hard drive. Despite taking steps to protect your privacy, we can never fully guarantee that your privacy will be protected.

To protect the security of all of your personal information, we will use pseudonyms on interview transcripts, researcher memos, data analysis, the final written report, and any subsequent papers or presentations. Despite these precautions, we can never fully guarantee the confidentiality of all study information.

Individuals and organizations that conduct or monitor this research may be permitted access to inspect research records. This may include private information. These individuals and organizations include the Institutional Review Board that reviewed this research at Portland State University and the faculty committee for this dissertation.

\section{What if I want to stop participating in this research?}

Your participation is voluntary. You do not have to take part in this study, but if you do, you may stop at any time. You have the right to choose not to participate in any study activity or completely withdraw from participation at any point without penalty or loss of benefits to which you are otherwise entitled. Your decision whether or not to participate will not affect your relationship with the researchers or Portland State University.

Taking part in this research will not result in any associated costs for you as the participant.

\section{Will I be paid for participating in this research?}

You will be paid through a $\$ 40$ to $\$ 60$ Visa gift card, at the conclusion of the final interview (i.e., \$20 per individual interview, up to three interviews total). For remote interviews, the gift card will be mailed to you, the participant, at the address that you specify. 
Who can answer my questions about this research?

If you have questions or concerns, contact the researcher at:

Bethany Potts (Student Investigator) Michael J. Smith, PhD (Faculty Advisor, PI)

[Bethany's phone number]

[Michael's email address]

[Bethany's email address]

Who can I speak to about my rights as a research participant?

The Portland State University Institutional Review Board ("IRB") is overseeing this research. The IRB is a group of people who independently review research studies to ensure the rights and welfare of participants are protected. The Office of Research Integrity is the office at Portland State University that supports the IRB. If you have questions about your rights, or wish to speak with someone other than the research team, you may contact:

Office of Research Integrity

PO Box 751

Portland, OR 97207-0751

Phone: (503) 725-5484

Toll Free: 1 (877) 480-4400

Email: hsrrc@pdx.edu

\section{Consent Statement}

I have had the opportunity to read and consider the information in this form. I have asked any questions necessary to make a decision about my participation. I understand that I can ask additional questions throughout my participation.

By checking the box below, I understand that I am volunteering to participate in this research. I understand that I am not waiving any legal rights. I have been provided with a copy of this consent form. I understand that if my ability to consent for myself changes, either I or my legal representative may be asked to provide consent prior to me continuing in the study.

I consent to participate in this study. Check one: Yes $\square$ No \begin{tabular}{|l|l|}
\hline Name of Adult Participant: & Date:
\end{tabular} 
For remote interviews: At the conclusion of the final interview, where would you like your gift card to be sent? Please enter your mailing address in the text box below. This address will be used for no other purpose, other than to mail you your gift card.

Researcher Acknowledgment (to be completed when the participant's informed consent is received)

I have explained the research to the participant and answered all of his/her questions. I believe that he/she understands the information described in this consent form and freely consents to participate.

Name of Researcher

Date: 


\section{Appendix J: Informed Consent Form for Department Coordinator Interviews}

Project Title:

Researcher:
An Exploratory Study of How Institution-Facilitated Professional Development Shapes the Adjunct Experience

Bethany Potts, College of Education

Portland State University

Researcher Contact: [Bethany's email address] / [Bethany's phone number]

You are being asked to take part in a research study. The box below highlights key information about this research for you to consider when making a decision whether or not to participate. Carefully review the information provided on this form. Please ask questions about any of the information you do not understand before you decide to participate.

\section{Key Information for You to Consider}

- Voluntary Consent. You are being asked to volunteer for a research study. It is up to you whether you choose to participate or not. There is no penalty if you choose not to participate or discontinue participation.

- Purpose. The purpose of this study is to explore adjunct faculty experiences with institution-facilitated professional development. Motivators for faculty participation is one factor that will be prioritized in the inquiry. The way in which adjunct faculty professional growth is shaped, as a result of participation, will also be explored.

- Duration. It is expected that your participation will last for one in-person or virtual (via Zoom) interview that is 45-60 minutes in length. The interview will take place during the 2019/2020 or the 2020/2021 academic school year.

- Procedures and Activities. You will be asked to verbally share about your work with adjunct faculty in your academic department at Portland State University, including information about professional development and/or training experiences offered for faculty. This verbal exchange will take place during one in-person or virtual interview. The interview will be one-on-one between you and the interviewer.

- Risks. There are no foreseeable risks or discomforts associated with your participation. The magnitude of harm is minimal.

- Benefits. A direct benefit is that you will receive a \$20 Visa gift card for participation in one interview. The gift card will be provided at the conclusion of the interview. In addition, an indirect benefit is that the researcher hopes to learn more about adjunct faculty experiences with institution-facilitated professional development in order to influence institutional planning, including intentional policies and procedures that consider the large adjunct faculty body. 
This indirect benefit could impact your work within the department and within the institution. It could also shape a faculty culture that is inclusive of all faculty types.

- Alternatives. Participation is voluntary and the only alternative is to not participate.

\section{What happens to the information collected?}

Information collected for this research will be used to write the researcher's dissertation for the Educational Leadership EdD program at Portland State University. No identifiable information will be included.

\section{How will my privacy and data confidentiality be protected?}

We will take measures to protect your privacy including excluding all identifiable information from interview transcripts and by saving all gathered information, including informed consent forms and interview transcripts, on a password protected external hard drive. Despite taking steps to protect your privacy, we can never fully guarantee that your privacy will be protected.

To protect the security of all of your personal information, we will use pseudonyms on interview transcripts, researcher memos, data analysis, the final written report, and any subsequent papers or presentations. Despite these precautions, we can never fully guarantee the confidentiality of all study information.

Individuals and organizations that conduct or monitor this research may be permitted access to inspect research records. This may include private information. These individuals and organizations include the Institutional Review Board that reviewed this research at Portland State University and the faculty committee for this dissertation.

\section{What if I want to stop participating in this research?}

Your participation is voluntary. You do not have to take part in this study, but if you do, you may stop at any time. You have the right to choose not to participate in any study activity or completely withdraw from participation at any point without penalty or loss of benefits to which you are otherwise entitled. Your decision whether or not to participate will not affect your relationship with the researchers or Portland State University.

Taking part in this research will not result in any associated costs for you as the participant.

\section{Will I be paid for participating in this research?}

You will be paid through a $\$ 20$ Visa gift card, at the conclusion of the interview. For remote interviews, the gift card will be mailed to you, the participant, at the address that you specify.

\section{Who can answer my questions about this research?}


If you have questions or concerns, contact the researcher at:

Bethany Potts (Student Investigator) [Bethany's phone number] [Bethany's email address]
Michael J. Smith, PhD (Faculty Advisor, PI) [Michael's email address]

\section{Who can I speak to about my rights as a research participant?}

The Portland State University Institutional Review Board ("IRB") is overseeing this research. The IRB is a group of people who independently review research studies to ensure the rights and welfare of participants are protected. The Office of Research Integrity is the office at Portland State University that supports the IRB. If you have questions about your rights, or wish to speak with someone other than the research team, you may contact:

Office of Research Integrity

PO Box 751

Portland, OR 97207-0751

Phone: (503) 725-5484

Toll Free: 1 (877) 480-4400

Email: hsrrc@pdx.edu

\section{Consent Statement}

I have had the opportunity to read and consider the information in this form. I have asked any questions necessary to make a decision about my participation. I understand that I can ask additional questions throughout my participation.

By checking the box below, I understand that I am volunteering to participate in this research. I understand that I am not waiving any legal rights. I have been provided with a copy of this consent form. I understand that if my ability to consent for myself changes, either I or my legal representative may be asked to provide consent prior to me continuing in the study.

\section{I consent to participate in this study. Check one: Yes $\square$ No}

\begin{tabular}{|l|l|}
\hline Name of Adult Participant: & Date:
\end{tabular}


For remote interviews: At the conclusion of the interview, where would you like your gift card to be sent? Please enter your mailing address in the text box below. This address will be used for no other purpose, other than to mail you your gift card.

Researcher Acknowledgment (to be completed when the participant's informed consent is received)

I have explained the research to the participant and answered all of his/her questions. I believe that he/she understands the information described in this consent form and freely consents to participate.

Name of Researcher:

Date: 